\title{
THE RISING AGE AT RETIREMENT IN INDUSTRIAL COUNTRIES
}

\author{
Gary Burtless* \\ CRR WP 2008-6 \\ Released: April 2008 \\ Draft Submitted: January 2008
Center for Retirement Research at Boston College
Hovey House
140 Commonwealth Avenue
Chestnut Hill, MA 02467 \\ Tel: 617-552-1762 Fax: 617-552-0191 \\ http://www.bc.edu/crr
}

* Gary Burtless is the John C. and Nancy Whitehead Chair in Economic Studies at The Brookings Institution. The research reported herein was performed, in part, pursuant to a grant from the U.S. Social Security Administration (SSA) funded as part of the Retirement Research Consortium. The opinions and conclusions expressed are solely those of the author and should not be construed as representing the opinions or policy of SSA, any agency of the Federal Government, The Brookings Institution, or Boston College.

(C) 2008, by Gary Burtless. All rights reserved. Short sections of text, not to exceed two paragraphs, may be quoted without explicit permission provided that full credit, including (C) notice, is given to the source. 


\title{
About the Center for Retirement Research
}

The Center for Retirement Research at Boston College, part of a consortium that includes parallel centers at the University of Michigan and the National Bureau of Economic Research, was established in 1998 through a grant from the Social Security Administration. The Center's mission is to produce first-class research and forge a strong link between the academic community and decision makers in the public and private sectors around an issue of critical importance to the nation's future. To achieve this mission, the Center sponsors a wide variety of research projects, transmits new findings to a broad audience, trains new scholars, and broadens access to valuable data sources.

\author{
Center for Retirement Research at Boston College \\ Hovey House \\ 140 Commonwealth Avenue \\ Chestnut Hill, MA 02467 \\ phone: 617-552-1762 fax: 617-552-0191 \\ e-mail: crr@bc.edu \\ www.bc.edu/crr
}

\author{
Affiliated Institutions: \\ American Enterprise Institute \\ The Brookings Institution \\ Center for Strategic and International Studies \\ Massachusetts Institute of Technology \\ Syracuse University \\ Urban Institute
}




\section{Abstract}

In the half century after World War II labor force participation in the population past age 60 fell substantially in nearly all rich countries. Declining participation rates became a matter of major concern when it became clear that population growth rates were slowing and the average age of citizens in most rich countries was rising. A rapidly growing number of aged was living longer but spending a smaller number of years in the paid workforce. This paper examines recent trends in retirement behavior in 21 rich countries. It proposes three straightforward measures of labor force exit, and it estimates labor force exit rates using a variety of labor supply indicators, including the labor force participation rate, the employment rate, average work hours in the population, and average weekly earnings in the population. The results suggest that in recent years exit rates from paid work are declining among older citizens. This pattern is found both for men and women, and it is found in a large majority of countries in the analysis. In many countries labor force participation rates at older ages reached a low point in the 1990s, but since that time participation rates have increased. The rebound in male participation rates has been substantial in several countries. On average across the 21 countries, participation rates among 6064 year-old men have rebounded over 9 percentage points since a low point in the participation rate was reached, usually in the 1990s. This rise in the participation rate of 60-64 year-old men has offset almost one-quarter of the decline in participation rates that occurred between 1960 and the low point of participation rates. 
IN THE HALF CENTURY after World War II labor force participation in the population past age 60 fell in nearly all rich countries. Declines in participation were particularly noticeable among men, and the falloff in labor force engagement was evident among men as young as 50. Among 50-54 year-olds, the drop in male participation was more than offset by participation gains among women, so the overall activity rate in this age group typically increased over time. At older ages, however, labor force declines among men in most countries were larger than the increases among women, implying that overall labor force participation fell in the population age 55 and older.

Declines in participation rates have been small among 50-54 year-old men, but they were much bigger both absolutely and proportionately in older age groups. Between 1950 and 1995, for example, the average participation rate of 60-64 year-old men in 21 rich industrial countries fell by almost half. ${ }^{1}$ Participation trends among older women contrast with the trends among men. Female activity rates increased or at least remained roughly constant at older ages, offsetting some of the impact of a lower male participation rate. In one respect, however, the male and female trends were identical. The falloff in participation rates as people grow older was considerably faster after age 55 in 1995 than it was 45 years earlier, and this is true for both men and women. According to International Labour Organization (ILO) statistics, in 1950 the average activity rate of 60-64 year-old men was 13 percentage points (or 14 percent) lower than that of 50-54 year-olds. By 1995 the participation-rate difference between these two age groups was 42 percentage points (or 50 percent). If activity rates in both 1950 and 1995 are treated as estimates of a stable lifetime participation pattern in the two years, they imply much faster exit rates from the workforce in 1995 than in 1950 (Burtless 2004). A similar change in exit rates occurred among women. In 1950 women aged 60-64 had a participation rate that was 9 percentage points (or 30 percent) lower than that of women aged 50-54. By 1995 the gap was 39 percentage points (or 65 percent). Female exit rates between ages 50-54 and 60-64 increased from 30 percent in 1950 to 65 percent in 1995.

The long trend toward earlier labor force exit came to an end for U.S. men between the mid-1980s and mid-1990s (Burtless and Quinn 2001 and 2002). Since reaching a low point in the 1985-1995 decade, the labor force participation rate of 60-64 year-old men has increased

\footnotetext{
${ }^{1}$ This average refers to 21 rich and large countries in the Organisation for Economic Co-operation and Development (OECD), including the United States. See Burtless (2004) for additional details.
} 
almost 6 percentage points (11 percent), and the participation rate among 65-69 year-old men has increased about 10 percentage points (41 percent). Participation rates among American women in the same age groups have increased even faster, especially when gains are measured in proportional terms. One explanation for this reversal is the change in incentives for work in later life created by reforms in the U.S. social security program and the gradual transformation of the nation's employer-based occupational pension system. In comparison to the 1960s and 1970s, social security now offers fewer and smaller disincentives to work after workers reach the benefit-claiming age. Employer-sponsored retirement plans are now much more likely to provide defined-contribution pensions rather than defined-benefit pensions. The latter type of plan often creates powerful incentives for workers to leave career jobs once they have attained the benefit-claiming age, whereas defined-contribution plans create much weaker incentives to retire at a particular age (Burtless and Quinn 2001; see also Anderson et al. 1999).

Since 1990 many OECD countries have adopted reforms that scale back old-age pensions, reduce the generosity of unemployment benefits for older workers, and offer stronger work incentives after workers attain the pension-claiming age (Casey et al. 2003). This paper examines whether the turnaround apparent in U.S. old-age labor force participation rates is also evident in other countries' labor force statistics. Have participation rates in later life increased? Has the trend toward earlier retirement slowed or reversed? Do trends in other indicators of oldage labor supply, such as full-time employment rates and average hours of work, mirror the trends in participation?

A number of analysts have examined the long-term trend in labor force participation at older ages (Gendell and Siegel 1992; Peracchi and Welch 1994; Gendell 2001; Quinn 1999). Several have also analyzed cross-national differences in these trends (Latulippe 1996; Gendell 1998; Blöndal and Scarpetta 1999; Scherer 2002; Burtless 2004). This paper broadens the analysis of earlier work in several ways. First, it extends the analysis period up to 2006. This is an important extension because in recent years there has been a change in the decades-long trend toward earlier retirement in many countries. Second, it considers indicators of labor market withdrawal in addition to the decline in the labor force participation rate. A number of countries make labor force survey data available to researchers in the form of micro-census computer files. When these data are available it is possible to tabulate reductions in work hours and weekly earnings as well as the proportional reduction in participation and employment rates as workers 
grow older. The analysis in this paper shows that in most countries total work hours fall faster than labor force participation and employment rates as a cohort grows older. In the United States, where it is possible to track the decline in average weekly earnings as well as work hours, I find a faster proportional decline in earnings than in either participation rates or average hours worked. Finally, the paper considers three alternative measures of the speed of labor force exit, examines the relationship between them, and offers alternative estimates of cross-national trends in labor force exit over the four and a half decades since 1960. The alternative measures of exit consistently show that male exit rates have recently declined in most OECD countries, pushing up labor force participation rates in older age groups. Participation rates have also increased among older women, but it is less clear how much of this trend is explained by slower labor force exit and how much represents the delayed effect of higher participation rates at younger ages. In nearly all OECD countries middle-aged women now enter their retirement years with much more labor market experience than women in earlier generations. In some countries it is clear that exit from the labor force has slowed among women. In others the evidence is more ambiguous.

The remainder of the paper is organized as follows. The next section describes basic patterns of labor force withdrawal in the industrialized countries and offers a simple method of

measuring the exit rate in old age. The section presents estimates of exit rates using information from a single point in time, and it compares exit rates across countries using a variety of indicators of workers' labor supply. Exit rates estimated with information from a single point in time suffer obvious shortcomings when labor supply patterns are changing from one generation to the next. Section 2 proposes two measures of the exit rate based on labor supply trends within a single birth cohort or within a number of adjacent birth cohorts. These rates are estimated using detailed data on men and women in the United States and using more aggregated data for 20 other industrial countries. The last main section compares trends in retirement exit rates and labor force participation rates in 21 countries. The paper ends with a brief summary.

\section{The Retirement Process in Rich Countries}

When workers retire they withdraw from paid employment, either gradually or completely. At the level of national labor force statistics, this process is reflected as a gradual or steep decline in employment rates at older ages. Figures 1 and 2 illustrate this pattern by showing the association between overall work effort and age over the adult life course in 2004. 
The top panel in each figure shows the labor force participation rate, by age group, between ages 15 and 74. The lower panel shows average paid work hours per week in the same age groups. The estimates in the lower panel show the work hours in a typical week of all people in the age group, including those who are out of the labor force, unemployed, or temporarily absent from their job in the reference period covered by the survey. Because the paid work patterns of men and women differ sharply in many countries, estimates have been separately calculated for the two sexes. Figure 1 shows lifetime work patterns among men, and Figure 2 shows patterns among women. Both sets of charts present estimates for western Europe and the United States. ${ }^{2}$ The European estimates are weighted to reflect the relative population sizes of the 14 European countries in the sample.

The charts all show a characteristic hump-shaped pattern of lifetime labor supply, both for men and women and for both measures of paid work effort. Labor supply rises steeply between ages 15 and 30, reaches a high plateau between ages 30 and 49, and then begins to decline. These work patterns are broadly similar whether work effort is measured using the labor force participation rate or average hours worked in a typical survey week. The peak level of work effort is higher among men than among women, but the lifetime cycles of entry and exit are roughly the same. There are some interesting differences between lifetime work patterns on the two sides of the Atlantic. At both younger and older ages Americans are more likely to be at work than Europeans of the same age. On the other hand, in the prime working years Europeans have slightly higher participation rates than their American counterparts. Europeans concentrate a higher proportion of their lifetime labor supply in their primary working ages; Americans work more at the beginning and end of the life course. Even though Europeans have slightly higher participation rates in prime working years, Americans have higher work hours in those years. This is mainly the result of a slightly longer work week and a lower rate of absence from work among the people who are employed. The consequences of these differences are especially striking for American women. At some ages American women have lower labor force

2 The European countries included in the estimates are the 14 countries that make micro-census data available from the Eurostat Labour Force Survey (LFS): Austria, Belgium, Denmark, Finland, France, Germany, Greece, Ireland, Italy, the Netherlands, Norway, Portugal, Spain, and Sweden. Unfortunately, the United Kingdom does not allow access to these micro-census records. The U.S. estimates are derived from the monthly Current Population Survey (CPS) files. Both the European and U.S. data cover survey weeks throughout the 2004 calendar year with the exception of Germany where only data from the second calendar quarter are available. 
participation rates than women in Europe, but at every age U.S. women work substantially longer average hours.

Measuring the exit rate. The focus of this analysis is on retirement, or the withdrawal from paid work occurring late in life. Figure 3 shows a stylized representation of this withdrawal. Average labor supply is shown at each year of age, $a$, between a year of peak labor supply, designated $R$, and a later year, $S$. The figure contains two schedules of labor force withdrawal. The lower line shows a faster rate of exit; the upper line indicates a slower rate of withdrawal. Note that the peak rate of labor supply, at age $R$, is indicated as 100 . Labor supply at later ages is measured as a percentage of this peak level. The two lines in the chart are drawn to correspond to the patterns of decline in male labor force participation in Europe and the United States between the ages of 50 and 75 (the right portion of the top chart in Figure 1). For American men it is possible to chart the decline in participation rates by exact year of age. The monthly CPS files for a full calendar year contain enough observations to permit reasonably accurate age-by-age calculations. The European labor force survey files are smaller and do not give survey respondents' exact year of age, so the estimates for Europe reflect approximations based on participation rates within 5-year age intervals.

For European men, the average level of work effort between ages $R$ and $S$, measured as a percentage of their work effort at age $R$, is simply the area under their labor force exit schedule measured as a percentage of the total area in the chart, that is $A /(A+B+C)$. A straightforward indicator of the speed of retirement is the percentage decline in work effort during the interval between ages $R$ and $S$ below the level it would have been if the population continued to work at the peak level. In Figure 3, this retirement indicator can be measured as $1-[A /(A+B+C)]$, or $(B+C) /(A+B+C)$. This measure of the speed of retirement, which I shall refer to as the "exit rate" or "retirement rate," ranges between 0 and 1 (or, in percentage terms, between 0 percent and 100 percent). Note that the exit rate for American men is $C /(A+B+C)$, which is lower than the exit rate for European men. A higher retirement rate does not necessarily mean that European men supply less labor between ages $R$ and $S$ than American men. If European men have higher work levels at the age of peak labor supply, $R$, they may supply more labor between $R$ and $S$ than American men, even though they retire at a faster rate. In fact, Figure 1 shows that European men have a somewhat higher labor force participation rate at age 50 than Americans, though average weekly work hours of American men are higher than average hours worked by 
European men. As should be clear in Figures 1 and 2, older American men work more on average than older European men, and this is mainly the result of their slower labor force exit. The peak levels of labor supply on both sides of the Atlantic are similar.

Figure 3 illustrates the retirement process using data on labor force participation rates by age in two sets of countries. It is based on cross-sectional evidence obtained at a single point in time, so I will refer to it as the "single period exit rate" or more simply as the "period exit rate." The same kind of analysis can be applied to comparisons between retirement at two points in time, say, 1980 and 2000. Though it is customary to measure retirement using participation rates, there is no reason to restrict analysis to this one variable. Table 1 shows the derivation of single period exit estimates for three other variables, the employment/population ratio, the percentage of the population actually working in a given week, and average work hours in the population (that is, among all members of the age group, whether or not they work). Entries in the table show estimates of each indicator variable for the United States and the 14 European countries which supply micro-census labor force survey files covering calendar year 2004. Each column shows estimates for a particular age group. The separate estimates for each sex show, first, the average level of the labor supply indicator for the group and, second, the implied labor force exit rates relative to average work effort in the 45-49 year-old age group. Since the labor force data used in the table can only be tabulated for 5-year age groups, I assume peak lifetime labor supply is attained between ages 45-49 and measure the exit rate as a percentage decline from this level. The second through the sixth columns in the table show labor force indicators and period exit rates for 5-year age groups, while the column on the right averages these results over the 25-year age span from 50 through $74 .^{3}$

An overwhelming share of labor force exit occurs between ages 50 and 74. Under every measure of labor supply, aggregate work levels between ages 70-74 are at least 90 percent below their level in the 45-49 year-old age group. Among women, the apparent labor supply decline is more than 95 percent. In general the table suggests that labor force exit occurs faster among women than among men, and this is true for all four measures of labor supply. Between ages 60

3 Note that the estimate in the sixth column is the arithmetic average of the participation rates in the 50-54, 55-59, 60-64, 65-69, and 70-74 year-old age groups. The estimate differs from the participation rate in the 50-74 year-old population because of the unequal sizes of the five age groups. The average participation rate is not intended to measure the true participation rate in a nation's 50-74 year-old population. Instead, it is intended to measure the expected average labor supply of a worker between his or her $50^{\text {th }}$ and $75^{\text {th }}$ birthdays. 
and 64 average work hours among women are 71 percent lower compared with the average level among women who are 45-49 years old. In contrast, the percentage reduction among men 60-64 years old is only 59 percent. As we shall see, some of the apparent difference between male and female exit patterns is explained by changing work patterns among people who are far from their retirement years. Among men younger than 50 there has been a small, long-term decline in labor force engagement, while women have seen a substantial, long-term rise in participation and work hours. Women who are now in their 60s and 70s did not fully participate in the revolution that brought more women into the workplace, and their employment levels when they were under 50 were lower than levels that are now common. Most of the apparent drop in women's labor supply between ages 45-49 and 60-74 is due to a genuine decline in work effort as women grow older, but part of it can be explained as a consequence of different pre-retirement work experiences in successive generations.

The estimates in Table 1 suggest that the speed of retirement is faster when labor supply is measured under a more comprehensive definition. Although there is little practical difference between the exit rates measured using the labor force participation rate and the employment-topopulation ratio, the exit rate is faster when labor supply is estimated using the percentage of the population actually at work in a typical survey week, and it is still higher when estimated using average actual work hours in an age group. The first result indicates that absence from work is more common among aged than non-aged workers. The second implies that the average workweek of employed people declines as workers grow older. Although both of these findings may seem easily predictable, they are not inevitable. Most of the drop in labor supply is connected with a drop in labor force participation and actual employment. Since workers who leave the workforce tend to be less healthy than average, the ones who remain might be less prone to absence and more inclined to work long hours. The results in Table 1 imply that this potential effect of self-selection into retirement is more than offset by older workers' higher absence rates and their voluntary or involuntary choice of a shorter workweek.

Earnings reductions. In principle, the most comprehensive measure of labor force exit would account not only for hours worked but also for the differing wage levels of workers who leave or elect to remain in the workforce at successively higher ages. Many arguments for a higher retirement age focus on the macroeconomic benefits of higher old-age employment rates, but nearly all the claimed benefits flow out of higher aggregate earnings rather than out of higher 
employment per se. If the labor supplied at older ages increased 20 percent, but all of the additional participants were drawn from the ranks of the least skilled and most poorly paid, the earnings and social security contributions of the aged would increase much less than 20 percent.

Information in the monthly CPS files allows us to calculate the weekly earnings as well as the employment status and actual work hours of Americans in the survey (Schmitt 2003). Figure 4 shows estimates based on tabulations of the CPS monthly records covering the years 2003-2005. The chart shows the pattern of labor force exit for three measures of aggregate labor supply or productivity: the labor force participation rate, the average weekly hours of all persons (including the jobless and workers who are absent from their jobs), and the estimated average weekly earnings in the population (including people without earnings). The benchmark for peak labor supply is the work effort or earnings of people who are exactly 50 years old. The work effort and earnings of people who are between 50 and 74 are measured as percentages of this benchmark. Between ages 51 and 56 there is little difference in exit rates as measured with these three indicators, but the differences become greater at successively higher ages. The pattern of difference is similar for men and women. Labor force exit is slower as measured using the participation rate than it is when using either average work hours or weekly earnings, and the exit rate is higher when estimated based on weekly earnings compared with when it is based on average hours worked.

The results in Figure 4 can be summarized by translating the tabulations into a retirement index indicating the overall drop in labor supply between ages 50 and 74. This percentage is estimated relative to the level that would be observed if supply remained constant at the age-50 level between ages 50 and 74. For American men the retirement indices for the labor force participation rate, average hours, and average earnings are, respectively, 38 percent, 43 percent, and 44 percent. For American women, the same retirement indices are 43 percent, 47 percent, and 49 percent, respectively. While the drop in average hours worked between ages 50 and 74 is proportionately larger than the decline in labor force participation, the drop in average weekly earnings is only slightly larger than the fall in average hours. This finding suggests that the average productivity of work hours supplied by older workers does not decline appreciably at higher ages. ${ }^{4}$ At least in the United States the labor force exit rate estimated using average hours

\footnotetext{
${ }^{4}$ Since the estimates of weekly earnings depend on wage information available in the CPS outgoing rotation group $(\mathrm{ORG})$ files, readers should recognize that limitations in the data file will affect our
} 
of work is a reasonably good approximation of the exit rate measured using average weekly earnings. Both these measures, however, show a faster exit rate than one based on the participation rate or the employment-to-population ratio.

Public-use versions of the European labor force survey do not include information about respondents' weekly or annual earnings, so it is impossible to derive estimates of exit rates based on measures of the value of labor supplied. The LFS contains information on respondents' educational attainment, however, and this information can be used as a rough gauge of worker productivity. Using Eurostat's educational classifications and constructing a comparable classification of Americans interviewed in the monthly CPS, I divided survey respondents into three educational groups - low, moderate, and high. The low schooling attainment group has educational qualifications below those of a U.S. high school graduate. People in the middle group have at least completed high school and may have attended college, but they have not attained the equivalent of a junior (two-year) college degree. Those in the top educational group have attained the equivalent of at least a junior college diploma. ${ }^{5}$ Table 2 shows labor force participation rates and estimated labor force exit rates in Europe and the United States among people in the three educational groups. The estimates are based on responses obtained in labor force surveys covering calendar year 2004, and they focus on exit in the population between 50 and 69 years old. Three estimates are shown for results within each sex and educational group. The first estimate is the unweighted average for all 15 countries included in the analysis. The second and third estimates show separate results for the United States and Europe. The European estimates reflect population-weighted totals for the 14 European countries. Since European countries differ greatly in population, weighting their results seems appropriate for purposes of making useful comparisons with the U.S.

The top panel in Table 2 shows, not surprisingly, that the labor force participation rate of older citizens differs sharply across the three education groups. In the United States men in the

conclusions. In particular, the earnings estimates on the file are top-coded by the Bureau of Labor Statistics before they are released for public use. This may affect estimates of average earnings at successive ages if they are differentially affected by the top-coding procedures used by the BLS or by the Center for Economic and Policy Research when it developed the basic files we used. For an excellent discussion, see Schmitt (2003).

${ }^{5}$ In the United States, about 14 percent of the population between 50 and 69 is in the lowest attainment group, 50 percent is in the intermediate group, and 36 percent is in the high education 
highest educational attainment group have a participation rate that is 22 percentage points higher than the participation rate in the lowest attainment group. In Europe, the equivalent participation-rate gap is 16 percentage points. The three columns on the right present estimates for women. These also show a large participation-rate gap between the highly educated and the less educated. Of course, these participation-rate differences are also evident in younger groups in the population (not shown in the table).

One reason for the lower participation rates in less educated groups is their faster exit from the workforce. The second panel in the table shows exit rates measured using the labor force participation rate. The exit rate in this table is estimated as the percentage decline in labor supply between ages 50 and 69 compared with the level that would be observed if supply did not decline below the level among 45-49 year-olds. (Labor supply between ages 45-49 rather than at age 50 is used as a benchmark because the European LFS survey provides an indication of respondents' age only within 5-year age bands.) In general, less educated workers withdraw from the labor force faster than more educated workers. This is true on both sides of the Atlantic, for both sexes, and under all three definitions of labor force exit. For example, the retirement index for average weekly hours shows a 44 percent reduction among low-education U.S. women versus only a 32 percent drop among U.S. women in the highest education category. Among European women, the comparable exit rates are 56 percent in the lowest schooling attainment group versus just 46 percent in the highest group. In Europe as in the United States the most comprehensive measure of labor force exit, shown in the bottom panel, tends to show faster labor supply reductions than the narrower measures. That is, total hours of work tends to fall faster between ages 50 and 69 than labor force participation rates. In Europe, unlike the United States, this phenomenon is concentrated mainly among workers in the top two education categories. Among European workers in the lowest schooling attainment group, hours of work fall roughly in proportion to the decline in participation rates.

The results in Table 2 clearly show that the best educated workers are the slowest to reduce their labor supply in old age. The finding may seem to imply that the average earnings of aging workers will fall more gradually than either participation rates or average hours of work. The most educated workers, after all, are also the ones who earn the highest wages. If they

category. For Europe the equivalent proportions are 50 percent, 34 percent, and 16 percent, respectively. A small percentage of respondents do not report educational attainment. 
remain in the workforce it seems logical to expect earnings will decline more slowly than employment. This conclusion is contradicted by the evidence in Figure 4, which shows that average earnings among Americans between ages 50 and 69 falls somewhat faster with age than either participation rates or average hours of work. At least in the United States the slower exit of well-educated workers compared with less-educated workers is not enough to reverse the effects of relative wage decline among aging workers. Even though the 65-year-old workforce may be better educated than would be the case if the retirement rate were the same in every educational class, the real hourly wage of 65-year-old workers is slightly below the wage of workers who are somewhat younger. ${ }^{6}$

Cross national comparisons. In addition to shedding light on the effects of educational attainment, the tabulations in Table 2 also show that labor force exit occurs at an earlier age in Europe than it does in the United States. The estimates were obtained using labor force survey data in public use files. Some of the largest OECD countries, including Japan and the United Kingdom, do not make such data easily accessible to researchers. However, they provide summary statistics to the OECD that can be used to estimate two kinds of labor force exit - exit from the labor force and exit from paid work. ${ }^{7}$ Since estimated exit rates using these two statistics are essentially the same, I will focus on exit from the labor force.

Tables 3 and 4 show period exit rates for 21 OECD countries, including all the 15 countries covered in Tables 1 and 2 plus Australia, Canada, Japan, New Zealand, Switzerland, and the United Kingdom. The results in Table 3 show exit rates for men, and those in Table 4 show rates for women. In both tables the countries are ranked according to their estimated exit rate over the age interval from 50 through 69 (column 6). (For many countries, the OECD does not provide data on participation rates in the 70-74 year-old age group.) Among men in the OECD, the average labor force participation rate between ages 50-69 is more than one-third lower than the participation rate of men age 45-49. The period exit rate is therefore 37 percent.

${ }^{6}$ This interpretation of the findings is supported when we examine labor force exit within the same birth-year cohorts rather than across age groups at the same point in time. On average in the 15 countries covered by Table 2, the members of a birth cohort who have more schooling tend to remain in the labor force longer than members of the cohort who have less.

${ }^{7}$ Some countries did not always provide the OECD with participation rate data for each of the 5year age groups between ages 45 and 69 . In some cases I was able to supplement the OECD data with my own tabulations of the European LFS data, and in a few cases the OECD data could be supplemented with data published by national statistical agencies or supplied to the International Labour Organization (ILO). 
The period exit rate among women is much higher (46 percent), though this estimate is affected by the long-term change in female participation rates at ages 45-49.

The table shows considerable cross-country variation in period exit rates. In Austria, Belgium, France, and Italy, male labor force participation between ages 50 and 69 is at least 50 percent below the rate of men who are 45 to 49 . In Japan, the drop in male participation rates over this age range is only 21 percent. Among women the range in period exit rates is approximately as wide. There is a strong correlation between the national exit rates of men and women. The simple correlation between male and female exit rates is 0.92 , which strongly suggests that the factors encouraging early labor force exit in one sex have equally powerful effects on the exit behavior of the other sex. Countries in continental Europe tend to have faster than average exit rates, though most of the Scandinavian countries and Portugal represent exceptions. The slowest labor force exit both for men and women occurs in Japan, New Zealand, Norway, Sweden, Switzerland, and the United States. On the whole, countries with the fastest exit rates tend to have national pension systems that provide more generous benefits at the standard retirement age, while most of the countries with the slowest exit rates have pensions that are somewhat less generous than average (Blöndal and Scarpetta 1999; Burtless 2004; Casey et al. 2003; and Duval 2003).

For countries where it is possible to make a comparison across labor supply measures, the period exit rates as measured with the labor force participation rate are highly correlated with period exit rates measured using more comprehensive labor supply measures, including the employment-to-population ratio, the percentage of the population actually at work in a survey week, and the average work hours of the population. For most countries, these indicators of labor supply fall in a similar pattern in late adulthood, with somewhat faster rates of decline when exit is measured using more comprehensive indicators of supply. In some countries, such as France and Greece, aggregate work hours in the population declines at approximately the same rate as the labor force participation rate. In other countries aggregate work hours decline more rapidly than the participation rate. This pattern implies that a higher job absence rate or a shorter workweek also plays a role in explaining falling labor supply in old age. Countries where work hours fall faster than labor force participation rates include the Netherlands, Germany, Denmark, Norway, Sweden, Portugal, and the United States (see appendix Tables A1 and A2). Total hours of work might fall faster than participation rates either because the workers 
who remain employed work shorter hours than the workers who retire or because workers tend to experience higher absence rates or work on shorter work schedules as they grow older.

\section{Retirement within a Birth Year Cohort}

The estimates reported so far derive approximations of the retirement rate using labor supply information from a cross-section of the population, drawn at a single point in time. An implicit assumption behind these estimates is that they reflect the retirement patterns that will prevail in the long run if current age-specific levels of labor supply are stable. This assumption is not realistic. Retirement behavior is interesting precisely because it has varied over time. At the turn of the last century, retirement in the United States was relatively rare but not unknown. Two out of three men past age 65 were gainfully employed, but one-third of aged men did not hold a job (U.S. Census Bureau 1975, p. 132). By the middle of the twentieth century retirement was much more common. Fewer than half of men 65 and older held jobs in 1950. In 2000 the proportion at work had fallen still further. Just 18 percent of American men over 65 were employed or actively seeking a job. Eighty-two percent were outside the labor force. Rich countries have also seen important changes in labor supply patterns at younger ages. These affected the level of labor supplied before retirement begins. It may seem reasonable to measure labor force exit from some standard age, such as age 50, but this is only true if labor supply at age 50 has been stable over long periods. This is approximately true for men in most countries, but it is not true for women. As we have seen, rising female participation rates at younger ages can produce an overstatement of women's retirement rates if these are estimated with information from a single cross-section survey.

Cohort retirement rates. An alternative to point-in-time estimates of the retirement rate is an estimate based on the labor force experiences of individual birth-year cohorts. The "cohort retirement rate" provides a more meaningful indicator of labor force withdrawal than the singleperiod estimates described above. Cohort retirement rates are calculated using labor supply indicators not from a single year, but from the sequence of years in which a birth-year cohort makes the transition from peak labor supply to complete labor force withdrawal. The challenge in producing estimates of the cohort retirement rate is that good historical data on labor supply by age or year of birth are hard to obtain. The U.S. decennial census provides reasonably consistent information on participation and employment by year of age, but the data are collected too infrequently to allow accurate calculation of activity rates for any birth-year cohort. For 
1976 and later years the Bureau of Labor Statistics has disseminated public-use files containing labor force survey data from the monthly CPS. The samples are large enough to produce good estimates of participation, employment, and work hours by exact year of age. The problem is that the span of years covered by these files is too short to allow us to observe completed retirement patterns for a large number of cohorts.

Figure 5 shows estimates of labor force exit for American men and women who retired in the late 1980s and early 1990s. The top chart shows exit rates measured with cross-sectional data for 1988-1992. The exit rate is derived by first calculating labor force participation rates at each year of age and then computing the proportional reduction in participation below the level observed for people who are age 50. The "period exit rate" estimates suggest that women left the labor force faster than men. The female retirement index shows that average labor supply between ages 50 and 74 was 48 percent below the level at age 50. The comparable retirement index for men was only 42 percent, indicating a slower rate of workforce exit.

The lower panel in Figure 5 shows average exit rates for men and women born between 1926 and 1930. The monthly CPS files for 1976 through 2004 contain data on the labor force status of these birth cohorts at every age between 50 and 74. The data permit us to calculate exact "cohort exit rates" for people born between 1926 and 1930, because we can estimate the exact sequence of labor force participation rates as members of these cohorts aged from 50 to 74 . In contrast to the top panel, estimates in the lower panel suggest that men and women born around 1930 exited from the labor force at almost exactly the same rate. The estimated retirement index for both men and women is 41 percent, indicating that labor force participation rates between ages 50 and 74 were about two-fifths below the participation rate of these birth cohorts when they were 50 years old. The cohort exit rate of men born between 1926 and 1930 is very close to the period exit rate estimated using cross-sectional 1988-1992 data. In contrast, the cohort exit rate for women is much lower than the period exit rate. The explanation for this difference is that whereas male labor supply at age 50 was relatively constant between 1976 and 2004, female labor supply rose strongly during the period. The results suggest that while period exit rates may provide reasonable approximations to the speed of retirement among men, they are less reliable for women.

Cohort exit rates can be used to compare the speed of labor force withdrawal under different labor supply definitions. Figure 6 shows the pattern of labor exit for American men and 
women born between 1929 and 1931. The estimates are based on data from the CPS ORG files for calendar years 1979-2005. ${ }^{8}$ Like Figure 4, which was calculated using cross-sectional estimates of the labor supply variables in 2003-2005, Figure 6 tracks three measures of aggregate labor supply and productivity: the labor force participation rate, the average weekly hours of all persons, and the estimated average weekly earnings in the population. The work effort and earnings of people who are between 50 and 74 are measured as percentages of labor supply or earnings at age 50. For men there is little difference in exit rates as measured with these three indicators between ages 51 and 59, but the differences become greater at successively higher ages above 59. Starting at age 60 both hours of work and average weekly earnings fall more rapidly than the labor force participation rate. For women average earnings decline more slowly up through age 61 than either labor force participation or hours of work. This implies that the weekly wages of women who remain employed tend to rise. ${ }^{9}$ Either women with low weekly earnings are the earliest to drop out of the job market or, alternatively, the women who remain employed experience healthy gains in their real hourly wages. After age 62, women's average hours and earnings decline more rapidly than their participation rate, precisely the same pattern we see among men. Labor force exit is slower as measured using the participation rate than it is when using either average work hours or weekly earnings.

The results in Figure 6 can be translated into a retirement index indicating the overall drop in labor supply between ages 50 and 74. For men born between 1929 and 1931 the retirement indices for the labor force participation rate, average hours, and average earnings are, respectively, 41 percent, 45 percent, and 46 percent. For American women, the same retirement indices are 41 percent, 44 percent, and 42 percent. Unlike the male and female retirement patterns estimated with cross-sectional data, the cohort exit rates imply that American men and women born in the same year have a very similar pattern of exit from the workforce. The rate of earnings decline for women is somewhat slower than it is for men, but this is probably due to differences in labor market experience before age 50. By age 50 most men born in 1929-31 had

\footnotetext{
${ }^{8}$ The ORG files did not contain useable information on respondents' wages until 1979.

9 This pattern is also found for younger birth cohorts of women. For the cohorts born between 1929 and 1945, the wage data in the CPS ORG files show that earnings either rose or fell more slowly than women's employment rates and average weekly hours of work at ages between 51 and 61 . Starting at age 62, their average earnings decline more quickly than their participation rate or average hours of work. It is not possible to track earnings from age 50 onwards for birth cohorts born in 1928 or earlier years.
} 
been continuously in the workforce for 25 or more years. Few of them were enjoying big annual pay gains because they were accumulating extra job experience. Women born in the same years were more likely to have experienced a break in labor force participation between age 20 and 45 associated with marriage or child-bearing. As a result, many women in their early 50s may have obtained better than average annual pay increases because of sizeable percentage gains in their lifetime job experience.

Partial cohort analyses. Though cohort retirement rates are usually more informative than period retirement rates, especially for women, they have a major disadvantage. At least twenty years' data are needed to estimate the retirement patterns of a single birth cohort. Only a few countries have published high quality labor statistics for periods much longer than twenty years. Thus, the use of cohort exit rates greatly restricts our ability to measure retirement trends over time, since only a few birth cohorts have completed the retirement process within the time span covered by the data. Moreover, if we include only the experiences of birth cohorts that have substantially completed their retirement we will miss recent trends in labor supply in the 50-64 year-old population. These trends may indicate an acceleration or a reversal of the trends that affected the somewhat older cohorts just completing the retirement process. For these reasons it is worthwhile to measure labor force exit using a gauge that measures labor force withdrawal with cohort data, but that combines information from cohorts currently at different stages in the retirement process. In most countries labor force statistics are available for 5-year age groups. Suppose the retirement process is concentrated mainly in the 20 years between ages 50 and 69. Suppose also that labor statistics are available for four birth cohorts within this 20year span, say, cohorts $i=1,4$, where 1 designates the youngest and 4 the oldest cohort. Define the labor force retention rate, $r_{i}$, as a cohort's labor supply in period $t+5$ measured as a fraction of the amount supplied by the cohort five years earlier, $r_{i}=L_{i, t+5} / L_{i, t}$, where $L_{i, t}$ is the level of labor supply in cohort $i$ in year $t$. With estimates of $r_{i}$ for each of the cohorts between 50 and 69, it is straightforward to calculate a "partial cohort" exit rate as:

$$
\mathrm{E}_{t}=1-\left(r_{1}+r_{1} r_{2}+r_{1} r_{2} r_{3}+r_{1} r_{2} r_{3} r_{4}\right) \text {. }
$$

This measure of the exit rate combines estimates of the 5-year cohort exit rate from four birth cohorts to derive an estimate of the overall exit rate over a 20 -year age span. To obtain a prediction of average labor supply over ages 50 to 69 , we can combine information about the 
partial cohort exit rate with information about contemporaneous labor supplied at the life cycle peak, say, LS $_{45-49, t}$ :

(2) Predicted $\mathrm{LS}_{50-69, t}=\mathrm{LS}_{45-49, t} \times\left(1-\mathrm{E}_{t}\right)$.

Figures 7 and 8 use U.S. labor force participation rate data from 1960 through 2006 to calculate exit rates under the three definitions just considered. All three estimates use information on participation rates in 5-year age groups. The period exit rate is calculated using information from a single calendar year, while the cohort rate is calculated using information from a sequence of years, every fifth year, starting when a birth cohort is 45-49 years old. The partial cohort rate is estimated with information on participation rates for two calendar years separated by 5 years. The exit rates for men, shown in the top panel of Figure 7, show a longterm rise in exit rates followed by a recent decline under all three definitions. Both the period exit rate and partial cohort exit rate show a substantial increase in the pace of retirement between the mid-1960s and mid-1980s followed by a leveling off in the retirement rate. After the mid1990s, the two measures show a drop in the retirement rate. The period rate falls 5 percentage points to 28 percent, and the partial cohort rate drops 7 percentage points to 29 percent. The cohort exit rate also shows a decline, though it is more modest. The slower rate of decline indicates that part of the trend pushing down male retirement rates is occurring in birth cohorts which have not yet attained age 65-69. There is a strong likelihood that as these younger cohorts attain 65 the cohort retirement rate will continue to fall.

The lower panel in Figure 7 shows the average labor force participation rate of American men between 50 and 69 years old as implied by the estimated exit rates shown in the top panel. For both the period and cohort exit rates, the participation rate average can be calculated as the averages of the participation rates in the 50-54, 55-59, 60-64, and 65-69 age groups for the relevant calendar year or birth cohort. Using the partial cohort exit rate, the implied average level of the participation rate between ages 50 and 69 is $\operatorname{LFP}_{45-49, t} \times\left(1-E_{t}\right)$, where $L P_{45-49, t}$ is the labor force participation rate at age 45-49 in year $t$ and $\mathrm{E}_{t}$ is the exit rate in that same year. The lower panel in Figure 7 shows that the average male participation rate between ages 50 and 69 fell steeply between the mid-1960s and mid-1980s and then leveled off. Since the mid-1990s there has been a rise in the average participation rate according to all three measures, partly reversing the steep fall in participation rates that occurred in earlier decades. 
Figure 8 displays comparable tabulations for American women. There is less consistency in the long-term pattern reflected by the three exit rate measures than there is for American men. The period exit rate for women shows a steep long term rise in the retirement rate from the mid1960s through the mid-1980s followed by a large decline over the next two decades. As we have seen, however, the period exit rate can provide a misleading picture of retirement when the level of labor supply at the lifetime peak is changing significantly from decade to decade. The cohort exit rate shows a much smaller change in the retirement rate among the cohorts that attained age 65-69 between 1980 and 2006. The cohort exit rate trended upward, but the overall change was relatively small. The partial cohort exit rate shows a steep rise in the speed of retirement between the mid-1960s and mid-1970s, but only cyclical changes thereafter. The lower panel in Figure 8 shows trends in average labor force participation rates between age 50 and 69 using three alternative measures or assumptions. All three show a substantial increase in female labor force participation rates at older ages. Both the period and cohort estimates suggest there has been a generally smooth upward trend in the average participation rate, with an acceleration in the rate of increase for cohorts which attained age 65-69 after the early 1990s. The third estimate displayed, which is based on the partial cohort exit rate, shows large swings in expected old-age participation rates, driven partly by major swings in the retirement rate and partly by increases in women's peak lifetime labor supply, measured as their labor force participation rate when they are 45-49 years old. The cyclical sensitivity of the partial cohort exit rate should not be surprising. The 5-year retention rate, $r_{i}$, is measured as the ratio of labor supply in year $t+5$ to labor supply in year $t$. If there is a recession between years $t$ and $t+5$, participation rates and observed retention rates may fall for reasons that have little to do with long-term retirement trends.

The results in Figures 7 and 8 present a clear picture of recent drops in the retirement rate of American men, contrary to the conclusion of Gendell (2001) who found that the average U.S. retirement age continued its long term decline during the 1990s. In fact, all three estimates of the male retirement rate imply that the rate fell in the 1990s and continued to fall after the turn of the century. In spite of a small drop in participation rates in the prime working ages, average male participation rates between ages 50 and 69 have been climbing. ${ }^{10}$ Trends in the retirement rate of

${ }^{10}$ In order to make the estimates comparable to estimates that can be made for other OECD countries, the calculations in Figures 7 and 8 exclude the experiences of Americans who are between 70 
American women are more ambiguous. The two most meaningful indicators of the speed of labor force exit are the cohort exit rate and the partial cohort rate. The former shows little obvious trend since 1990, while the partial cohort rate shows cyclical swings but no clear secular trend. Nonetheless, old-age labor force participation among women past 50 has risen strongly since 1990, primarily because peak lifetime participation rates are now considerably higher than they were in the past. If women's retirement rate remains relatively unchanged in the future, past increases in women's participation rates at age 45-49 will continue to push up old-age participation rates for at least the next decade.

Cohort exit rates at selected ages. Cohort exit data can be presented in a way that pinpoints the ages at which changes in workforce withdrawal patterns are affecting labor supply in old age. Figures 9 and 10 show trends in the cohort exit rate at selected ages. The exit rate is measured as the proportional drop in the labor force participation rate that occurs as a birth cohort grows 5 years older. These withdrawal rates can be calculated using historical data on participation rates in 5-year age groups. The results in Figure 9 show estimates of these withdrawal patterns for five groups of American men. The top panel displays estimates for men in two younger age groups, and the bottom panel shows estimates for three older groups. Cohort exit rates in all five age groups increased sharply between the mid-1960s and mid-1970s, but in later periods the trends were less consistent in different age groups. After the mid-1970s there were cyclical changes in the rate of withdrawal of men as they age from 45-49 to 50-54, but there has been very little systematic trend. As men age from 50-54 to 55-59 their exit rates generally rose in a cyclical pattern from the mid-1970s to the mid-1990s, but since 1995 the exit rate at these ages has fallen. The same general pattern is apparent for men as they age from 55-

and 74 years old. When these participation rate data are included, the proportional drop in the U.S. male exit rate since 1990 is even larger than shown in Figure 7. Gendell's conclusion regarding the trend in retirement in the 1990s may be partly due to adjustments he makes for predicted mortality and for new interviewing methods the BLS introduced into the CPS in 1994. He suggests the change in interviewing methods led to a bias in estimated participation rates for older people. This does not seem persuasive, first, because it is hard to see any break in the trend toward higher old-age participation rates after 1993 and, second, because the trend toward lower old-age exit rates from the labor force is evident both before and after the change in interviewing methods. Gendell also makes demographic adjustments for his estimates of the age distribution within 5-year age groups. If we use the monthly CPS files, we can calculate labor force exit rates by single year of age. No adjustments are needed for the unequal sizes of single-year birth cohorts within a 5-year group. My finding that the U.S. labor force exit rates in old age have generally declined since the early 1990s is confirmed when partial cohort exit rates are estimated using labor force participation rate data by single years of age. 
59 to 60-64, except that the decline in exit rates after 1995 was more pronounced. In the oldest two age groups the cohort exit rate has been falling since the mid-1980s. Between the 1985 and 2005 the exit rate of men as they age from 60-64 to 65-69 has declined about 20 percentage points. In the same period, the exit rate of men as they age from 65-69 to 70-74 declined 16 percentage points. The exit rates in these two groups of older men are now lower than they have been at any time since the mid-1960s. These results suggest that the main reason for the recent decline in overall exit rates is that the exit rate of men in their 50s has stopped rising while men who are past age 60 have been slower to leave the workforce.

Results for American women are displayed in Figure 10. In many ways these are similar to those for men. All five age groups experienced a sharp increase in exit rates between the late 1960s and mid-1970s, but since that time the experience of the groups has diverged. Exit rates in the two youngest age groups have gone up, while exit rates in the two oldest age groups have declined. Women in the middle age group have experienced a recent decline in exit rates after a long period of relative stability. Note that the rise in women's exit rates in the two youngest groups is from a very low rate in the period up through the early 1980s. In the early and late 1970s, women in the youngest age groups experienced negative exit rates as they aged from 4549 to 50-54. More women in these cohorts entered the workforce than left between these ages. By the end of the 1990s the cohort exit rates of women in the two youngest age groups are similar to those of men the same age. Over the past decade the relative stability of women's overall exit rate after age 50 has been the result of small increases in the exit rate before age 60 combined with modest declines in the exit rate after 60. Thus, for women as for men a major trend that has driven old-age participation rates in recent years has been the slowing of labor force exit after age 60 .

\section{Cross-national Trends in the Retirement Rate}

Even though few countries have labor force statistics that extend as far back as those for the United States, it is possible to calculate cohort exit rates for most of them. Tables 5 and 6 show alternative estimates of exit rates for 21 countries. For all these countries we can calculate both period exit rates and partial cohort exit rates for 2006, since the data requirements for this calculation are not very burdensome. Three countries lack time series data going back far enough to calculate the cohort retirement rate for the population that was between 65 and 69 in 2006. This leaves 18 countries for which it is possible to calculate the cohort retirement rate. 
Each country's period exit rate is displayed in column 1, its cohort exit rate is shown in column 2, and its partial cohort exit rate is shown in column 3. Countries are listed in order of their partial cohort exit rates, from highest to lowest rate. The three columns on the right show the average labor force participation rate for people when they are between 50 and 69 years old. For example, for the cohort of Belgian men who attained age 65-69 in 2006, this average was 39 percent (see column 5 in Table 5). That is, the average of this birth cohort's participation rates in 1991 (when it was 50-54), in 1996 (when it was 55-59), in 2001 (when it was 60-64), and in 2006 (when it was 65-69) was 39 percent. For the 19 countries where it is possible to calculate the cohort, the average participation rate for men in the 18 countries was 57 percent, substantially higher than the average rate among older Belgian men.

The crucial comparison is among labor force withdrawal rates as measured by the period exit rate, the cohort exit rate, and the partial cohort exit rate. All three measures of the exit rate present a generally similar picture in the case of men (Table 5). The correlation between the period exit rate and cohort exit rate is 0.96 . The correlation between the period exit rate and the partial cohort rate is even higher, 0.98. The rank order of the countries would change very little if we used the period exit rate or the cohort exit rate rather than the partial cohort exit rate to rank the countries. In the case of women there is a bigger difference among the three measures of the exit rate (Table 6). The correlation between the period and cohort rates is only 0.70 , and the correlation between the period and partial cohort exit rates is just 0.72 . The relative ranking of the countries is also affected by the measure of exit we use. Using the period exit rate, Spanish women appear to have rapid labor force exit. Using the cohort exit rate, their withdrawal rate is much slower. For women in Denmark the situation is reversed. One lesson from Tables 5 and 6 is that period, cohort, and partial cohort exit rates present a generally similar picture of crossnational differences in the case of male retirement, but they present contrasting pictures of crosscountry differences in female retirement. In countries where middle-aged women's participation rates have been changing rapidly, the period retirement rate offers an unreliable indicator of the speed of retirement. Note that the all-country average period exit rate is considerably higher for women than it is for men (45 percent versus 37 percent). In contrast, the average cohort exit rate is only slightly higher among women than among men (42 percent versus 39 percent), and the partial cohort exit rates are virtually the same on average across the 21 countries (36 percent for women versus 35 percent for men). While the period exit rates suggest that women typically 
retire faster than men, the cohort and partial cohort rates imply that the systematic difference between the average retirement rates of men and women is small.

Cross-country differences in labor force exit are usually similar, though not identical, for men and women. All measures of the exit rate show that Austria, Belgium, France, and Italy have exit rates that are well above average, and this is the case for both men and women. Australia, Japan, New Zealand, and the United States have slower than average exit rates under all three definitions and for both sexes. Not surprisingly, there is a strong inverse correlation between exit rates and average labor force participation rates in old age. In countries with high exit rates, participation rates at older ages are typically low. Women in Denmark and Finland represent a partial exception. Old-age participation rates among Danish and Finnish women are above average, but so, too, are labor force exit rates. Women in these countries have elevated labor force participation in middle age. This means that their rapid withdrawal from the labor force still leaves them with above-average participation rates between ages 50 and 69 .

Trends in labor force exit rates. Comparing retirement trends across countries requires suitable data on labor supply, by age, covering a lengthy span of years. Both the OECD and the ILO disseminate information on labor force participation rates, by age, for a sample of countries. The OECD data are obtained from labor force surveys conducted by national statistical agencies (OECD 2006). The estimates are generally based on standard labor force status definitions which are reasonably consistent across time within the same country and are plausibly consistent across countries. The ILO data attempt to estimate economic activity rates within age and sex groups in a consistent way based on national census data and labor force surveys, where such data are available. They are based on demographic interpolations and projections where reliable survey data for a particular year are not available (ILO 1997). When the ILO data can be compared with OECD labor force survey estimates covering the same historical year, there is usually a close correspondence between estimates in the two files. The advantage of the ILO data is that they cover a uniform set of historical years $(1950,1960,1970,1980,1990$, and 1995). Their disadvantage is that they are not necessarily derived from a high quality labor force survey, nor are they always based on a survey conducted in the indicated year. The OECD labor force data, though more accurate and consistent, do not cover a uniform time span for the countries in the file, and for many countries the span of years covered is not very long. Bearing 
these limitations in mind, it is straightforward to compare trends in labor force exit rates for the OECD countries we have considered thus far.

Tables 7 and 8 show changes in labor force exit rates in selected time intervals, with each interval ending in 2006. Results displayed in the five columns on the left show changes in period exit rates, while the results in the five columns on the right indicate changes in partial cohort exit rates. The estimates in the tables are based on labor force data from the OECD. Since the data cover an unequal span of years for these countries, it is not always possible to calculate changes in exit rates for a uniform set of years. For both definitions of the exit rate it is possible to calculate the change in the exit rate between 2000 and 2006 for all 21 countries (the fifth and tenth data columns in the tables). The overwhelming majority of countries saw a decline in labor force exit rates, under both definitions, between those two years. In 16 out of the 21 countries, both the period exit rate and the partial cohort exit rate declined among men. In 18 of the 21 countries, both measures of the exit rate declined among women. On average the partial cohort exit rate fell 4.4 percentage points among men and 6.7 percentage points among women, implying there was a sizeable decline in the rate of labor force withdrawal during the period.

When the span of comparison years is extended back to 1995, the falloff in labor force exit rates is even greater. On average for men in the 21 countries, the period exit rate declined 3.6 percentage points between 1995 and 2006, and the partial cohort exit rate fell 7.3 percentage points in the 19 countries where a calculation is possible. The comparable declines among women were 6.5 percentage points in the period exit rate and 9.1 percentage points in the partial cohort exit rate. For several countries the drop in the partial cohort exit rate exceeded 10 percentage points. Men in Australia, Canada, Denmark, Finland, the Netherlands, New Zealand, and the United Kingdom experienced a drop this large, as did women in Australia, Canada, Denmark, Finland, Ireland, Italy, the Netherlands, and New Zealand. As we extend the comparison period back to 1990, 1985, and 1980, a progressively larger number of countries drops out of the analysis because of data limitations. Among the countries which remain, there is less evidence of a long-term decline in the exit rate. For example, we can calculate the change in period exit rates between 1985 and 2006 for 15 countries. In 9 of these countries, the male exit rate has increased since 1985 even if only slightly. Among all 15 of these countries, the average period exit rate among men increased 0.6 percentage points between 1985 and 2006. 
The results in Tables 7 and 8 suggest that there has been a recent drop in labor force exit rates in old age in nearly all the large industrial countries. The recent drop has been larger in some countries than in others, and it began earlier in some countries than in others. In those countries where the falloff in exit rates was large for men, it is also likely that it was large for women. Because good labor force statistics by year of age do not cover a uniform set of years for each country, it is impossible to determine with the OECD data whether cross-country trends in the exit rate are also similar in the more distant past.

Table 9 assesses the trend in old-age labor force participation over a longer span of years by combining information from the ILO and OECD files. The ILO file provides estimates of the labor force participation rate in 1960, and the OECD file provides estimates of the labor force participation rate in a sequence of years up through 2006. Unfortunately, the number of years varies from one country to the next because of differences in the time span covered by good labor force surveys. The tabulations in the table show the total change in labor force participation rates between 1960 and 2006. This change is divided into two components: (a) the drop in participation between 1960 and the year when labor force participation reached its low point (according to the OECD estimates); and (b) the increase in participation between the year when the participation rate reached its low point and 2006. Note that data limitations prevent us from knowing with certainty the low point of labor force participation between 1960 and 2006. For a particular country, the OECD file may not include data from the year when the participation rate reached its minimum. Nonetheless, the tabulations in Table 9 permit us to see whether participation rates in recent years have risen and to see whether the increase is large in relation to the drop in participation that occurred after 1960.

Table 9 is divided into four panels, 9A through 9D. Each shows participation rate trends in one of four age groups, men between 45-49, 50-54, 55-59, or 60-64. Results are not presented for women, because the trend in female participation at older ages has been dominated by the rapid rise in participation rates at younger ages rather than by changes in the exit rate. For men, the trend in old-age participation rates has been mainly driven by changes in labor force exit rates. The ILO estimates of the participation rate in 1960 are presented in column 3, while the OECD estimates of the 2006 participation rate are displayed in column 5. Column 4 contains the OECD estimate of the lowest participation rate in the years covered by their file. Column 2 shows the year in which the lowest participation rate was observed. In a very small number of 
cases, the low point of participation was attained in the very last year covered by the OECD file, 2006. In an overwhelming share of cases, however, the low point was achieved in an earlier year. Column 1 shows the first year covered by data in the OECD file. ${ }^{11}$ With only one exception - Austrian men age 55-59 - the low point of participation occurs after the first year covered by the OECD file, suggesting there is a high probability that the year between 1960 and 2006 with the lowest participation rate is included in the OECD file.

Changes in the labor force participation rate between 1960 and 2006 are indicated in the two columns on the right. The first of these columns shows the total drop in the participation rate between 1960 and the likely low point of participation between 1960 and 2006. The second shows the total rebound in the participation rate between that low point and 2006. For example, on average the participation rate of 45-49 year-old men fell 5.4 percentage points between 1960 and the average low point of participation. In the years after the low point in participation was attained, the participation rate of 45-49 year-old men increased 1.3 percentage points, or about one-quarter of the earlier decline.

Participation rate changes in the early retirement years, ages 50-54, are displayed in Table panel 9B. On average across the 21 countries, the male participation rate in this age group fell 8.5 percentage points between 1960 and the probable low point of participation. The average year when the minimum was achieved is 1996. Since that low point was attained, the participation rate has increased by an average of 2.7 percentage points, almost one-third of the earlier decline. Men in every country except Switzerland have experienced an increase in participation rate, though in some cases the gain was small and may not be statistically significant. The biggest declines in participation between 1960 and the low point of participation occurred in the Netherlands, Ireland, Belgium, Italy, the United Kingdom, and Italy. Several of these countries have seen a rebound in male participation that has substantially offset the earlier decline. In Belgium and the Netherlands the rebound in participation rates has offset about onehalf of the earlier decline, and in Italy it has offset four-fifths of the decline. Men in Japan, France, Switzerland, and Germany saw a relatively small participation rate decline in this age

${ }^{11}$ The OECD data on the participation rate extends back to 1960 for the United States and to various years in the 1960s for France, Japan, and Sweden. However, data from these years are not needed to estimate the low point of labor force participation, since the low point occurred many years after 1970 for all these countries. 
group, so it is not surprising that they have seen little rise in their participation rates in recent years.

Changes in the participation rate of men between 55 and 59 have varied widely across countries (Table panel 9C). Men in the Netherlands, Belgium, Italy, Finland, and Austria experienced drops in their participation rate of 25 percentage points or more. In contrast, Japanese, Swiss, and Swedish men saw a decline of 9 percentage points or less. Among the countries with notable declines in labor force participation, New Zealand, Germany, Denmark, and the Netherlands have seen at least half of the decline reversed by a subsequent rise in the participation rate. In the Netherlands, for example, the participation rate of men age 55-59 fell from 95 percent in 1960 to 60 percent in 1994. Between 1994 and 2006 the participation rate increased 19 percentage points to 79 percent, reversing more than half of the 1960-1994 decline. Though the swings in Dutch participation are unusually wide, many other OECD countries saw participation rate movements that followed a similar pattern. In the United Kingdom, the participation rate fell 22 percentage points between 1960 and 1995, but after that year it increased 5 percentage points, reversing about one-fifth of the earlier decline. Across the 21 countries in the sample, the average low point of labor force participation in this age group was attained in 1996.

Among men who are 5 years older, the low point in labor force participation was attained two years later in 1998 (Table panel 9D). On average the participation rate of 60-64 year-old men fell 39.0 percentage points between 1960 and the likely low point of participation. After that low point was achieved, the participation rate increased by an average of 9.1 percentage points, reversing almost one-quarter of the earlier decline. Men in every country except Italy and Switzerland have experienced a recent increase in their participation rate. In a number of countries the increase was substantial. Finland, Germany, the Netherlands, Denmark, Australia, and Sweden saw participation-rate increases of 10 percentage points or more. In New Zealand the participation rate of 60-64 year-old men increased 40 percentage points, reversing all of the estimated drop in participation that occurred between 1960 and 1992. In the United States the low point of participation was in 1994, when the participation rate was 29 percentage points below its level in 1960. By 2006 the U.S. participation rate had increased to 59 percent, 6 percentage points above its 1994 low point. This increase offset about one-fifth of the 19601994 decline. In some countries with large participation-rate declines after 1960 there has been 
only a modest reversal in the long-term trend toward lower participation. Men in Belgium, France, Portugal, and Greece experienced participation-rate drops of at least 33 percentage points after 1960. In none of these countries has the recent rise in participation rates offset even onetenth of that decline. Relative to labor supply levels in 1960, male participation rates in these countries remain very low.

Because the ILO does not publish consistent historical estimates of participation rates for men between 65 and 69, for many countries it is not possible to track long-term trends in this age group. Table 10 presents statistics on participation-rate trends in this age group using only data supplied by the OECD. Because the span of years differs widely from one country to the next, we cannot derive an estimate of the early decline in participation rates during a consistent period of time. In Japan, Norway, Sweden, and the United States, the data series begin in the early 1970s, when old-age participation rates were substantially higher than they are today. In Austria, Germany, and Switzerland the data do not start until the 1990s, when participation rates among 65-69 year-olds had already reached low levels. Nonetheless, the data allow us to calculate changes in the participation rate that have occurred during the span of years included in each country's data. The right-hand column in the Table 10 shows the change in labor force participation rates between the year with the lowest labor force participation rate and 2006, the last year in the data file. For purposes of comparison, the second column from the right shows the change in the participation rate between the first year in the OECD data file and the year that has the lowest participation rate. On average, participation rates have increased 5.6 percentage points since the year with the lowest participation rate. New Zealand, Australia, the United States, Denmark, the United Kingdom, and Canada have seen the biggest gains in participation in this age group. Gains have been much smaller or negligible in Spain, Finland, Ireland, Italy, Germany, Japan, Greece, and France.

The tabulations in Tables 9 and 10 show that male participation rates after age 50 have recently been rising in most of the rich OECD countries. In many of these countries the recent gains in participation have been big enough to reverse a sizeable fraction of the decline in participation rates that occurred after 1960. On average the rebound in male participation rates began after a low point in participation that occurred in the middle or late 1990s. Some countries experienced participation-rate gains in all four age groups past age 50. Australia, Canada, Denmark, Finland, Ireland, the Netherlands, the United Kingdom and especially New Zealand 
saw notable increases in participation rates in all four groups. In other countries, participationrate increases were concentrated in particular age groups. The United States saw a major rise in the participation rate of men age 60 and older but has seen little increase in the participation rates of men between 50 and 59. In Italy participation rates increased among men in their 50s but changed little among men in their 60s. In most age groups Switzerland has seen major declines in male participation, though Swiss participation rates remain high compared with those in other OECD countries. French participation rates are not rising.

In future research it would be worthwhile to examine the policy changes and macroeconomic influences that have contributed to the common pattern of declining labor force exit rates and rising participation rates in older ages.

\section{Conclusions}

This paper proposes and estimates three simple measures of the speed of exit from the workforce. The period exit rate is the measure that imposes the least demanding information requirements. It can be estimated using data on labor supply, by age, for a single period of time. The measure can provide a misleading picture of the retirement process, however, when labor supply behavior is changing from one generation to the next. A second measure, the cohort exit rate, estimates labor force exit using a sequence of labor supply data for a single birth cohort. The data reflect the group's withdrawal from the labor market between an early age (near the peak of lifetime labor supply) and a late age (when retirement is substantially complete). Although this measure provides the most reliable indicator of exit rates, it also imposes heavy data requirements. This means it cannot be estimated for a large number of birth cohorts except in countries with a long history of good labor force surveys. The third measure, the partial cohort exit rate, uses cohort data for a number of birth cohorts that have begun or partially completed the retirement process in a given year. This measure is sensitive to business cycle influences, but it offers a less biased estimate of the rate of labor supply reduction than estimates based on information from a single cross-sectional survey. All three exit measures can be used to estimate labor supply reductions during retirement using a variety of indicators of labor supply, including the labor force participation rate, the employment rate, average hours of work, and average weekly earnings.

When estimates of the retirement process are derived using the cohort-based measures of labor force exit, I find that the retirement patterns of men and women are much more similar than 
they appear when they are estimated with a single year's data. The differences between the cohort-based and period exit rates are especially noticeable in the case of women, who experienced large increases in participation rates and paid work hours during the second half of the twentieth century.

The pattern of labor supply reduction during retirement looks broadly similar whether we use the labor force participation rate, the employment rate, average weekly work hours, or average weekly wages to measure the fall in supply. However, on average labor supply reductions appear to occur faster if labor supply is measured using a more comprehensive indicator, such as average work hours or average weekly earnings. This finding suggests that both the weekly hours of old people who remain employed and the weekly wages of aging workers tend to decline at older ages, pushing down aggregate hours and total earnings faster than the rate of decline in participation rates.

Like earlier researchers I find large and systematic differences across countries in the pattern of retirement. With important exceptions, countries in continental western Europe tend to have faster labor force exit than Japan or the English-speaking countries. Within continental Europe, Portugal, Switzerland, and most Scandinavian countries tend to have below-average exit rates. Within a given country there is a high degree of consistency between the retirement patterns of men and women. If men have high exit rates, it is likely that women in the same country will have above-average exit rates, and vice versa. For males, all three measures of the exit rate show a similar cross-national pattern of exit. Countries with a high period exit rate also have a high exit rate measured using either of the two cohort-based measures. For women there is less consistency between the period estimate and the cohort-based estimates. This suggests researchers should use caution in drawing conclusions about the trend in women's retirement based only on measures that are derived using age-group differences observed in a single crosssection survey.

Although there are major differences in the retirement patterns observed in different countries, the time series analysis shows there is one development that is relatively common across industrial countries. With few exceptions the rich countries have seen a recent decline in old-age exit rates compared with the rates that were common in the mid-1990s. The recent drop in exit rates is hardly uniform across countries, but evidence for a decline is reasonably robust in a large proportion of countries. Suppose we define the exit rate as the percentage decline in 
labor supply between ages 50 and 69 compared with the level that would be observed at those ages if labor supply did not decline below the level among 45-49 year-olds. Between 1995 and 2006 the period exit rate among older men fell an average of 3.6 percentage points in the 21 countries included in the analysis. The period exit rate of older women fell an average of 6.5 percentage points in the same countries. The partial cohort measure shows an even bigger drop in average exit rates between 1995 and 2006. For men in the 21 countries the average decline was 7.3 percentage points; for women it was 9.1 percentage points. Because the partial cohort exit rate is sensitive to changes in the labor market, it is possible that part of the decline is due to tighter labor markets in some of the countries. Much of the past increase in labor force exit rates occurred in an environment of very tight labor markets, however, so it is unclear how important this factor has been in explaining the recent trend toward slower rates of labor force exit.

We can use standard data on labor force participation to see whether lower exit rates have so far had a noticeable impact on participation rates in older age groups. To gauge the relative magnitude of the recent rise in male participation rates, I calculated the reduction that occurred between 1960 and the year between 1960 and 2006 when the participation rate was lowest. Since that low point in participation rate occurred, average participation rates have increased 2.7 percentage points among men 50-54 years old, 5.6 percentage points among men 55-59, 9.1 percentage points among men 60-64, and at least 5.6 percentage points among men between 65 and 69. These estimates represent average increases in male participation rates in 21 industrialized countries. In comparison with the long-term decline in participation rates that occurred after 1960, the recent increases in male participation are not trivial. The 2.7percentage-point average increase among men between 50 and 54 represents about one-third of the average drop in participation rates that took place between 1960 and the year with the lowest male participation rate. For men between 55 and 59 years old the recent rebound in participation has offset a little less than one-third of the earlier decline. For men between 60 and 64 it has offset a little less than one-quarter of the earlier decline. The recent rise in the participation rates of older men differs widely across countries, and a handful of countries have seen little recent rise. On average, however, recent statistics on male participation tend to confirm that old-age labor force exit rates have begun to drop, reversing a decades-long trend toward earlier retirement. 


\section{References}

Anderson, Patricia M., Alan L. Gustman, and Thomas L. Steinmeier. 1999. “Trends in Male Labor Force Participation and Retirement: Some Evidence on the Role of Pensions and Social Security in the 1970s and 1980s." Journal of Labor Economics 17(4): 757-83.

Blöndal, Sveinbjörn, and Stefano Scarpetta. 1999. “The Retirement Decision in OECD Countries." Economics Department Working Paper No. 202. Paris: OECD.

Burtless, Gary. 2004. "Pension Reform and Labor Force Exit: Cross-National Evidence." Paper presented at the "International Forum of the Collaboration Projects." Tokyo: Economic and Social Research Institute. http://www.esri.go.jp/ip/pri-rc/macro/macro15/02-1R.pdf (accessed May 2006).

Burtless, Gary, and Joseph F. Quinn. 2001. "Retirement Trends and Policies to Encourage Work among Older Americans." In Peter Budetti et al., eds. Ensuring Health and Income Security for an Aging Workforce. (Kalamazoo: W.E. Upjohn Institute for Employment Research). . 2002. "Is Working Longer the Answer for an Aging Workforce?" Center for Retirement Research Issue in Brief \#11. Chestnut Hill, MA: Boston College. http://www.bc.edu/centers/crr/issues/ib_11.pdf (accessed May 2006).

Casey, Bernard, et al. 2003. "Policies for an Ageing Society: Recent Measures and Areas for Further Reform.” Economics Department Working Paper No. 369 (Paris: OECD).

Duval, Romain. 2003. "The Retirement Effects of Old-Age Pension and Early Retirement Schemes in OECD Countries." Economics Department Working Paper No. 370 (Paris: OECD).

Gendell, Murray. 1998. "Trends in Retirement Age in Four Countries, 1965-95," Monthly Labor Review (August): 20-30. . 2001. "Retirement Age Declines Again in 1990s," Monthly Labor Review (October): 12-21.

Gendell, Murray, and Jacob S. Siegel. 1992. "Trends in Retirement Age by Sex, 1950-2005," Monthly Labor Review (July): 22-29.

International Labour Organization (ILO). 1997. Economically Active Population, 1950-2010, Fourth edition. (Diskette database) (Geneva: ILO). Available at http://unstats.un.org/unsd/cdb/cdb source xrxx.asp?source code=29 (accessed December 2007).

Latulippe, Denis. 1996. "Effective Retirement Age and the Duration of Retirement in the Industrial Countries between 1950 and 1990." Issues in Social Protection, Discussion Paper 2 (Geneva: ILO).

Organisation for Economic Co-operation and Development (OECD). 2006. Labour Force Statistics by Sex and Age, Volume 2006 release 01: SourceOECD Employment and Labour Market Statistics (Paris: OECD). 
Peracchi, Franco, and Finis Welch. 1994. "Trends in Labor Force Transitions of Older Men and Women," Journal of Labor Economics 12(2), 210-242.

Quinn, Joseph F. 1999. "Has the Early Retirement Trend Reversed?" Paper presented at the First Annual Joint Conference for the Retirement Research Consortium, "New Developments in Retirement Research," May 20-21, 1999. (Chestnut Hill, MA: Center for Retirement Research at Boston College). http://escholarship.bc.edu/cgi/viewcontent.cgi?article=1206\&context=econ papers.

Scherer, Peter. 2002. "Age of Withdrawal from the Labour Force in OECD Countries." OECD Labour Market and Social Policy Occasional Papers, No. 49. (Paris: OECD).

Schmitt, John. 2003. "Creating a Consistent Hourly Wage Series from the Current Population Survey's Outgoing Rotation Group, 1979-2002.” Working paper. (Washington: Center for Economic and Policy Research).

U.S. Census Bureau, Department of Commerce. 1975. Historical Statistics of the United States: Colonial Times to 1970 (Washington: Government Printing Office). 
Table 1. Labor Force Exit in Fifteen Industrialized Countries, 2004

\begin{tabular}{|c|c|c|c|c|c|c|c|}
\hline & \multicolumn{7}{|c|}{ Age group } \\
\hline & $45-49$ & $50-54$ & $55-59$ & $60-64$ & 65-69 & 70-74 & $50-74 / a /$ \\
\hline \multicolumn{8}{|l|}{ Men } \\
\hline Labor force participation rate (\%) & 92.2 & 87.0 & 72.9 & 41.3 & 14.9 & 7.9 & 44.8 \\
\hline Employment / population ratio (\%) & 88.0 & 82.9 & 68.9 & 39.5 & 14.7 & 7.9 & 42.7 \\
\hline $\begin{array}{l}\text { Percent of age group at work }(\%) / \mathrm{b} / \\
\text { Average weekly hours of persons }\end{array}$ & 80.3 & 74.9 & 61.6 & 35.1 & 13.4 & 7.2 & 38.4 \\
\hline in age group (hours) /c/ & 33.7 & 31.2 & 25.4 & 13.9 & 4.5 & 2.2 & 15.4 \\
\hline \multicolumn{8}{|l|}{ Implied exit rate $(\%) / \mathrm{d} /$} \\
\hline From labor force & --- & 5.6 & 20.9 & 55.1 & 83.7 & 91.3 & 51.3 \\
\hline From employment & --- & 5.8 & 21.6 & 55.0 & 83.3 & 91.0 & 51.4 \\
\hline From actual work & --- & 6.7 & 23.1 & 56.3 & 83.5 & 91.1 & 52.2 \\
\hline In weekly work effort & --- & 7.4 & 24.5 & 58.8 & 86.9 & 93.7 & 54.3 \\
\hline \multicolumn{8}{|l|}{ Women } \\
\hline Labor force participation rate $(\%)$ & 76.1 & 68.6 & 52.1 & 25.6 & 7.6 & 3.3 & 31.4 \\
\hline Employment / population ratio (\%) & 71.7 & 64.9 & 49.3 & 24.6 & 7.5 & 3.2 & 29.9 \\
\hline $\begin{array}{l}\text { Percent of age group at work }(\%) / \mathrm{b} / \\
\text { Average weekly hours of persons }\end{array}$ & 63.5 & 57.1 & 43.1 & 21.1 & 6.6 & 2.9 & 26.2 \\
\hline in age group (hours) /c/ & 21.6 & 19.2 & 14.2 & 6.6 & 1.8 & 0.7 & 8.5 \\
\hline \multicolumn{8}{|l|}{ Implied exit rate $(\%) / \mathrm{d} /$} \\
\hline From labor force & --- & 10.5 & 32.9 & 67.1 & 90.1 & 95.8 & 59.3 \\
\hline From employment & --- & 10.1 & 32.7 & 66.5 & 89.8 & 95.6 & 59.0 \\
\hline From actual work & --- & 10.6 & 33.4 & 67.5 & 89.9 & 95.7 & 59.4 \\
\hline In weekly work effort & --- & 11.5 & 35.6 & 70.7 & 92.1 & 97.1 & 61.4 \\
\hline
\end{tabular}

\footnotetext{
Notes:

/a/ Arithmetic average of rates for 50-54 to 70-74 age groups.

/b/ Percent of population that is both employed and at work in survey reference week.

/c/ Hours worked in the survey reference week, including zeroes for persons not employed or at work in that week.

/d/ Reduction in estimated work effort, measured as a percent of work effort among persons 45-49 years old.

Source: Author's tabulations of quarterly 2004 European Labour Force Survey (LFS) data for Austria, Belgium,

Denmark, Finland, France, Germany, Greece, Ireland, Italy, the Netherlands, Norway, Portugal, Spain, and Sweden, and tabulations of the U.S. Current Population Survey (CPS) files for January-December 2004. (The German data cover only the second calendar quarter of 2004; data for the other 13 European countries cover all four calendar quarters in 2004.) Entries in the table reflect unweighted averages for the fifteen countries
} 


\section{Table 2. Labor Force Exit in Fifteen OECD Countries, by Educational Attainment, 2004}

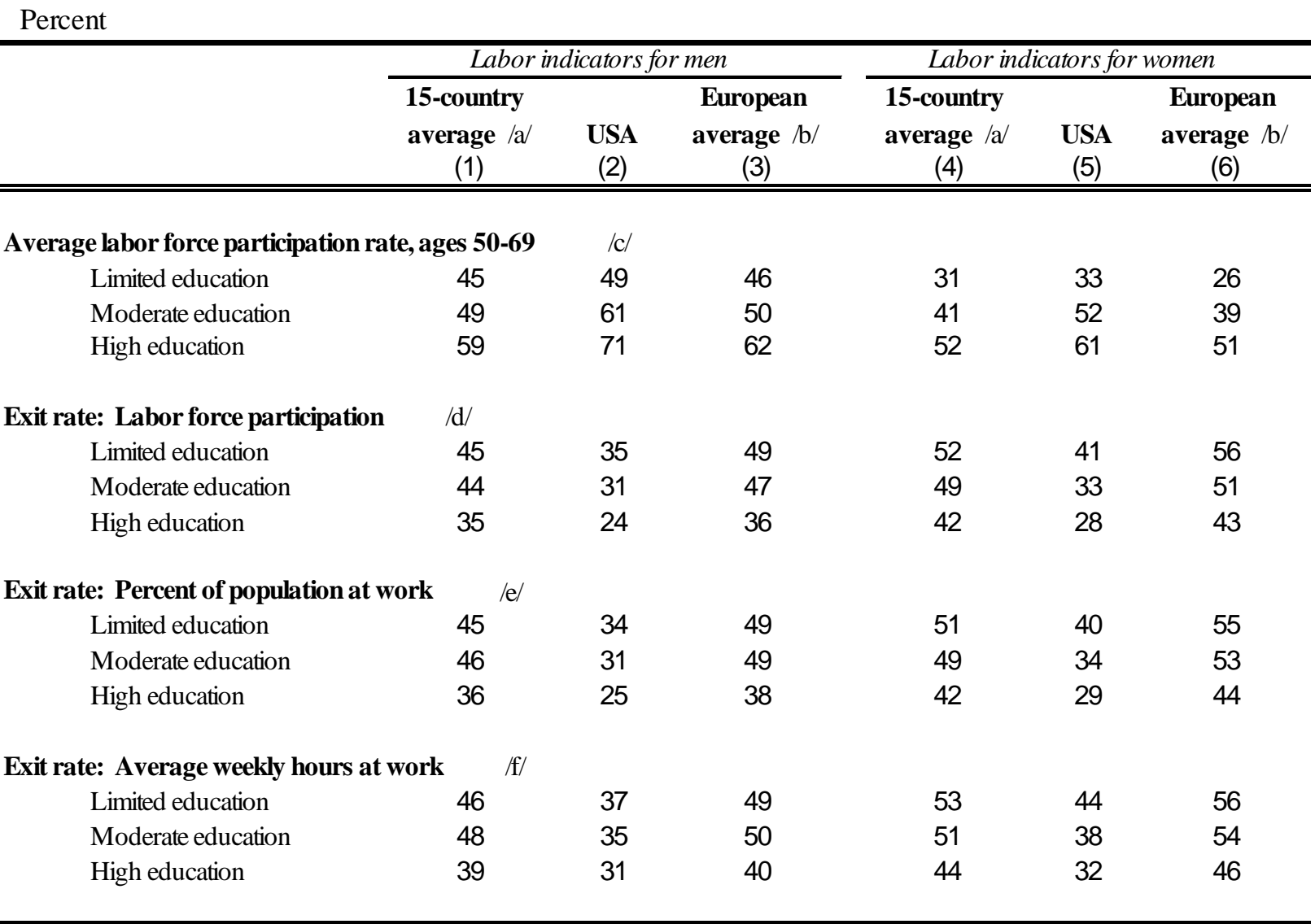

\footnotetext{
Notes:

la/ Unweighted average for all 14 European countries and the United States.

/b/Population-weighted average for 14 European countries.

/c/ Average labor force participation rate between ages 50 and 69.

/d/Reduction in estimated labor force participation between ages 50 and 69, measured as a percent of participation rate among persons 45-49 years old (see text).

le/ Reduction in estimated percentage of the population typically at work between ages 50 and 69 , measured as a percent of active work rate among persons 45-49 years old (see text).

/f/Reduction in average weekly hours at work in the population between ages 50 and 69, measured as a percent of average weekly hours among among the population $45-49$ years old (see text).

Source: Author's tabulations of quarterly 2004 European Labour Force Survey (LFS) data for Austria, Belgium,

Denmark, Finland, France, Germany, Greece, Ireland, Italy, the Netherlands, Norway, Portugal, Spain, and Sweden, and tabulations of the U.S. Current Population Survey (CPS) files for January-December 2004. (See sources of Table 1.)
} 


\section{Table 3. Male Labor Force Period Exit Rates in Twenty-one OECD Countries, 2003-2006}

\begin{tabular}{|c|c|c|c|c|c|c|c|}
\hline & \multirow{2}{*}{$\begin{array}{c}\text { Participation } \\
\text { rate, age } \\
\mathbf{4 5 - 4 9} \\
(1) \\
\end{array}$} & \multicolumn{4}{|c|}{ Exit rate through age -- } & \multirow{2}{*}{$\begin{array}{c}\text { Labor } \\
\text { force } \\
\text { exit rate, } \\
\mathbf{5 0 - 6 9} \\
(6)\end{array}$} & \multirow{2}{*}{$\begin{array}{c}\text { Average } \\
\text { participation } \\
\text { rate, } \\
\mathbf{5 0 - 6 9} \\
(7) \\
\end{array}$} \\
\hline & & $\begin{array}{c}\mathbf{5 0 - 5 4} \\
(2) \\
\end{array}$ & $\begin{array}{c}\mathbf{5 5 - 5 9} \\
(3) \\
\end{array}$ & $\begin{array}{c}60-64 \\
(4) \\
\end{array}$ & $\begin{array}{c}\mathbf{6 5 - 6 9} \\
(5) \\
\end{array}$ & & \\
\hline Belgium & 91 & 10 & 39 & 76 & 94 & 55 & 41 \\
\hline France & 94 & 3 & 29 & 80 & 96 & 52 & 45 \\
\hline Austria & 94 & 7 & 28 & 80 & 92 & 52 & 45 \\
\hline Italy & 94 & 7 & 39 & 68 & 88 & 51 & 47 \\
\hline Finland & 90 & 6 & 22 & 60 & 90 & 44 & 50 \\
\hline Netherlands & 91 & 4 & 15 & 65 & 87 & 43 & 52 \\
\hline Germany & 95 & 4 & 15 & 59 & 92 & 42 & 55 \\
\hline Greece & 95 & 6 & 23 & 53 & 84 & 42 & 56 \\
\hline Spain & 92 & 4 & 18 & 47 & 93 & 41 & 55 \\
\hline 21-country average & 92 & 4 & 17 & 48 & 79 & 37 & 58 \\
\hline Canada & 91 & 3 & 17 & 42 & 76 & 34 & 60 \\
\hline Ireland & 91 & 6 & 18 & 37 & 74 & 34 & 60 \\
\hline Australia & 90 & 4 & 16 & 41 & 74 & 34 & 59 \\
\hline Portugal & 93 & 6 & 22 & 45 & 63 & 34 & 62 \\
\hline United Kingdom & 91 & 4 & 14 & 39 & 79 & 34 & 60 \\
\hline Denmark & 92 & 2 & 4 & 44 & 79 & 32 & 62 \\
\hline Sweden & 91 & 2 & 7 & 28 & 81 & 30 & 64 \\
\hline Switzerland & 95 & 1 & 6 & 32 & 77 & 29 & 68 \\
\hline United States & 89 & 4 & 13 & 35 & 63 & 29 & 64 \\
\hline Norway & 90 & 3 & 9 & 30 & 71 & 28 & 65 \\
\hline New Zealand & 93 & 2 & 7 & 25 & 65 & 25 & 70 \\
\hline Japan & 97 & 1 & 4 & 27 & 52 & 21 & 77 \\
\hline
\end{tabular}

Note: The exit rate is the proportional drop in economic activity rates from age 45-49 to the indicated ages, on average, in the years 2003-2006. Countries are ranked from highest to lowest by their average exit rates (column 6). The reported 21country average represents the unweighted average of the countries included in the table.

Source: Author's estimates based on labor force participation rates obtained from SourceOECD supplemented with author's tabulations of Labour Force Survey data for selected European countries. 


\section{Table 4. Female Labor Force Period Exit Rates in Twenty-one OECD Countries, 2003-2006}

\begin{tabular}{|c|c|c|c|c|c|c|c|}
\hline & \multirow{2}{*}{$\begin{array}{c}\text { Participation } \\
\text { rate, age } \\
45-49 \\
(1) \\
\end{array}$} & \multicolumn{4}{|c|}{ Exit rate through age -- } & \multirow{2}{*}{$\begin{array}{c}\begin{array}{c}\text { Labor } \\
\text { force }\end{array} \\
\text { exit rate, } \\
50-69 \\
(6) \\
\end{array}$} & \multirow{2}{*}{$\begin{array}{c}\text { Average } \\
\text { participation } \\
\text { rate, } \\
\mathbf{5 0 - 6 9} \\
(7) \\
\end{array}$} \\
\hline & & $\begin{array}{c}\mathbf{5 0 - 5 4} \\
(2) \\
\end{array}$ & $\begin{array}{c}\mathbf{5 5 - 5 9} \\
(3) \\
\end{array}$ & $\begin{array}{c}60-64 \\
(4) \\
\end{array}$ & $\begin{array}{c}65-69 \\
(5) \\
\end{array}$ & & \\
\hline Belgium & 71 & 19 & 55 & 87 & 98 & 65 & 25 \\
\hline Austria & 81 & 12 & 53 & 90 & 95 & 63 & 30 \\
\hline Italy & 61 & 16 & 49 & 84 & 95 & 61 & 24 \\
\hline Spain & 63 & 19 & 43 & 68 & 95 & 56 & 27 \\
\hline Greece & 61 & 18 & 48 & 66 & 92 & 56 & 27 \\
\hline Netherlands & 77 & 13 & 37 & 77 & 94 & 55 & 34 \\
\hline France & 83 & 6 & 32 & 80 & 97 & 54 & 38 \\
\hline Germany & 83 & 6 & 24 & 75 & 95 & 50 & 41 \\
\hline Australia & 78 & 9 & 30 & 61 & 87 & 47 & 42 \\
\hline 21-country average & 77 & 8 & 27 & 62 & 87 & 46 & 42 \\
\hline Ireland & 64 & 10 & 31 & 58 & 88 & 46 & 34 \\
\hline Finland & 90 & 4 & 19 & 66 & 95 & 46 & 49 \\
\hline United Kingdom & 81 & 6 & 22 & 62 & 87 & 44 & 45 \\
\hline Canada & 82 & 6 & 26 & 58 & 86 & 44 & 46 \\
\hline Denmark & 86 & 3 & 10 & 67 & 91 & 43 & 49 \\
\hline Portugal & 78 & 11 & 33 & 53 & 72 & 42 & 45 \\
\hline Switzerland & 83 & 5 & 15 & 51 & 86 & 39 & 51 \\
\hline Japan & 73 & 6 & 19 & 46 & 67 & 34 & 48 \\
\hline New Zealand & 82 & 3 & 14 & 42 & 77 & 34 & 54 \\
\hline Sweden & 88 & 3 & 9 & 34 & 89 & 34 & 58 \\
\hline Norway & 84 & 2 & 14 & 38 & 78 & 33 & 56 \\
\hline United States & 78 & 4 & 16 & 41 & 70 & 33 & 52 \\
\hline
\end{tabular}

Note: The exit rate is the proportional drop in economic activity rates from age 45-49 to the indicated ages, on average, in the years 2003-2006. Countries are ranked from highest to lowest by their average exit rates (column 6). The reported 21country average represents the unweighted average of the countries included in the table.

Source: Author's estimates based on labor force participation rates obtained from SourceOECD supplemented with author's tabulations of Labour Force Survey data for selected European countries. 


\section{Table 5. Comparing 2006 Labor Force Exit Rates under Alternative Definitions: Men in Twenty-one OECD Countries}

\begin{tabular}{|c|c|c|c|c|c|c|}
\hline \multirow[b]{3}{*}{ Country } & \multirow{2}{*}{\multicolumn{3}{|c|}{ Labor force exit rate, ages 50-69/a/ }} & \multicolumn{3}{|c|}{$\begin{array}{c}\text { Average labor force participation rate, } \\
\text { ages } 50-69\end{array}$} \\
\hline & & & & \multirow[b]{2}{*}{$\begin{array}{c}\text { Actual, } \\
\mathbf{2 0 0 6} \\
(4)\end{array}$} & \multirow{2}{*}{$\begin{array}{c}\text { For } \\
\text { cohort } \\
\text { born in } \\
\text { 1937-41 } \\
(5) \\
\end{array}$} & \multirow{2}{*}{$\begin{array}{l}\text { Implied by } \\
\text { partial cohort } \\
\text { rate } / \mathrm{b} / \\
(6)\end{array}$} \\
\hline & $\begin{array}{c}\text { Period rate } \\
\text { (1) } \\
\end{array}$ & $\begin{array}{c}\text { Cohort rate } \\
(2) \\
\end{array}$ & $\begin{array}{c}\text { Partial cohort } \\
\text { rate } \\
(3) \\
\end{array}$ & & & \\
\hline Belgium & 54 & 58 & 53 & 42 & 39 & 43 \\
\hline France & 52 & 54 & 52 & 45 & 44 & 45 \\
\hline Austria & 49 & -- & 49 & 47 & -- & 47 \\
\hline Italy & 50 & 50 & 48 & 47 & 48 & 49 \\
\hline Netherlands /c/ & 42 & 49 & 42 & 52 & 46 & 53 \\
\hline Finland & 43 & -- & 41 & 52 & -- & 53 \\
\hline Greece & 41 & 42 & 40 & 56 & 55 & 58 \\
\hline Spain & 41 & 43 & 39 & 55 & 54 & 56 \\
\hline Germany & 40 & 47 & 38 & 56 & 52 & 59 \\
\hline Portugal & 35 & 33 & 35 & 61 & 62 & 61 \\
\hline All-country average & 37 & 39 & 35 & 59 & 57 & 60 \\
\hline Switzerland & 30 & -- & 33 & 67 & -- & 63 \\
\hline Canada & 34 & 38 & 31 & 60 & 57 & 62 \\
\hline Ireland & 33 & 34 & 31 & 61 & 59 & 64 \\
\hline United Kingdom & 33 & 37 & 29 & 61 & 59 & 64 \\
\hline Norway & 29 & 34 & 29 & 65 & 64 & 64 \\
\hline United States & 29 & 31 & 29 & 64 & 64 & 64 \\
\hline Denmark & 32 & 38 & 29 & 62 & 58 & 65 \\
\hline Australia & 32 & 37 & 28 & 61 & 58 & 65 \\
\hline Sweden & 29 & 34 & 28 & 65 & 63 & 66 \\
\hline Japan & 21 & 20 & 22 & 77 & 78 & 76 \\
\hline New Zealand & 22 & 29 & 17 & 72 & 68 & 77 \\
\hline
\end{tabular}

\section{Notes:}

/a/ The "labor force exit rate" is the percent reduction in labor supply between ages 50 and 69 below the level that would be observed if labor supply in those ages remained at its level between ages 45-49. For an explanation of "period," "cohort," and "partial cohort" exit rates, see text. Countries are ranked from highest to lowest by their partial cohort exit rates (column 3).

/b/ Calculated using the partial cohort exit rate and the labor force participation rate of 45-49 year-olds in 2006.

/c/ Estimates for the Netherlands are based on 1985-2005 data rather than data for 1986-2006. Consequently, the period estimates are based on cross-section data for 2005, and the cohort estimates refer to the population born between 19361940 rather than 1937-1941.

Source: Author's estimates based on labor force participation rates obtained from SourceOECD supplemented with author's tabulations of Labour Force Survey data for selected European countries. 


\section{Table 6. Comparing 2006 Labor Force Exit Rates under Alternative Definitions: Women in Twenty-one OECD Countries}

\begin{tabular}{|c|c|c|c|c|c|c|}
\hline \multirow[b]{3}{*}{ Country } & \multirow{2}{*}{\multicolumn{3}{|c|}{ Labor force exit rate, ages 50-69/a/ }} & \multicolumn{3}{|c|}{$\begin{array}{c}\text { Average labor force participation rate, } \\
\text { ages 50-69 }\end{array}$} \\
\hline & & & & \multirow[b]{2}{*}{$\begin{array}{c}\text { Actual, } \\
\mathbf{2 0 0 6} \\
(4)\end{array}$} & \multirow{2}{*}{ 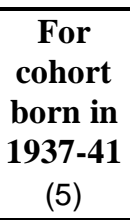 } & \multirow{2}{*}{$\begin{array}{c}\text { Implied by } \\
\text { partial cohort } \\
\text { rate /b/ } \\
(6)\end{array}$} \\
\hline & $\begin{array}{l}\text { Period rate } \\
\text { (1) }\end{array}$ & $\begin{array}{c}\text { Cohort rate } \\
\text { (2) }\end{array}$ & $\begin{array}{c}\text { Partial cohort } \\
\text { rate } \\
(3)\end{array}$ & & & \\
\hline Belgium & 64 & 65 & 54 & 27 & 15 & 34 \\
\hline Austria & 60 & & 51 & 33 & & 40 \\
\hline France & 54 & 52 & 49 & 39 & 32 & 43 \\
\hline Italy & 60 & 58 & 48 & 25 & 17 & 32 \\
\hline Greece & 56 & 50 & 42 & 28 & 22 & 37 \\
\hline Netherlands /c/ & 54 & 47 & 41 & 35 & 21 & 45 \\
\hline Finland & 43 & & 41 & 51 & & 54 \\
\hline Germany & 48 & 41 & 40 & 44 & 34 & 50 \\
\hline United Kingdom & 43 & 46 & 37 & 46 & 40 & 51 \\
\hline Denmark & 42 & 50 & 36 & 50 & 42 & 55 \\
\hline All-country average & 45 & 42 & 36 & 43 & 35 & 50 \\
\hline Norway & 34 & 37 & 35 & 55 & 52 & 55 \\
\hline Switzerland & 38 & & 34 & 52 & & 55 \\
\hline Canada & 42 & 42 & 33 & 48 & 38 & 55 \\
\hline Sweden & 33 & 38 & 33 & 59 & 57 & 59 \\
\hline Portugal & 42 & 28 & 32 & 46 & 39 & 54 \\
\hline Australia & 44 & 46 & 31 & 44 & 33 & 54 \\
\hline Japan & 34 & 31 & 30 & 49 & 47 & 52 \\
\hline United States & 31 & 30 & 29 & 53 & 49 & 55 \\
\hline Spain & 55 & 31 & 28 & 30 & 19 & 47 \\
\hline New Zealand & 32 & 37 & 24 & 56 & 47 & 62 \\
\hline Ireland & 42 & 27 & 16 & 38 & 23 & 56 \\
\hline
\end{tabular}

\section{Notes:}

/a/ The "labor force exit rate" is the percent reduction in labor supply between ages 50 and 69 below the level that would be observed if labor supply in those ages remained at its level between ages 45-49. For an explanation of "period," "cohort," and "partial cohort" exit rates, see text. Countries are ranked from highest to lowest by their partial cohort exit rates (column 3).

/b/ Calculated using the partial cohort exit rate and the labor force participation rate of 45-49 year-olds in 2006.

/c/ Estimates for the Netherlands are based on 1985-2005 data rather than data for 1986-2006. Consequently, the period estimates are based on cross-section data for 2005, and the cohort estimates refer to the population born between 19361940 rather than 1937-1941.

Source: Author's estimates based on labor force participation rates obtained from SourceOECD supplemented with author's tabulations of Labour Force Survey data for selected European countries. 


\section{Table 9A. Change in Labor Force Participation Rates in Twenty-one OECD Countries, 1960-2006: Males Age 45-49}

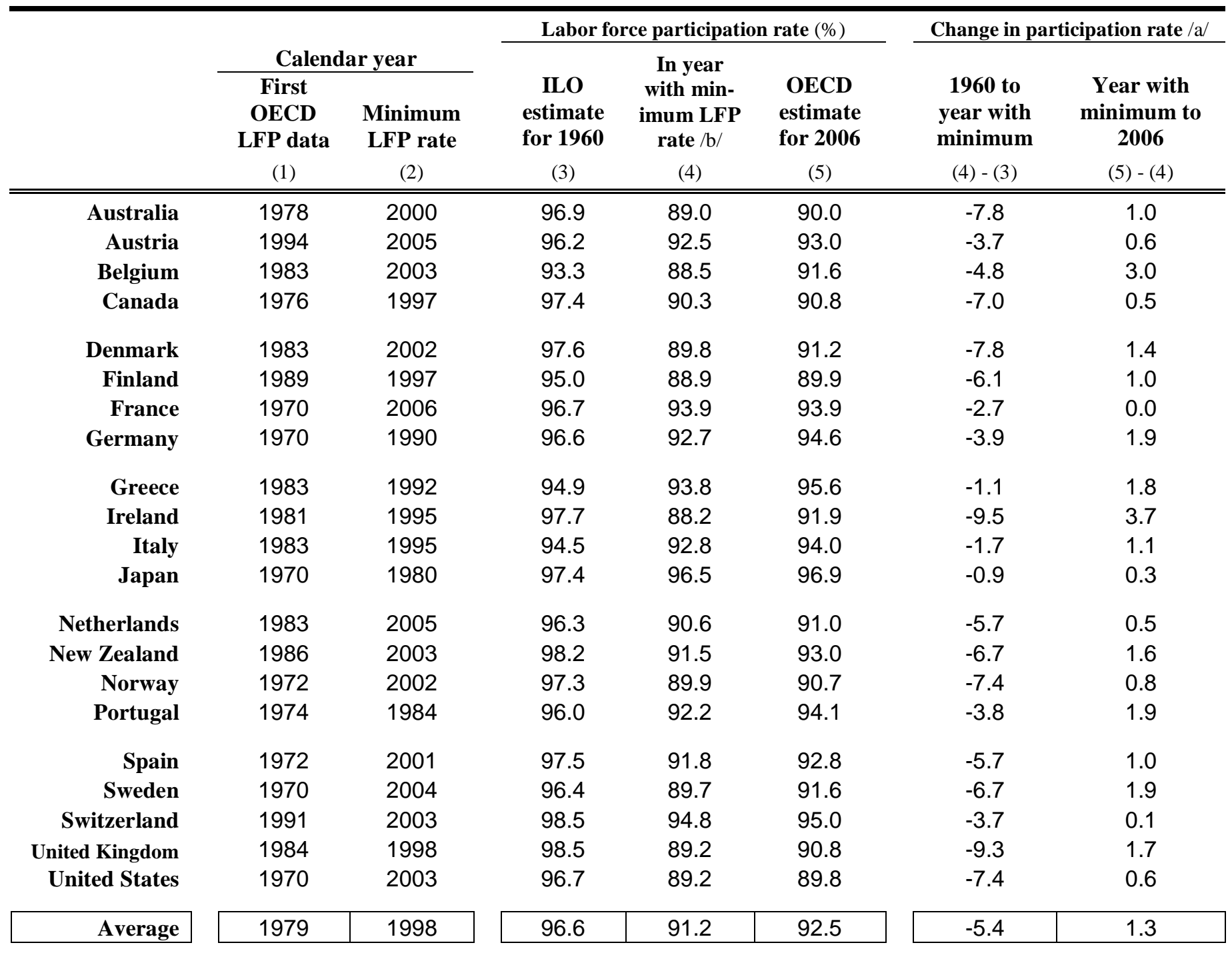

Notes:

/a/ Percentage-point change.

/b/ The year with minimum labor force participation rate in the OECD data bank. The actual year is indicated in column 2.

Source: Author's estimates based on labor force participation rates obtained from SourceOECD supplemented with author's tabulations of Labour Force Survey data for selected European countries. 


\section{Table 9B. Change in Labor Force Participation Rates in Twenty-one OECD Countries, 1960-2006: Males Age 50-54}

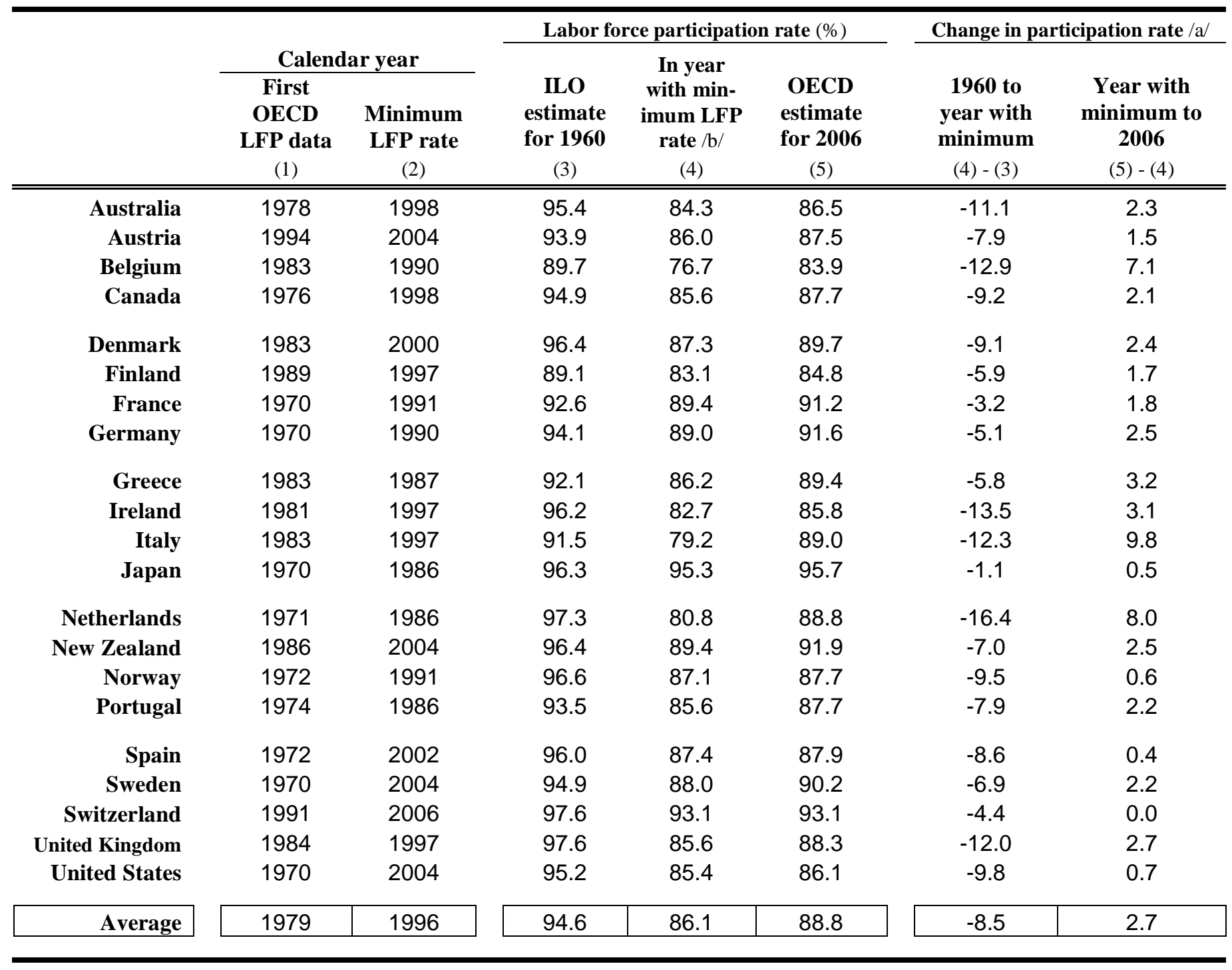

Notes:

/a/ Percentage-point change.

/b/ The year with minimum labor force participation rate in the OECD data bank. The actual year is indicated in column 2.

Source: Author's estimates based on labor force participation rates obtained from SourceOECD supplemented with author's tabulations of Labour Force Survey data for selected European countries. 


\section{Table 9C. Change in Labor Force Participation Rates in Twenty-one OECD Countries, 1960-2006: Males Age 55-59}

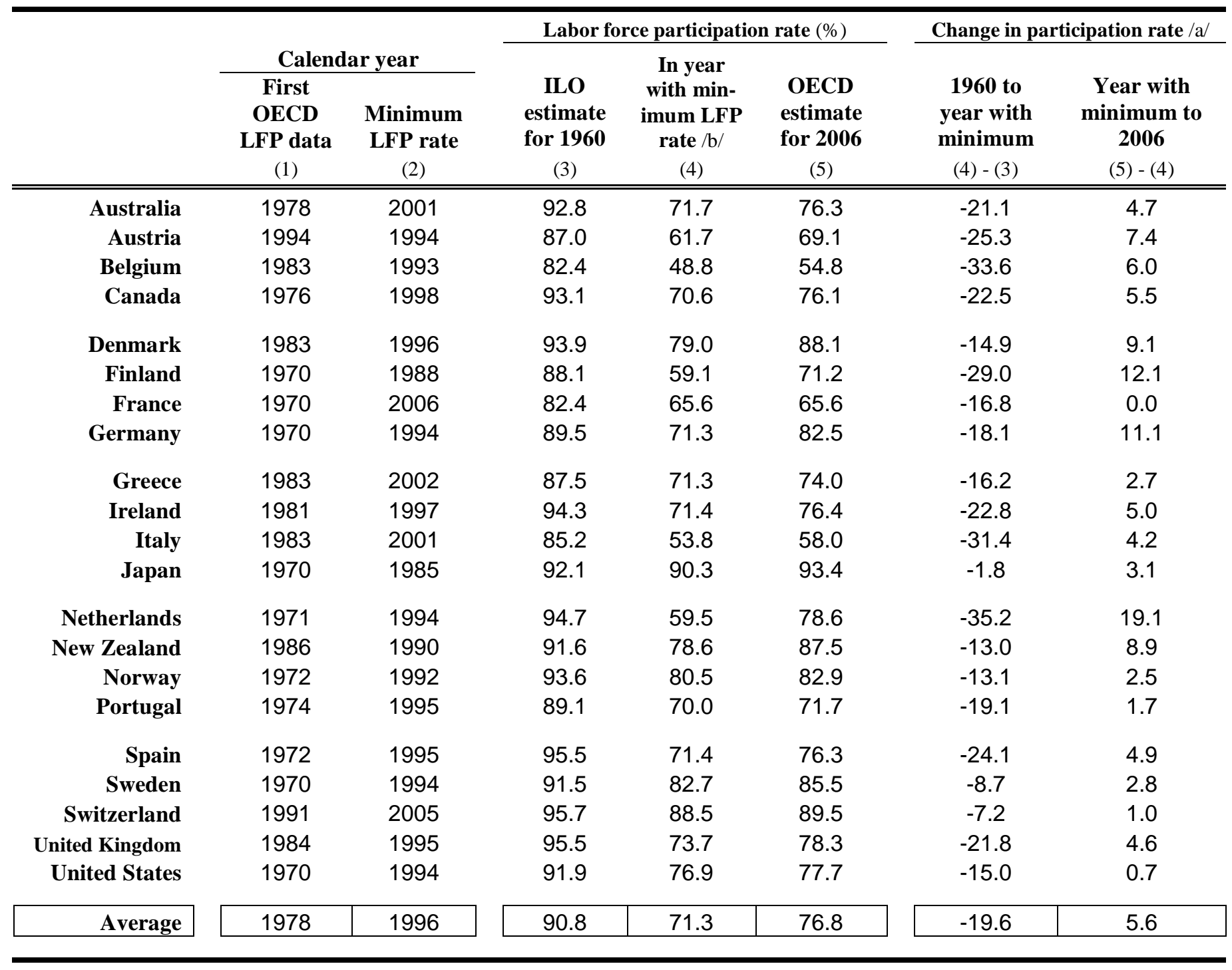

Notes:

/a/ Percentage-point change.

/b/ The year with minimum labor force participation rate in the OECD data bank. The actual year is indicated in column 2.

Source: Author's estimates based on labor force participation rates obtained from SourceOECD supplemented with author's tabulations of Labour Force Survey data for selected European countries. 


\section{Table 9D. Change in Labor Force Participation Rates in Twenty-one OECD Countries, 1960-2006: Males Age 60-64}

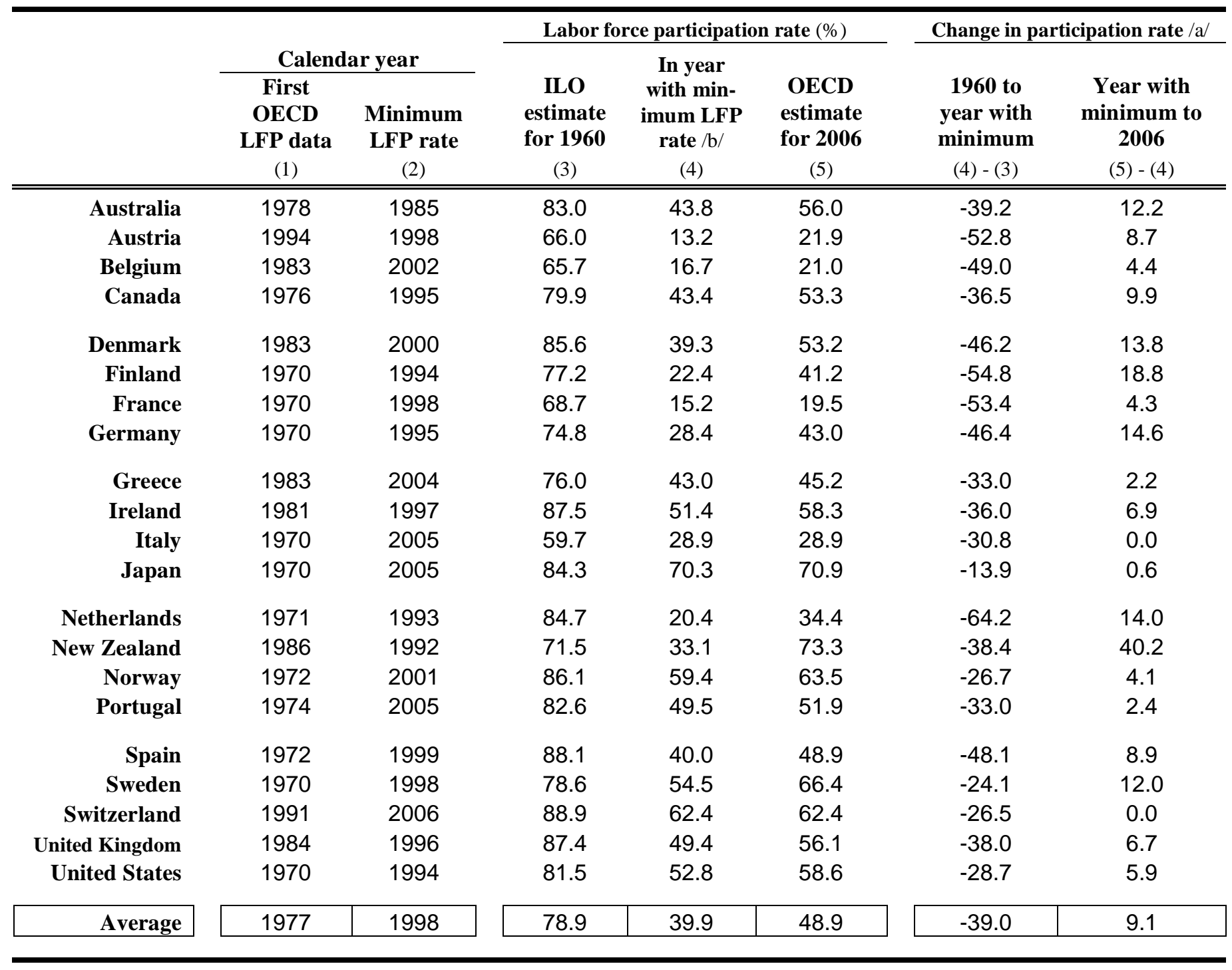

Notes:

/a/ Percentage-point change.

/b/ The year with minimum labor force participation rate in the OECD data bank. The actual year is indicated in column 2.

Source: Author's estimates based on labor force participation rates obtained from SourceOECD supplemented with author's tabulations of Labour Force Survey data for selected European countries. 


\section{Table 10. Change in Labor Force Participation Rates in Twenty-one OECD Countries, 1970-2006: Males Age 65-69}

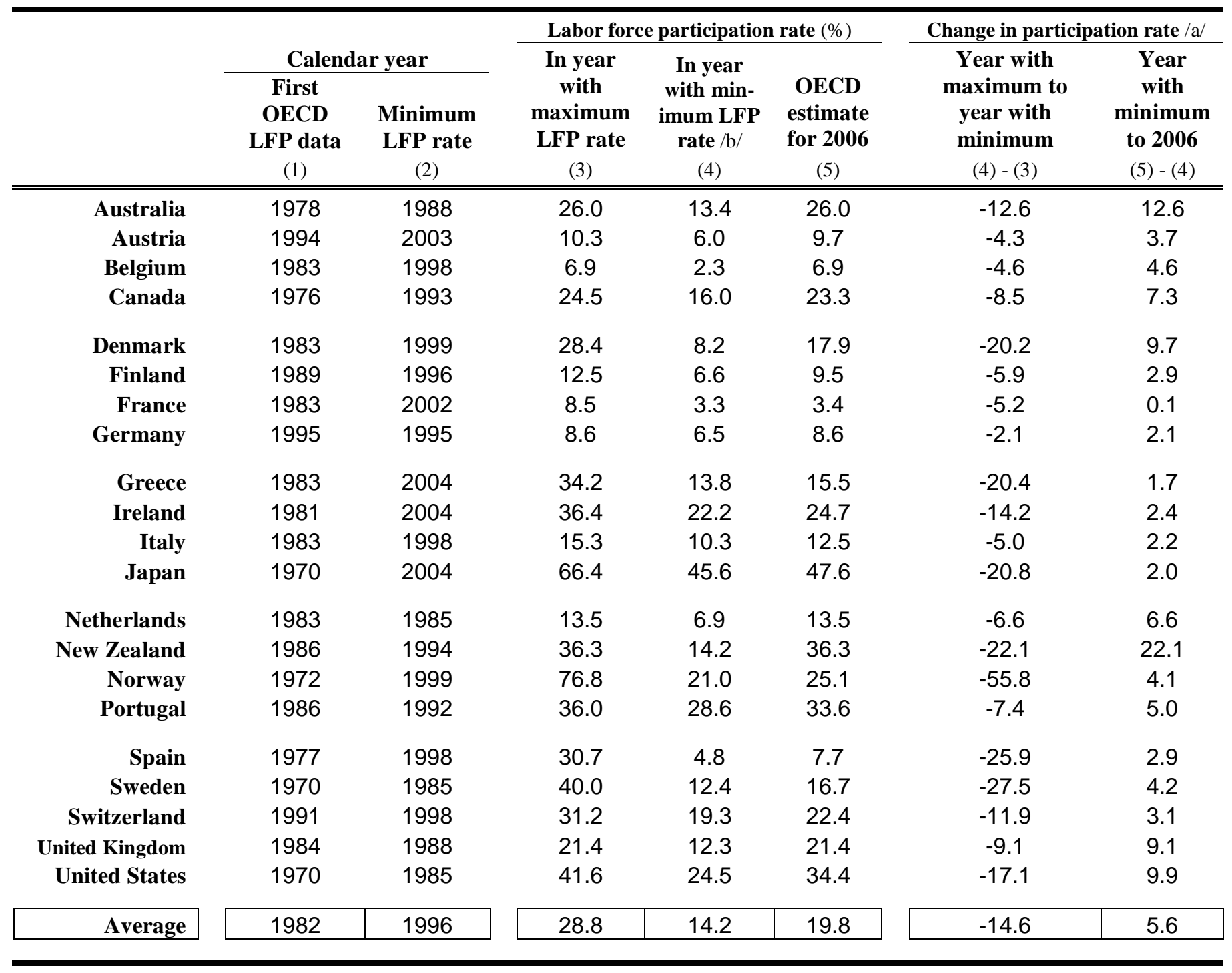

Notes:

/a/ Percentage-point change.

/b/ The year with minimum labor force participation rate in the OECD data bank. The actual year is indicated in column 2.

Source: Author's estimates based on labor force participation rates obtained from SourceOECD supplemented with author's tabulations of Labour Force Survey data for selected European countries. 


\section{Appendix Table A1. Male Labor Force Period Exit Rates in Fifteen OECD Countries, 2004}

\begin{tabular}{|c|c|c|c|c|c|c|}
\hline \multirow[b]{2}{*}{ Country } & \multicolumn{2}{|c|}{$\begin{array}{c}\text { Labor force } \\
\text { participation rate }\end{array}$} & \multirow{2}{*}{$\begin{array}{c}\text { Labor force } \\
\text { exit rate, ages } \\
50-74 \text { /a/ } \\
(3) \\
\end{array}$} & \multicolumn{2}{|c|}{$\begin{array}{l}\text { Average hours of work } \\
\text { per person } / \mathrm{b} /\end{array}$} & \multirow{2}{*}{$\begin{array}{c}\text { Labor force } \\
\text { exit rate, ages } \\
\mathbf{5 0 - 7 4} / \mathrm{c} / \\
(6) \\
\end{array}$} \\
\hline & $\begin{array}{c}\text { Age 45-49 } \\
(1) \\
\end{array}$ & $\begin{array}{c}\text { Age 50-74 } \\
\text { (2) } \\
\end{array}$ & & $\begin{array}{c}\text { Age 45-49 } \\
\text { (4) } \\
\end{array}$ & $\begin{array}{c}\text { Age 50-74 } \\
\text { (5) } \\
\end{array}$ & \\
\hline Belgium & 92.1 & 32.8 & 64 & 31.7 & 10.4 & 67 \\
\hline Austria & 93.4 & 35.8 & 62 & 37.4 & 13.6 & 64 \\
\hline France & 93.6 & 34.6 & 63 & 31.0 & 11.5 & 63 \\
\hline Italy & 94.0 & 37.8 & 60 & 34.8 & 13.5 & 61 \\
\hline Finland & 89.7 & 40.2 & 55 & 29.7 & 12.4 & 58 \\
\hline Netherlands & 93.1 & 43.9 & 53 & 31.6 & 13.3 & 58 \\
\hline Germany & 94.2 & 43.8 & 54 & 34.9 & 15.3 & 56 \\
\hline 15-country average $/ \mathrm{d} /$ & 92.2 & 44.8 & 51 & 33.7 & 15.4 & 54 \\
\hline Spain & 91.8 & 43.6 & 52 & 33.2 & 15.5 & 53 \\
\hline Greece & 94.9 & 44.7 & 53 & 39.0 & 18.3 & 53 \\
\hline Denmark & 92.5 & 51.3 & 45 & 32.8 & 16.3 & 50 \\
\hline Norway & 90.2 & 51.7 & 43 & 31.0 & 16.1 & 48 \\
\hline Sweden & 89.4 & 52.5 & 41 & 29.9 & 15.8 & 47 \\
\hline Ireland & 91.8 & 50.6 & 45 & 36.5 & 19.8 & 46 \\
\hline Portugal & 92.9 & 54.3 & 42 & 34.8 & 19.0 & 45 \\
\hline United States & 89.3 & 54.5 & 39 & 36.6 & 20.5 & 44 \\
\hline European average $/ \mathrm{e} /$ & 93.3 & 41.3 & 56 & 33.6 & 14.3 & 58 \\
\hline
\end{tabular}

Note: Countries are ranked by their work-hours exit rates, from highest to lowest exit rate (column 6).

/a/ Reduction in estimated labor force participation, measured as a percent of participation rate among persons 45-49 years old.

b/Hours worked in the survey reference week, including zeroes for persons not employed or at work in that week.

/c/Reduction in estimated weekly work hours, measured as a percent of average weekly hours in the population 45-49 years old.

/d/ Unweighted average of European countries and the United States.

/e/ Population-weighted average of fourteen European countries.

Source: Author's tabulations of quarterly 2004 European Labour Force Survey (LFS) data for Austria, Belgium, Denmark, Finland, France, Germany, Greece, Ireland, Italy, the Netherlands, Norway, Portugal, Spain, and Sweden, and tabulations of the U.S. Current Population Survey (CPS) files for January-December 2004.

(See sources of Table 1.) 


\section{Appendix Table A2. Female Labor Force Period Exit Rates in Fifteen OECD Countries, 2004}

\begin{tabular}{|c|c|c|c|c|c|c|}
\hline \multirow[b]{2}{*}{ Country } & \multicolumn{2}{|c|}{$\begin{array}{c}\text { Labor force } \\
\text { participation rate }\end{array}$} & \multirow{2}{*}{$\begin{array}{c}\text { Labor force } \\
\text { exit rate, ages } \\
\mathbf{5 0 - 7 4} \mathrm{la} / \\
(3) \\
\end{array}$} & \multicolumn{2}{|c|}{$\begin{array}{c}\text { Average hours of work } \\
\text { per person } / \mathrm{b} /\end{array}$} & \multirow{2}{*}{$\begin{array}{c}\text { Labor force } \\
\text { exit rate, ages } \\
\mathbf{5 0 - 7 4} / \mathrm{c} / \\
(6) \\
\end{array}$} \\
\hline & $\begin{array}{c}\text { Age 45-49 } \\
\text { (1) } \\
\end{array}$ & $\begin{array}{c}\text { Age 50-74 } \\
(2) \\
\end{array}$ & & $\begin{array}{c}\text { Age 45-49 } \\
\text { (4) } \\
\end{array}$ & $\begin{array}{c}\text { Age 50-74 } \\
\text { (5) } \\
\end{array}$ & \\
\hline Belgium & 71.3 & 20.0 & 72 & 17.6 & 4.7 & 73 \\
\hline Austria & 79.7 & 23.0 & 71 & 24.4 & 6.8 & 72 \\
\hline Italy & 61.0 & 19.0 & 69 & 17.2 & 5.4 & 69 \\
\hline Netherlands & 76.9 & 27.9 & 64 & 15.9 & 5.2 & 67 \\
\hline Greece & 60.8 & 21.1 & 65 & 20.7 & 7.1 & 66 \\
\hline Spain & 61.7 & 21.3 & 65 & 17.6 & 6.1 & 65 \\
\hline France & 81.3 & 28.8 & 65 & 21.4 & 7.5 & 65 \\
\hline Germany & 82.1 & 32.6 & 60 & 22.2 & 8.2 & 63 \\
\hline 15-country average /d/ & 76.1 & 31.4 & 59 & 21.6 & 8.5 & 61 \\
\hline Finland & 89.9 & 38.3 & 57 & 26.0 & 10.4 & 60 \\
\hline Ireland & 63.3 & 26.6 & 58 & 16.8 & 6.8 & 60 \\
\hline Denmark & 87.4 & 40.1 & 54 & 24.4 & 10.6 & 56 \\
\hline Portugal & 77.0 & 38.0 & 51 & 25.1 & 11.2 & 55 \\
\hline Norway & 83.7 & 43.9 & 48 & 22.3 & 10.9 & 51 \\
\hline Sweden & 87.7 & 46.8 & 47 & 24.5 & 12.1 & 51 \\
\hline United States & 78.2 & 44.2 & 43 & 27.3 & 14.3 & 48 \\
\hline European average $/ \mathrm{e} /$ & 74.2 & 27.6 & 63 & 20.3 & 7.3 & 64 \\
\hline
\end{tabular}

Note: Countries are ranked by their work-hours exit rates, from highest to lowest exit rate (column 6).

/a/ Reduction in estimated labor force participation, measured as a percent of participation rate among persons 45-49 years old.

b/ Hours worked in the survey reference week, including zeroes for persons not employed or at work in that week.

/c/ Reduction in estimated weekly work hours, measured as a percent of average weekly hours in the population 45-49 years old.

/d/ Unweighted average of European countries and the United States.

le/Population-weighted average of fourteen European countries.

Source: Author's tabulations of quarterly 2004 European Labour Force Survey (LFS) data for Austria, Belgium, Denmark, Finland, France, Germany, Greece, Ireland, Italy, the Netherlands, Norway, Portugal, Spain, and Sweden, and tabulations of the U.S. Current Population Survey (CPS) files for January-December 2004. (See sources of Table 1.) 


\section{Figure 1. Measures of Aggregate Work Effort among Men, by Age, 2004}

\section{Percent of male population in labor force}

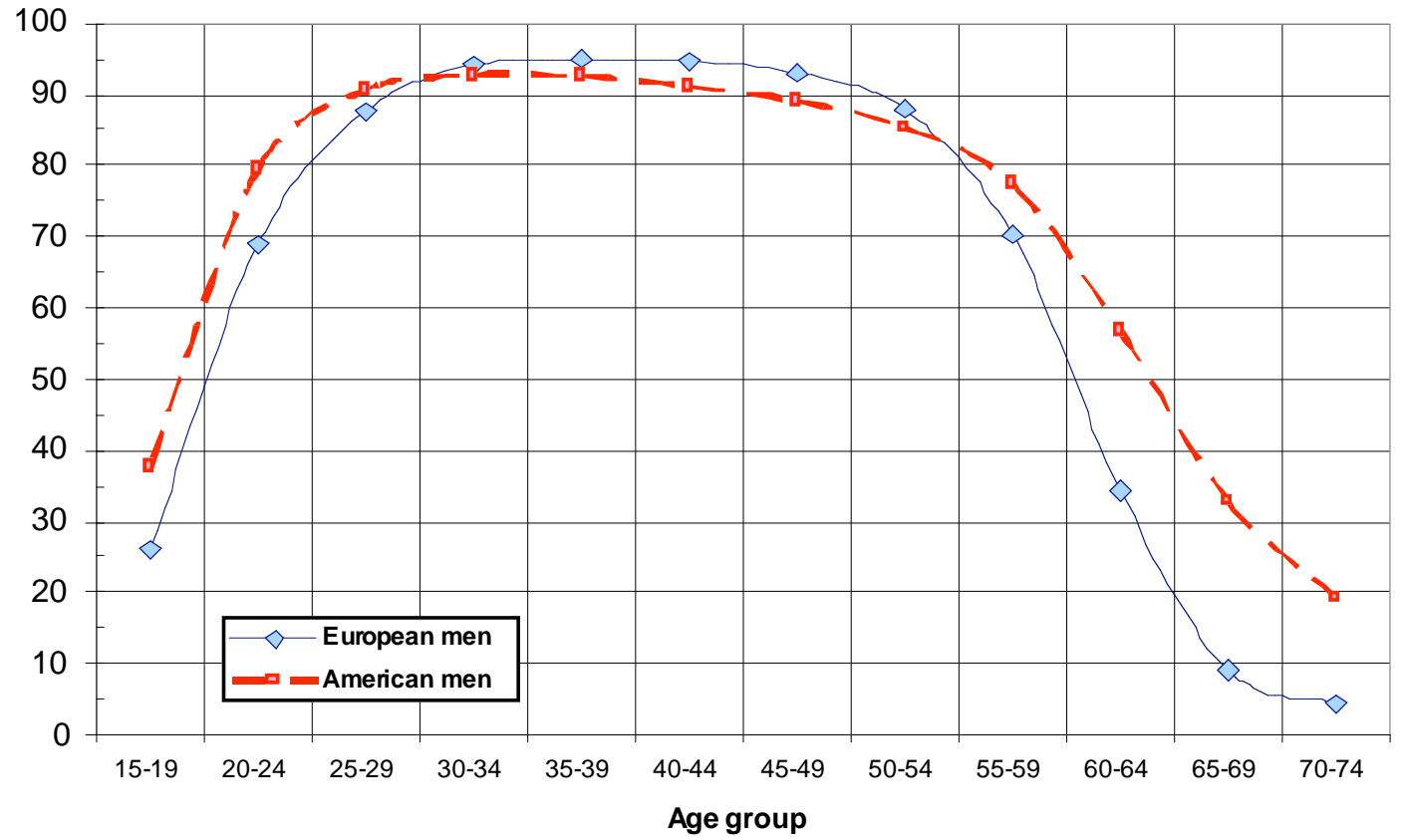

Unconditional average hours worked among men (per week)

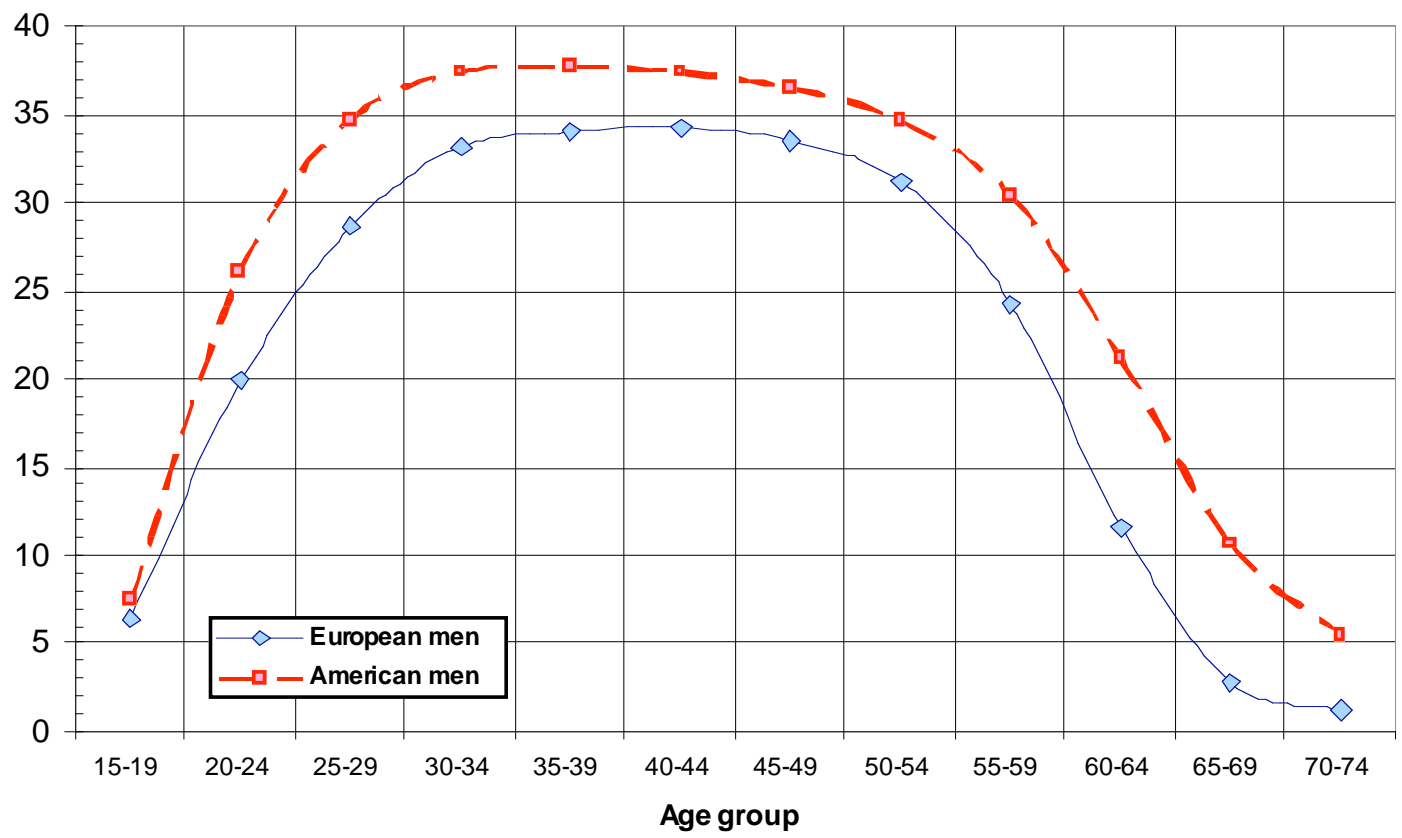

Source: Tabulations of European Labour Force Survey (LFS) data of the second quarter of 2004 for Germany and of quarterly 2004 European Labour Force Survey (LFS) data for Austria, Belgium, Denmark, Finland, France, Greece, Ireland, Italy, the Netherlands, Norway, Portugal, Spain, and Sweden, and tabulations of the U.S. Current Population Survey (CPS) files for January-December 2004. European estimates reflect weighted averages for the 14 European countries, where the weights are derived from national population counts for persons 15-74 years old. (See note to Table 1.) 


\section{Figure 2. Measures of Aggregate Work Effort among Women, by Age, 2004}

Percent of female population in labor force

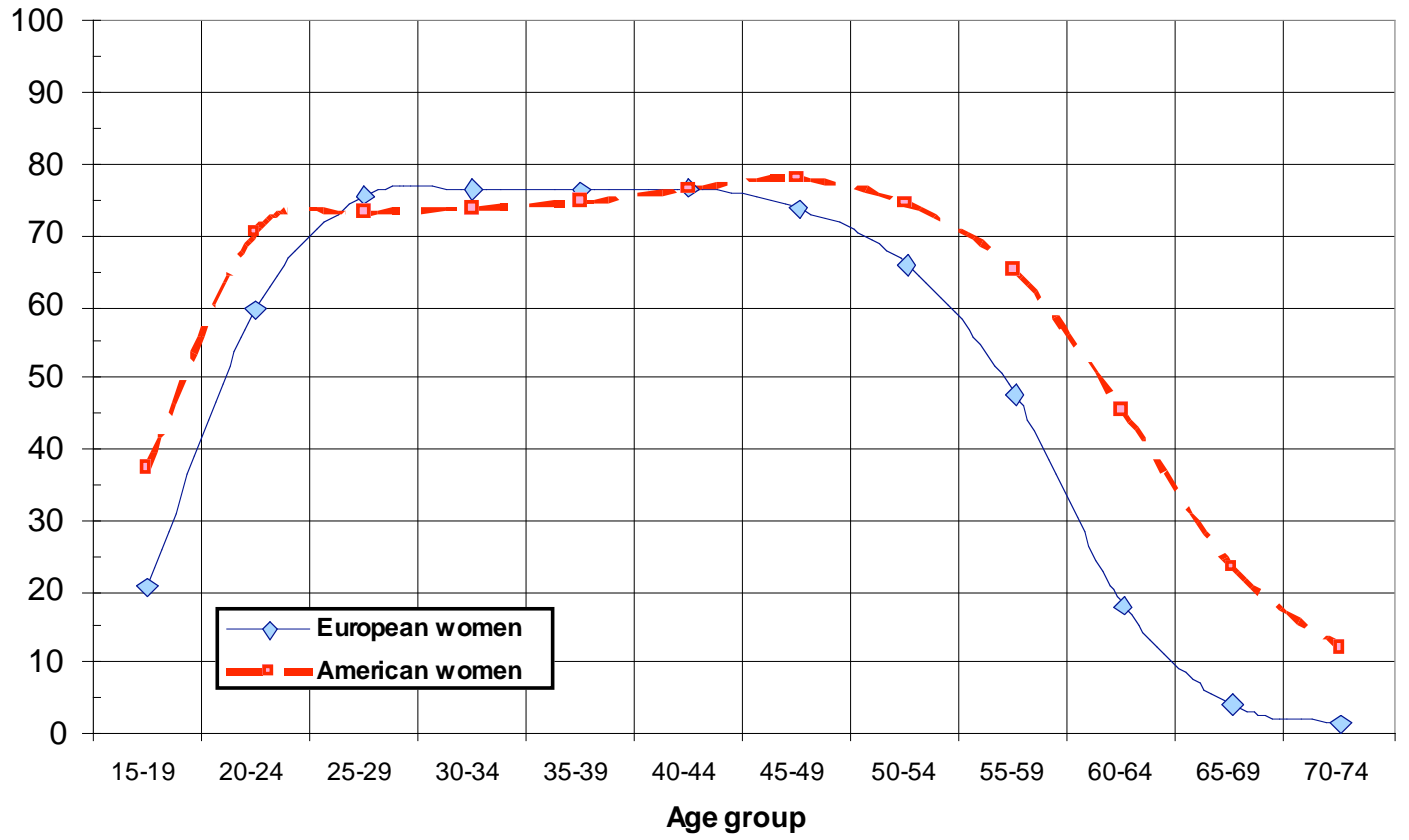

Unconditional average hours worked among women (per week)

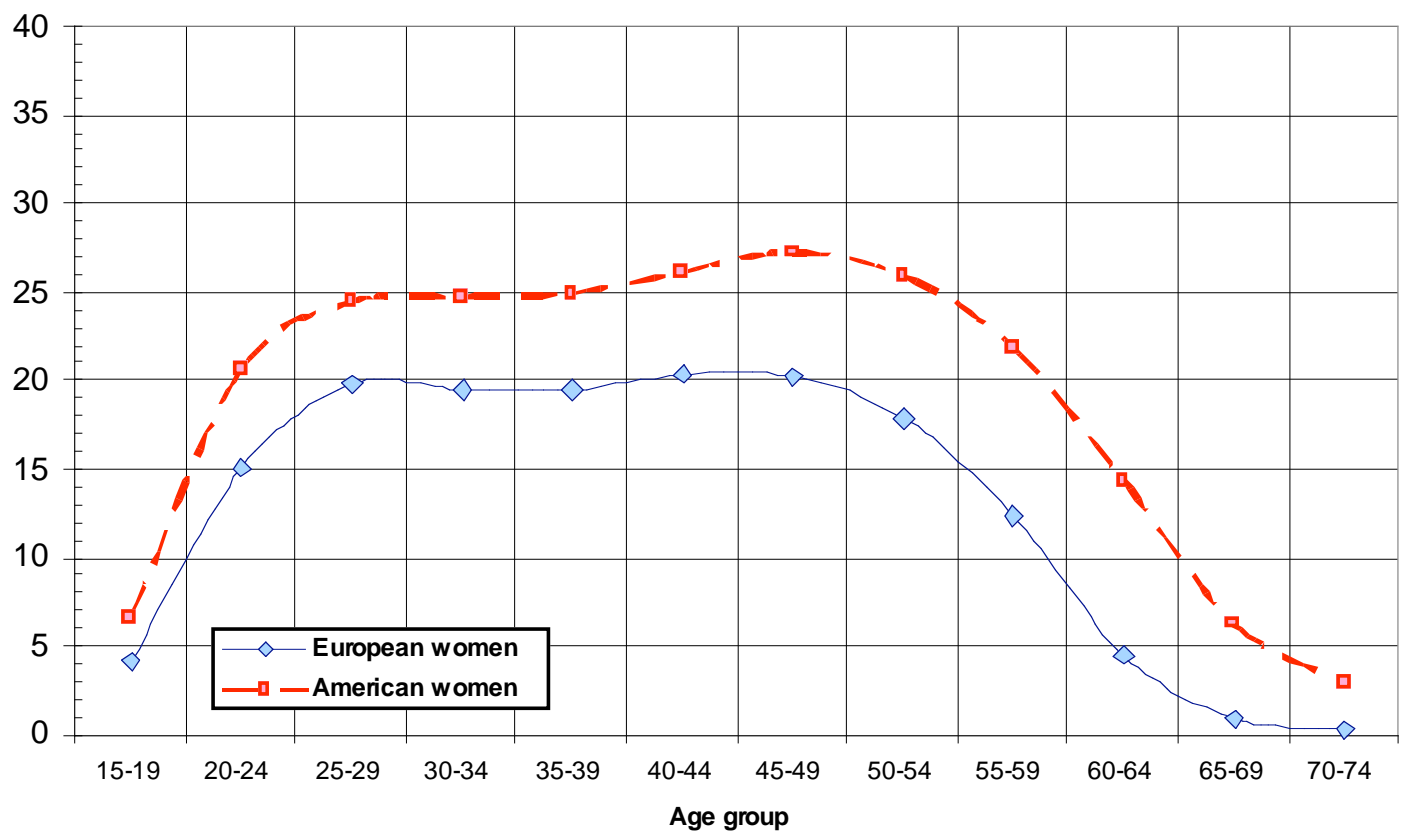

Source: Tabulations of European Labour Force Survey (LFS) data of the second quarter of 2004 for Germany and of quarterly 2004 European Labour Force Survey (LFS) data for Austria, Belgium, Denmark, Finland, France, Greece, Ireland, Italy, the Netherlands, Norway, Portugal, Spain, and Sweden, and tabulations of the U.S. Current Population Survey (CPS) files for January-December 2004. European estimates reflect weighted averages for the 14 European countries, where the weights are derived from national population counts for persons 15-74 years old. (See note to Table 1.) 
Figure 3. Speed of Retirement among European and American Men, 2004

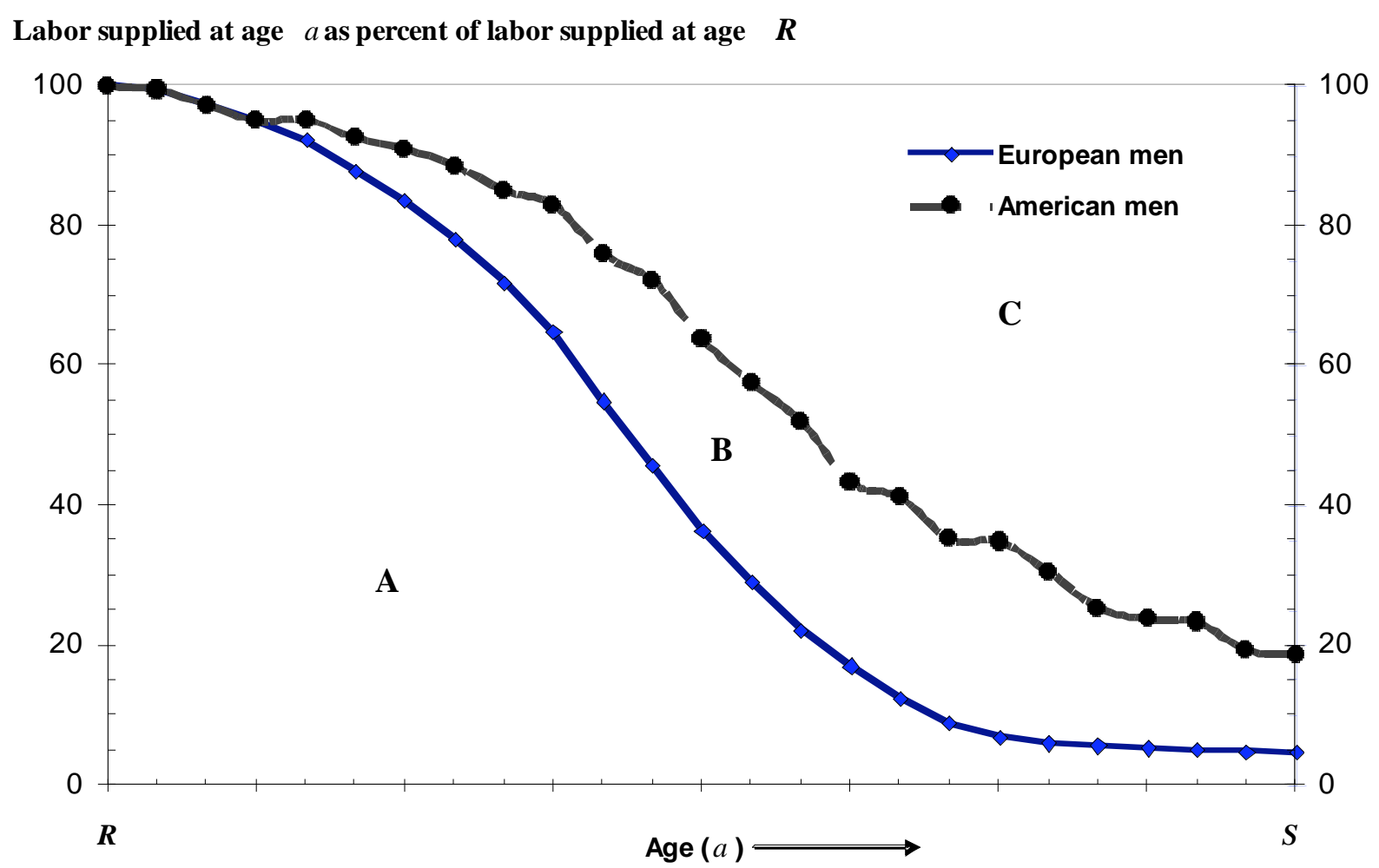

Source: See Figure 1. The indicator of labor supply used in this illustration is the male labor force participation rate. 


\section{Figure 4. Rate of Retirement Using Three Measures of Labor Force}

Withdrawal, U.S. Workers, 2003-2005

Labor supply at age $\mathbf{5 0}=\mathbf{1 0 0}$

American Men

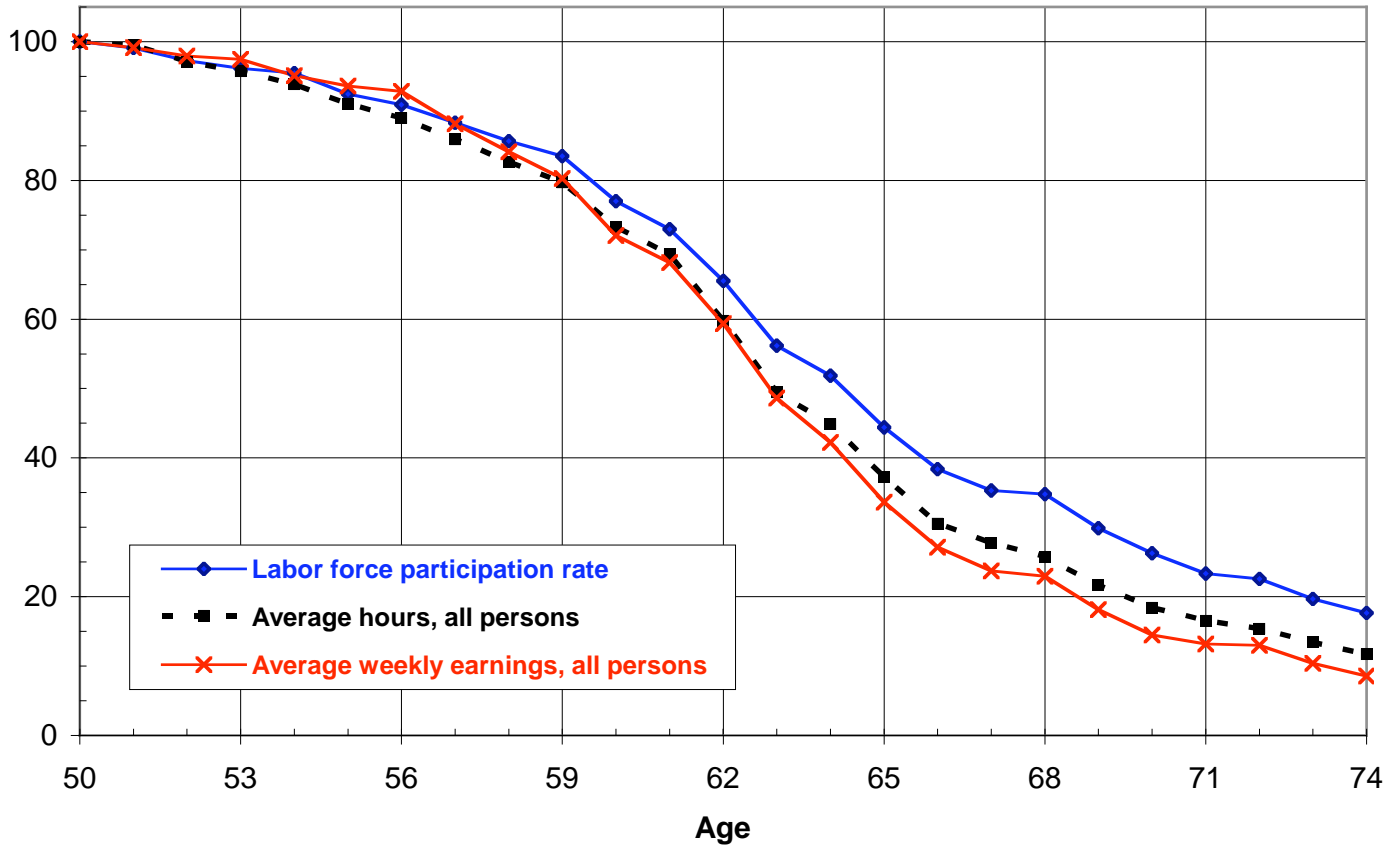

Labor supply at age $\mathbf{5 0}=\mathbf{1 0 0}$

American Women

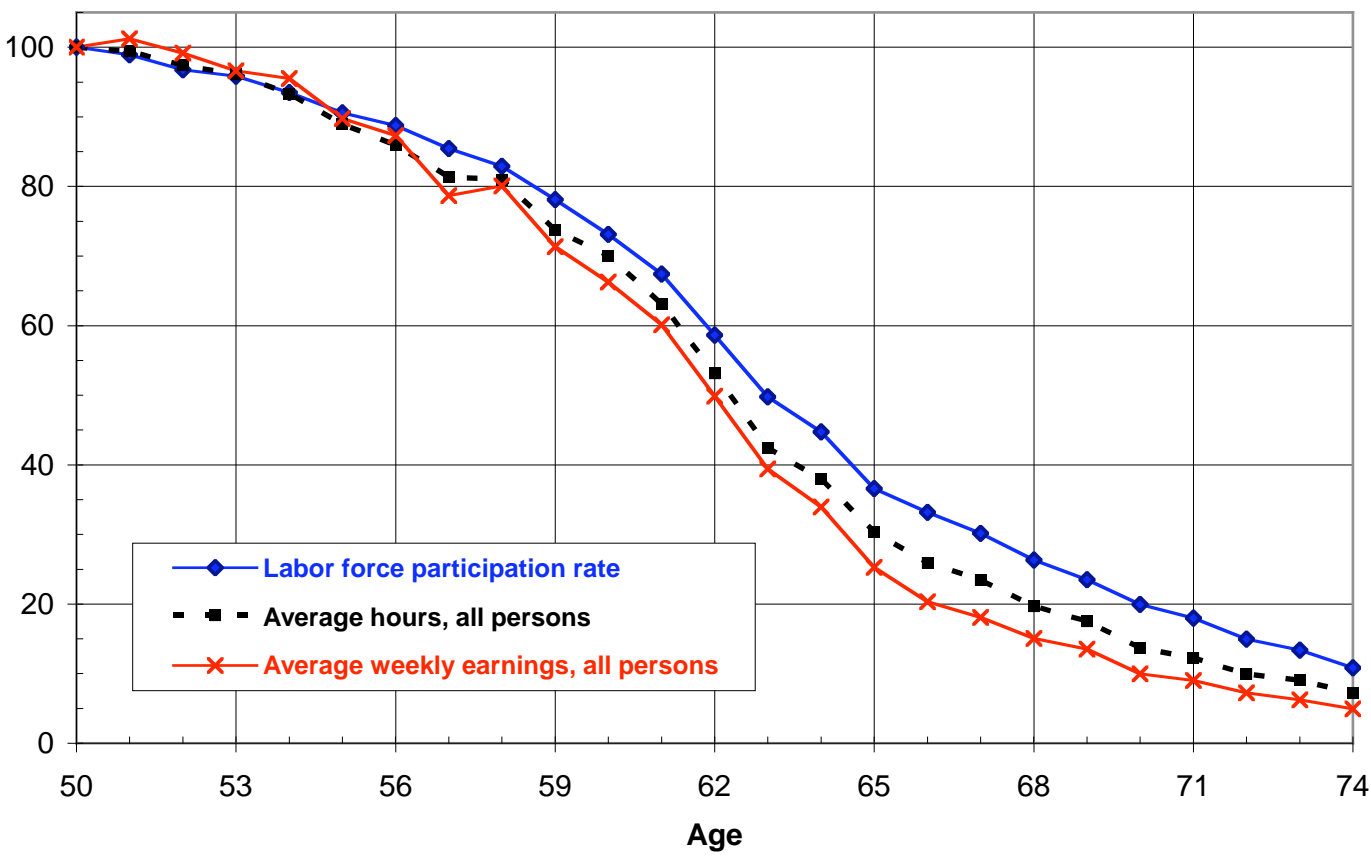

Source: Tabulations of January 2003 - December 2005 U.S. Current Population Survey outgoing rotation group files. The labor supply estimates at each year of age represent averages over the 36-month period. 
Figure 5. U.S. Labor Force Exit Measured with Cross-Section and Cohort Data

Labor force exit measured with cross-section data, 1988-1992

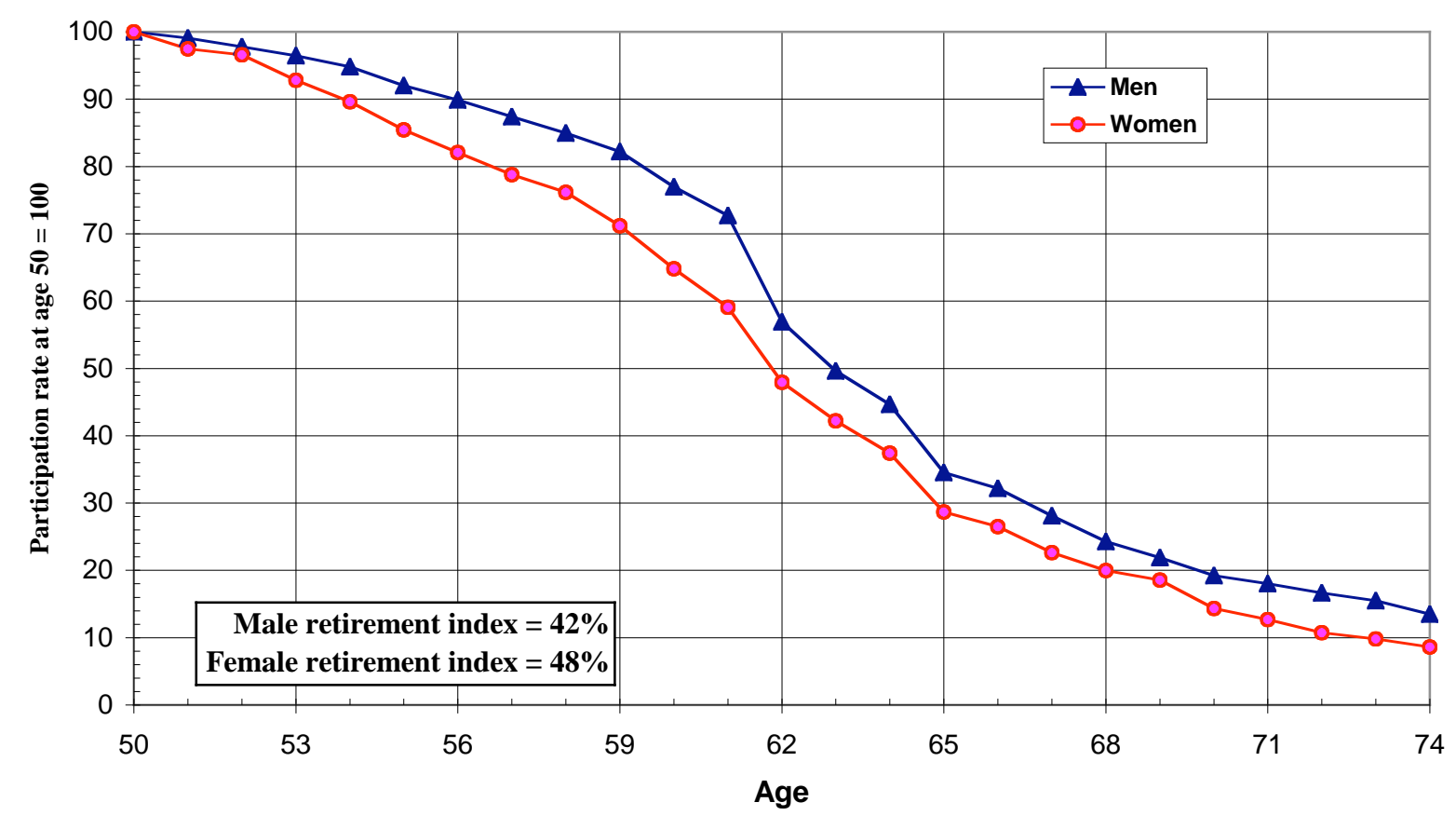

Labor force exit measured with cohort data for Americans born in 1926-1930

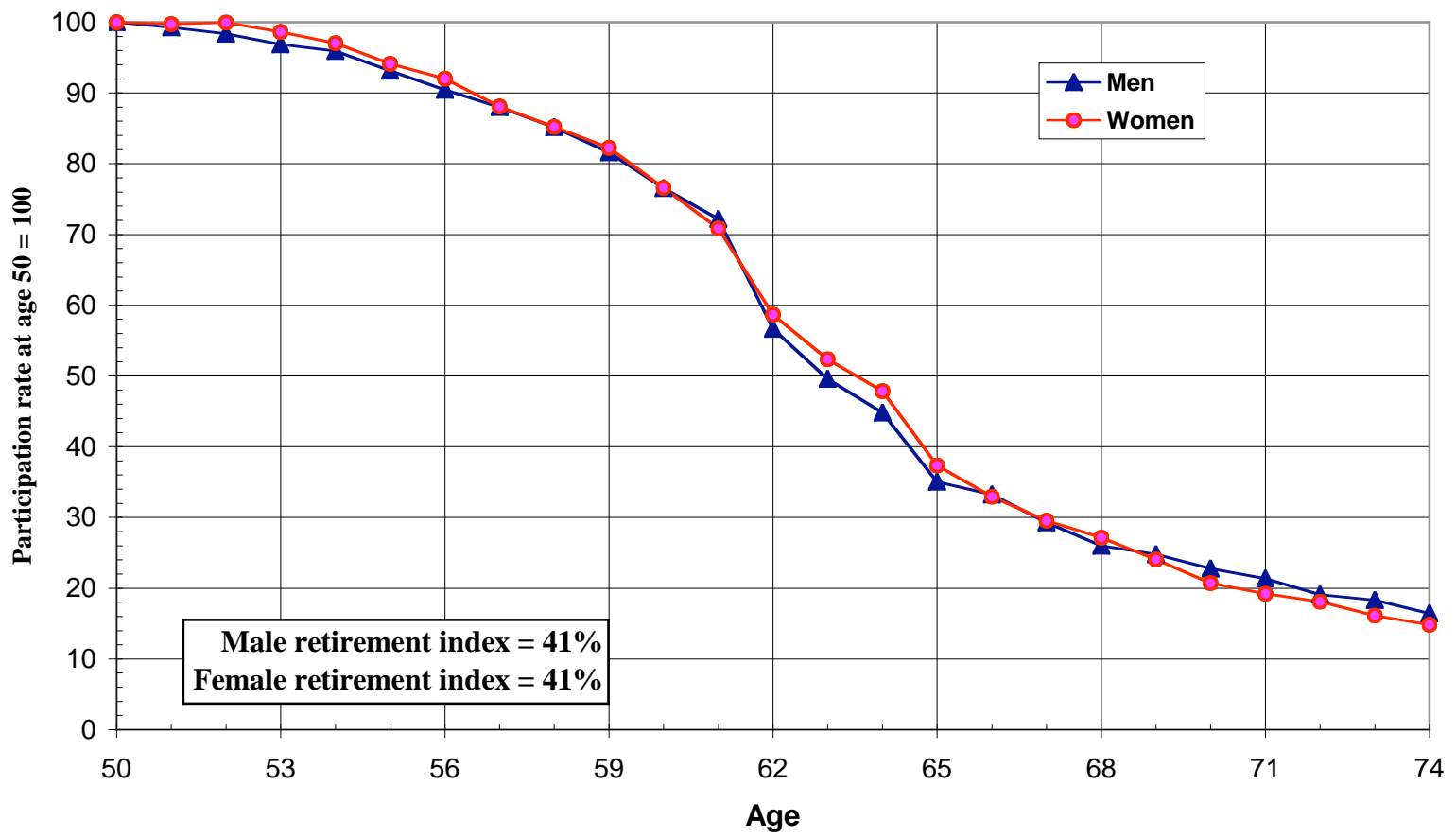

Source: Author's tabulations of 1988-1992 monthly CPS files (top panel) and 1977-2006 monthly CPS files (bottom panel). 
Figure 6. Rate of Retirement Using Three Measures of Labor Force Withdrawal, U.S. Workers Born between 1929 and 1931 [Cohort exit]

Labor supply at age $\mathbf{5 0}=\mathbf{1 0 0}$

American Men

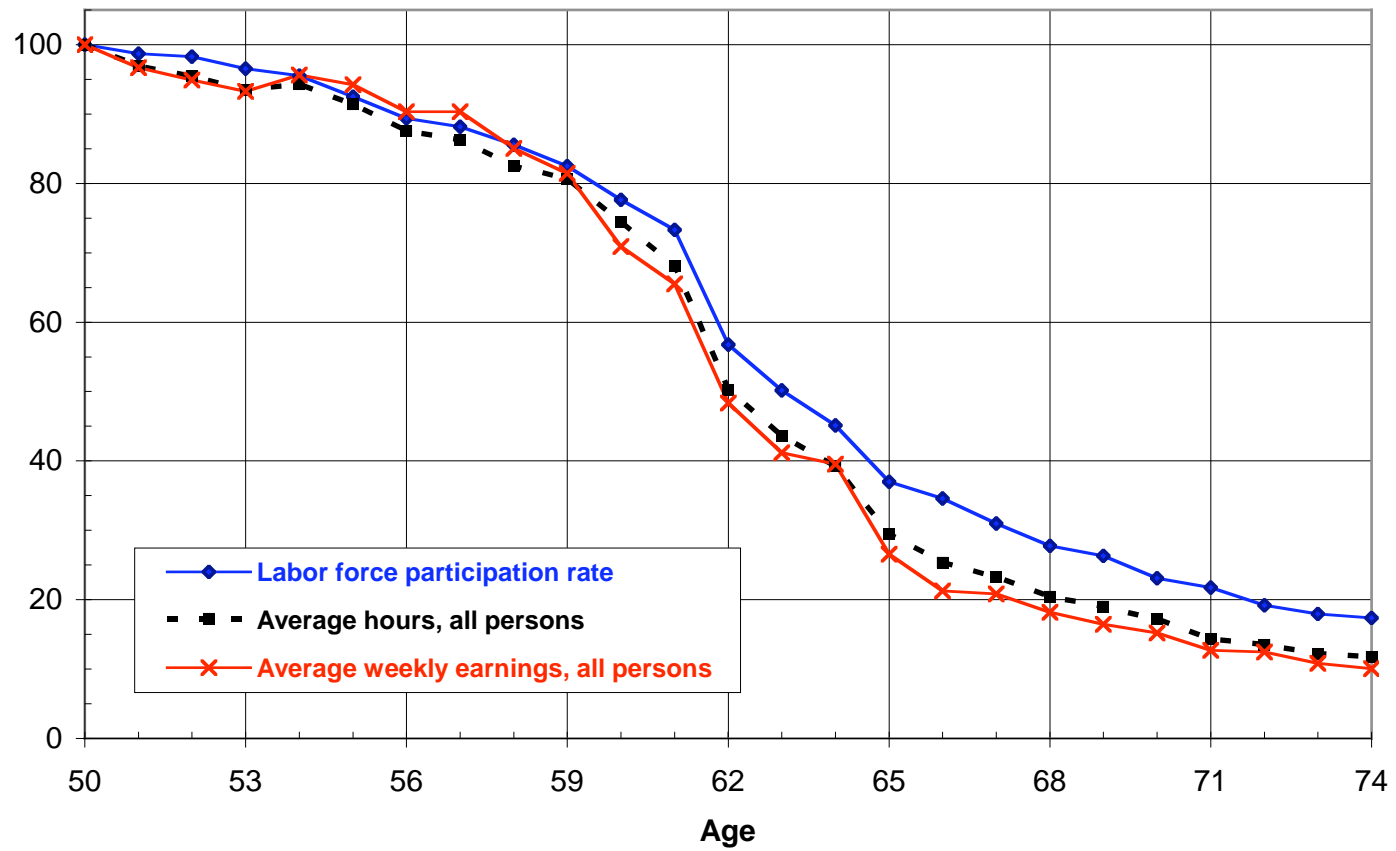

Labor supply at age $\mathbf{5 0}=\mathbf{1 0 0}$

American Women

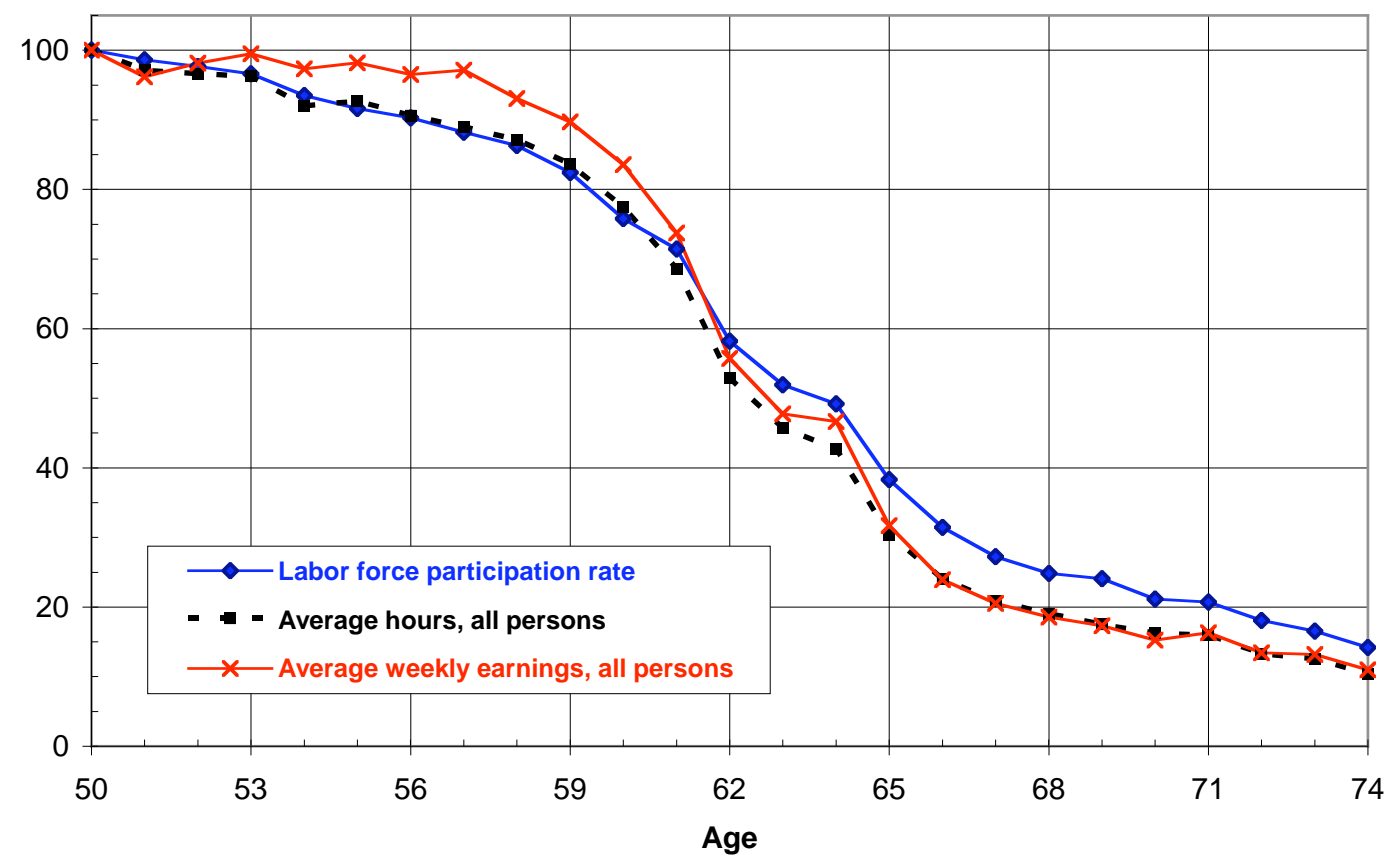

Source: Tabulations of January 1979 - December 2006 U.S. Current Population Survey outgoing rotation group files. The labor supply estimates at each year of age represent averages at that age for the three birth-year cohorts. 
Figure 7. Trend in Male U.S. Retirement Rate and Old-Age Labor Force Participation under Three Definitions, 1967-2006

Exit rate, ages 50-69 (\%)

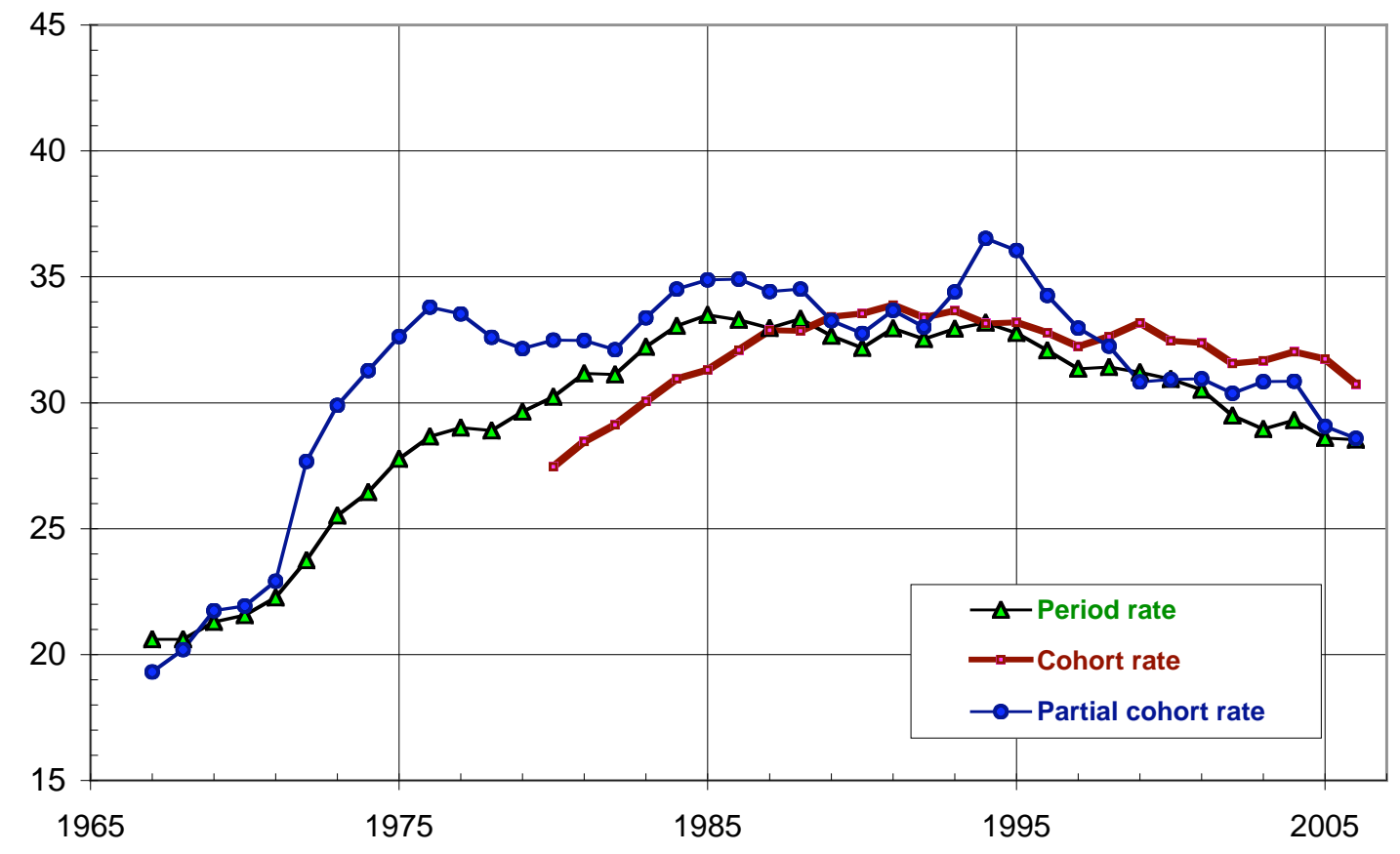

Average labor force participation rate, ages 50-69 (\%)

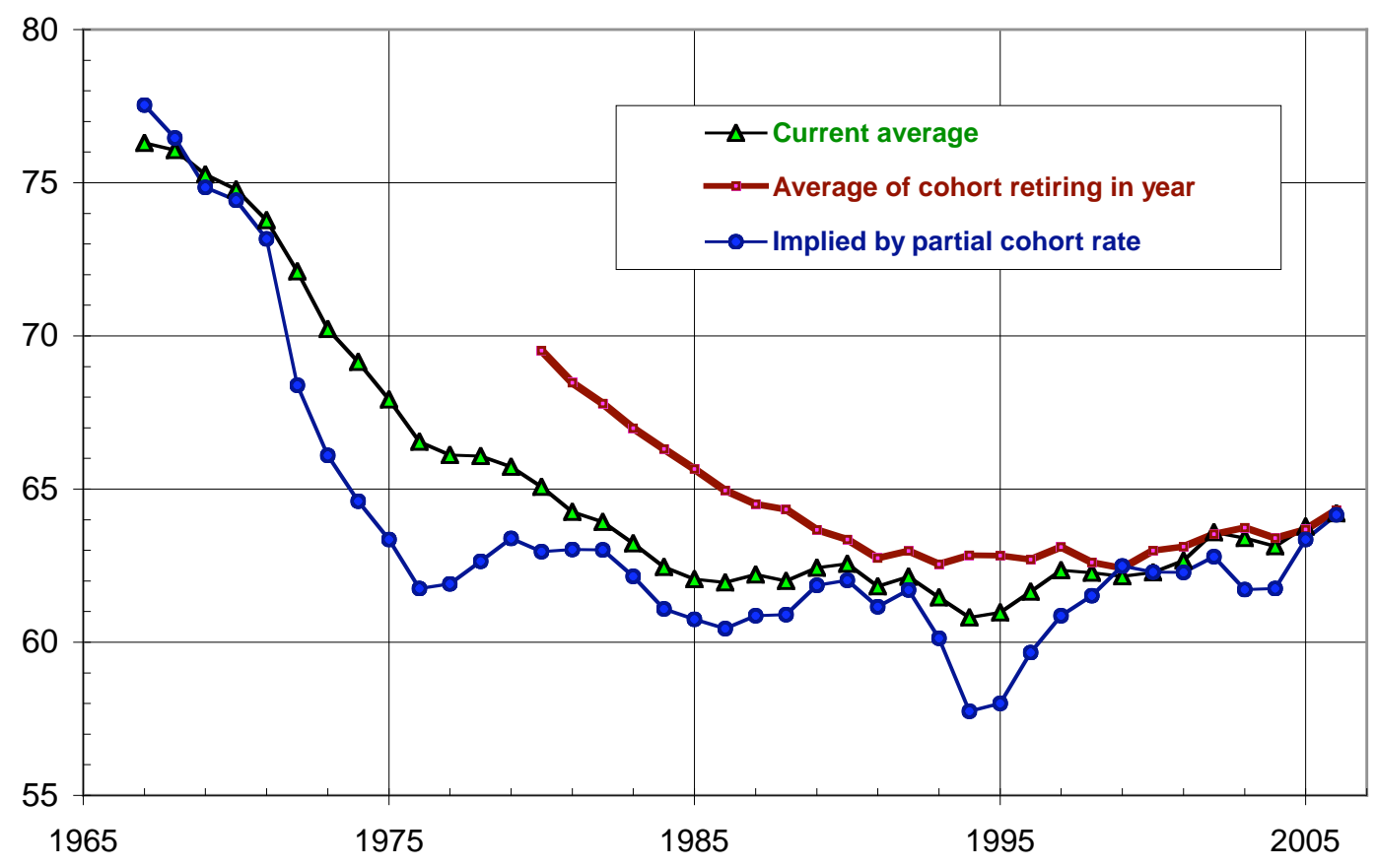

Source: Author's estimates based on labor force participation rates obtained from U.S. BLS and SourceOECD. 
Figure 8. Trend in Female U.S. Retirement Rate and Old-Age Labor Force Participation under Three Definitions, 1967-2006

Exit rate, ages 50-69 (\%)

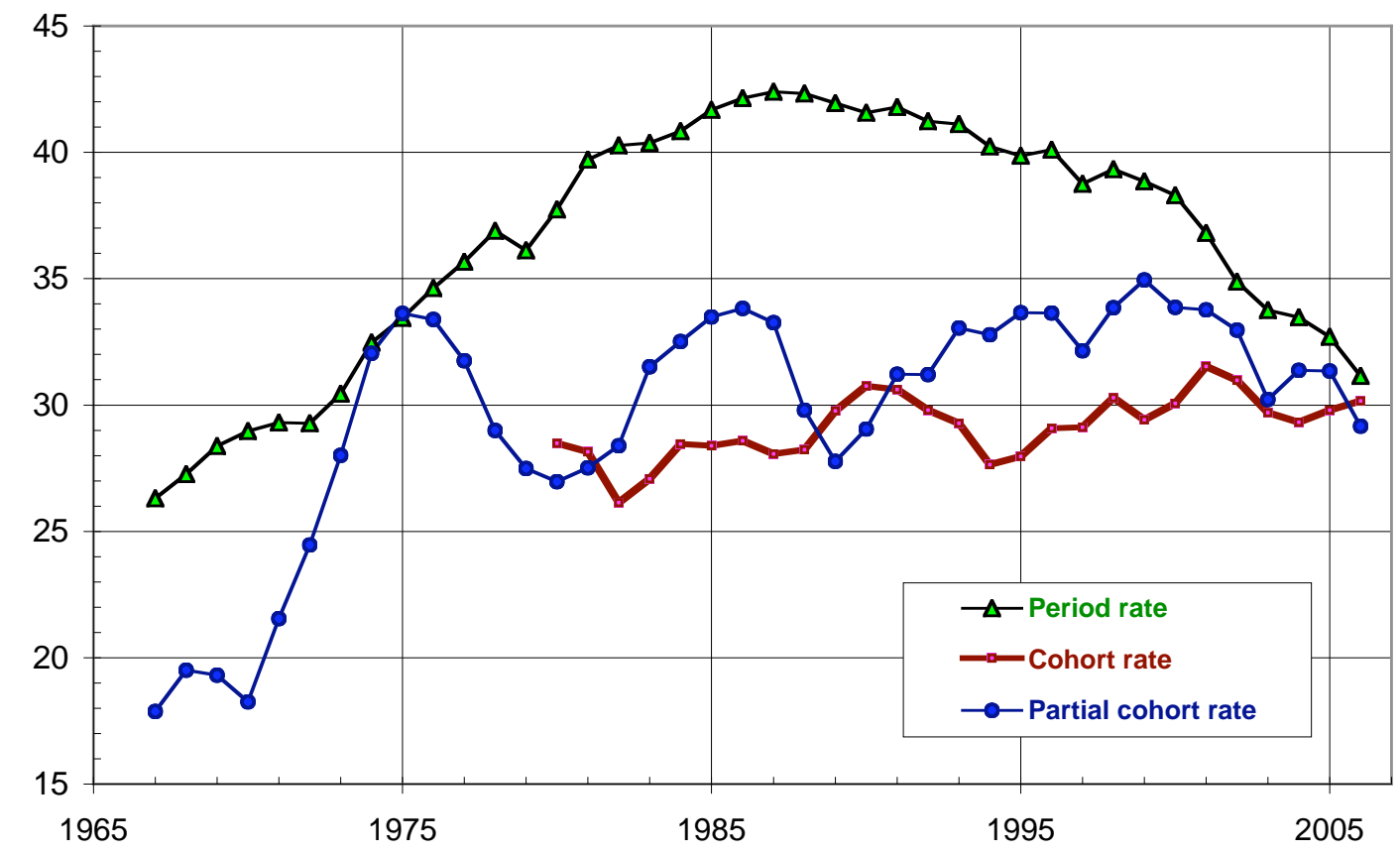

Average labor force participation rate, ages 50-69 (\%)

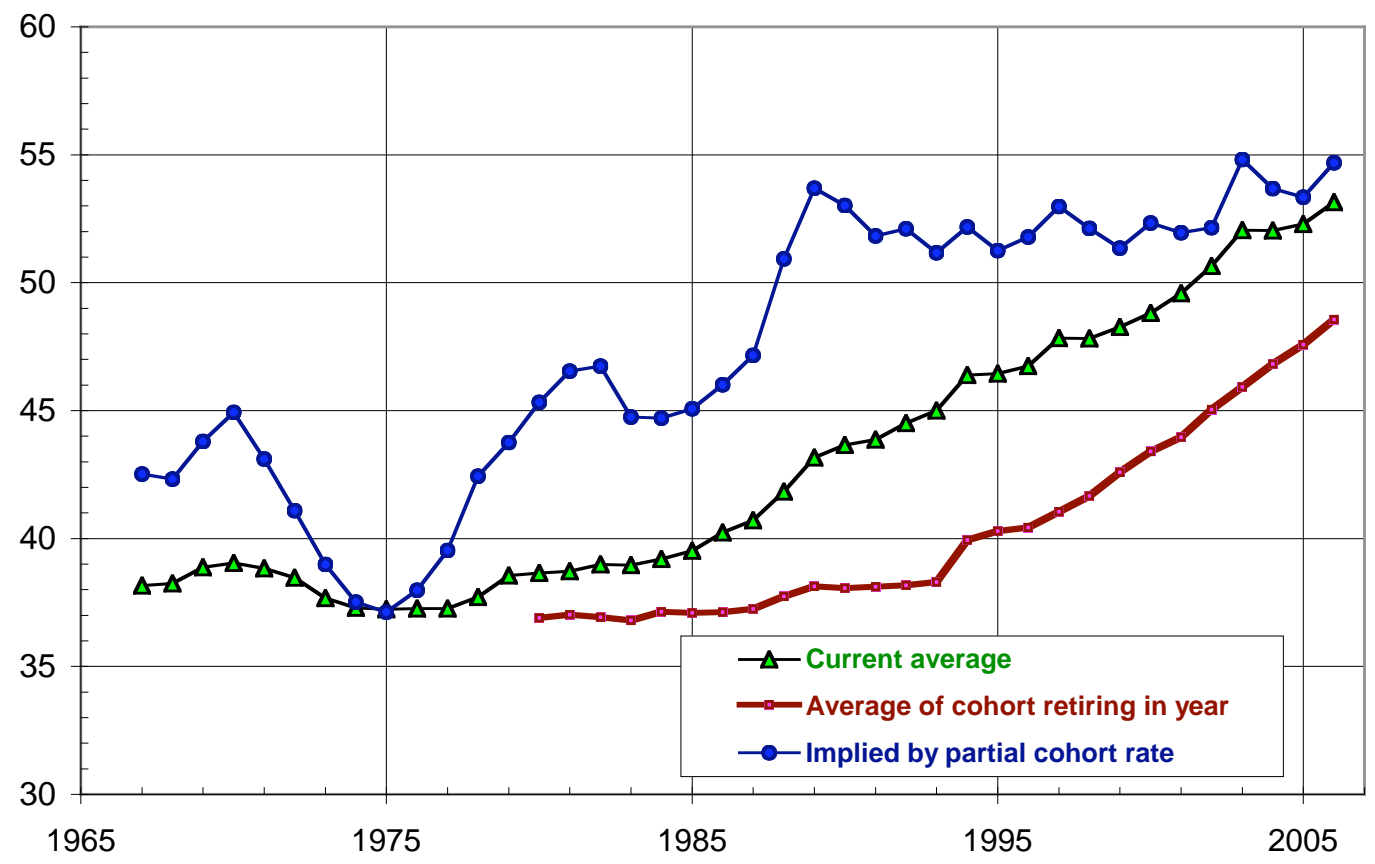

Source: Author's estimates based on labor force participation rates obtained from U.S. BLS and SourceOECD. 
Figure 9. U.S. Men's Labor Force Exit Rates over Five-year Periods Estimated with Cohort Data, 1965-2006

Labor force exit rates, younger ages (\%)

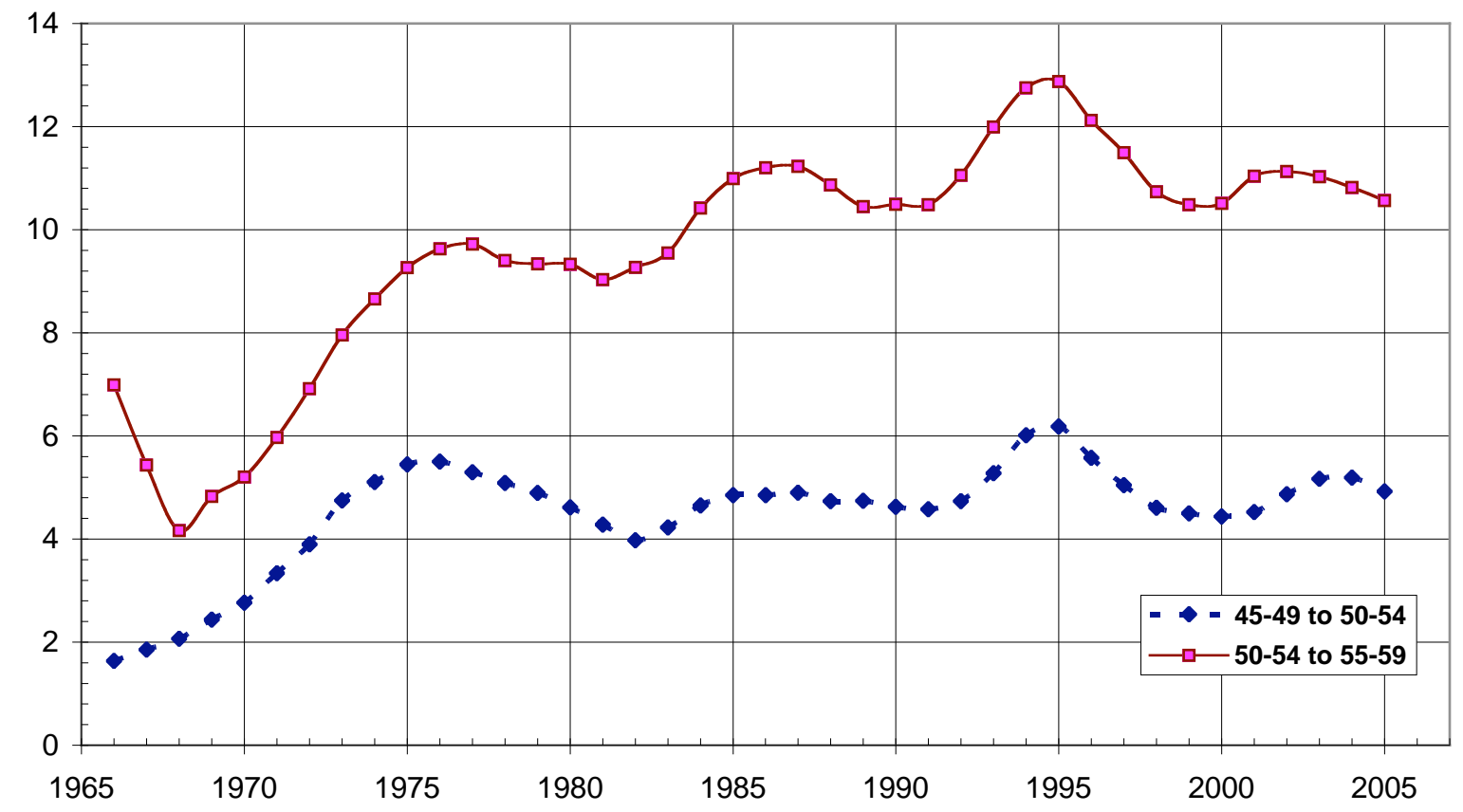

Labor force exit rates, older ages (\%)

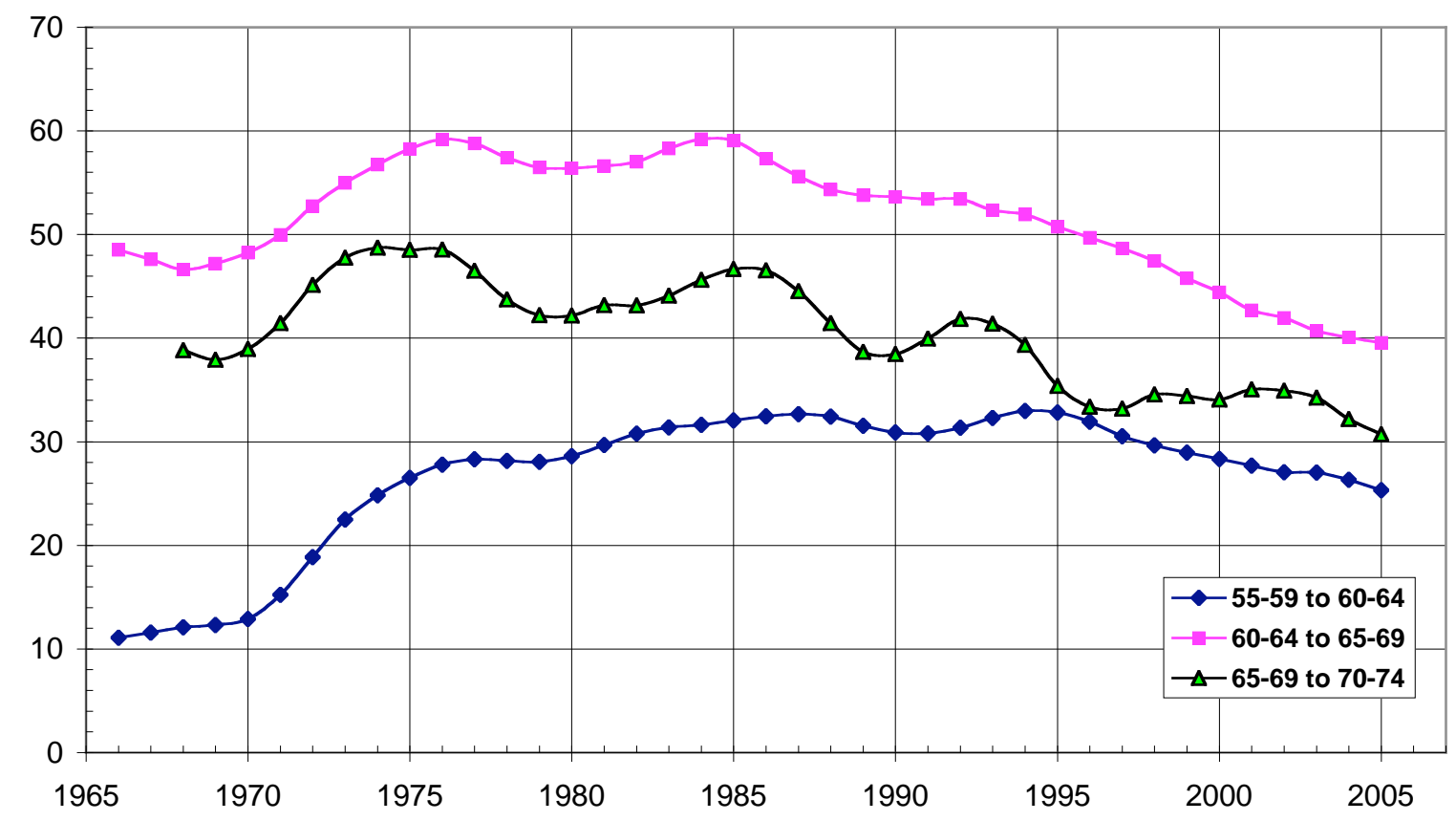

Note: The "cohort exit rate" is the proportional decline in the labor force participation rate for a birth cohort over a five-year period ending in the indicated years. The results shown represent centered 3-year averages of the estimated rates.

Source: Author's tabulations of labor force participation rate data from SourceOECD and U.S. BLS. 
Figure 10. U.S. Women's Labor Force Exit Rates over Five-year Periods Estimated with Cohort Data, 1965-2006

Labor force exit rates, younger ages (\%)

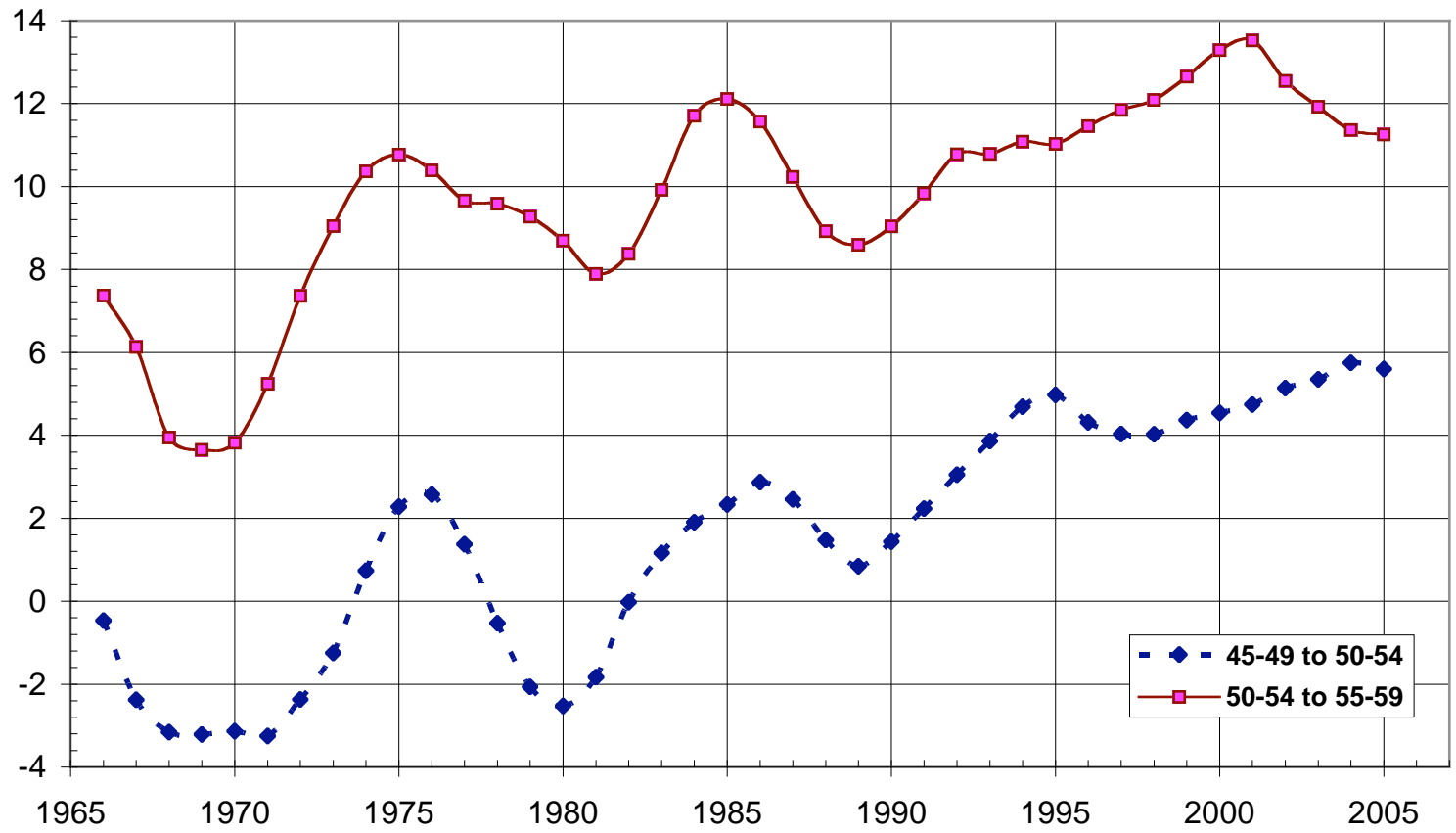

Labor force rates, older ages (\%)

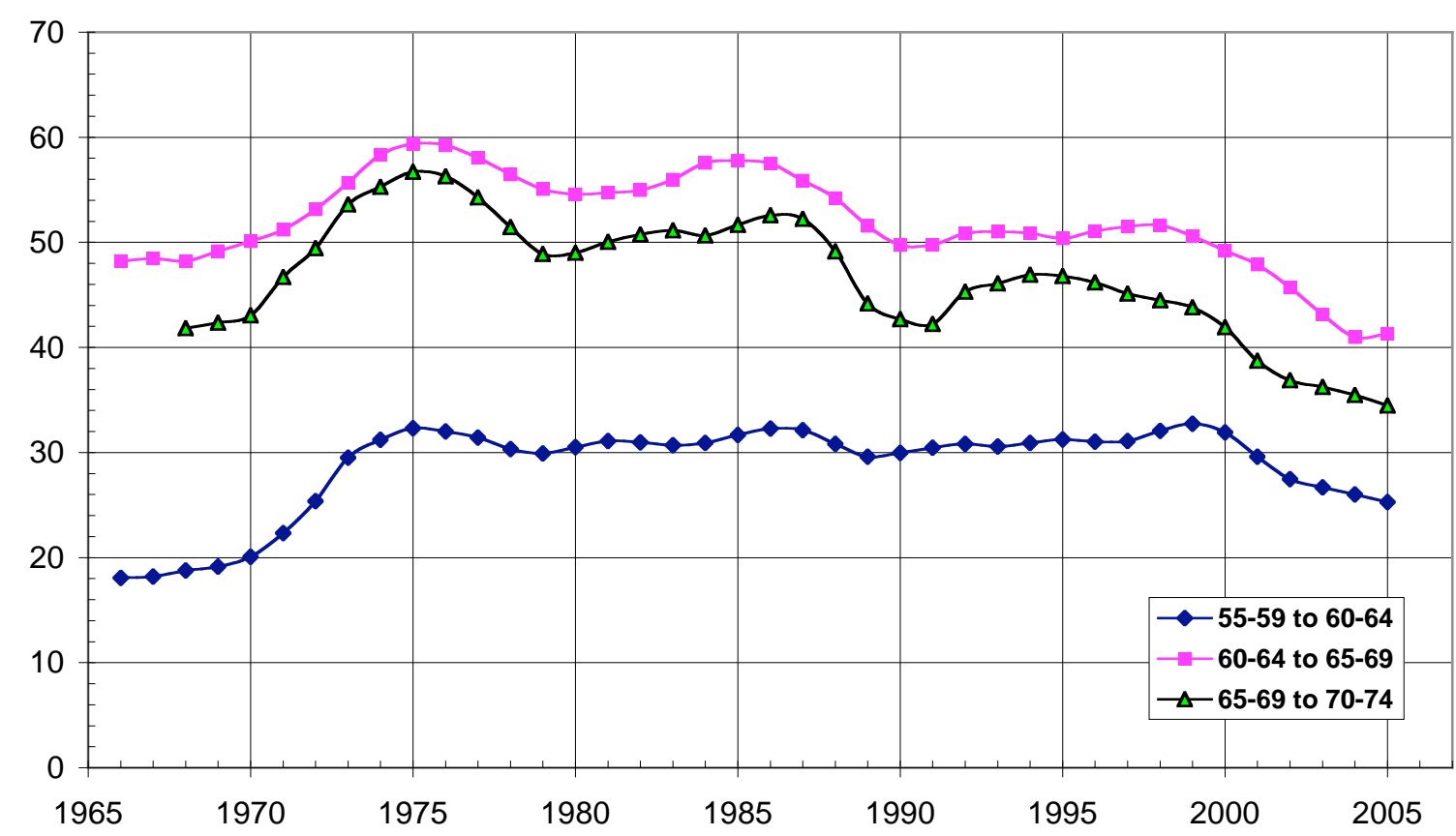

Note: The "cohort exit rate" is the proportional decline in the labor force participation rate for a birth cohort over a five-year period ending in the indicated years. The results shown represent centered 3-year averages of the estimated rates.

Source: Author's tabulations of labor force participation rate data from SourceOECD and U.S. BLS. 
Table 1. Labor Force Exit in Fifteen Industrialized Countries, 2004

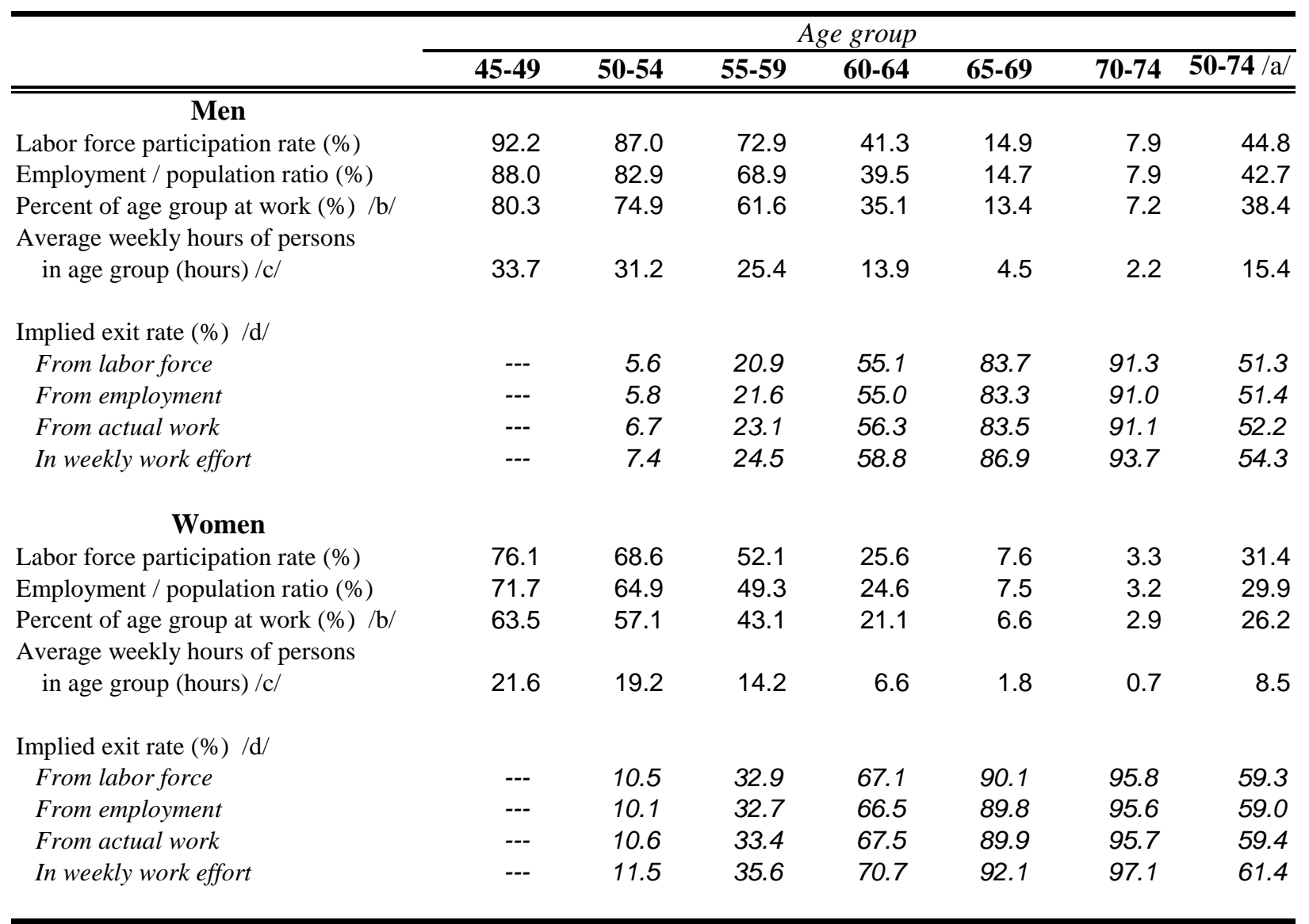

\section{Notes:}

/a/ Arithmetic average of rates for 50-54 to 70-74 age groups.

/b/ Percent of population that is both employed and at work in survey reference week.

/c/ Hours worked in the survey reference week, including zeroes for persons not employed or at work in that week.

/d/ Reduction in estimated work effort, measured as a percent of work effort among persons 45-49 years old.

Source: Author's tabulations of quarterly 2004 European Labour Force Survey (LFS) data for Austria, Belgium,

Denmark, Finland, France, Germany, Greece, Ireland, Italy, the Netherlands, Norway, Portugal, Spain, and Sweden, and tabulations of the U.S. Current Population Survey (CPS) files for January-December 2004. (The German data cover only the second calendar quarter of 2004; data for the other 13 European countries cover all four calendar quarters in 2004.) Entries in the table reflect unweighted averages for the fifteen countries 


\section{Table 2. Labor Force Exit in Fifteen OECD Countries, by Educational Attainment, 2004}

Percent

\begin{tabular}{|c|c|c|c|c|c|c|}
\hline & \multicolumn{3}{|c|}{ Labor indicators for men } & \multicolumn{3}{|c|}{ Labor indicators for women } \\
\hline & $\begin{array}{c}\text { 15-country } \\
\text { average /a/ } \\
\text { (1) }\end{array}$ & $\begin{array}{c}\text { USA } \\
(2)\end{array}$ & $\begin{array}{c}\text { European } \\
\text { average } / \mathrm{b} / \\
(3)\end{array}$ & $\begin{array}{c}\text { 15-country } \\
\text { average /a/ } \\
\text { (4) }\end{array}$ & $\begin{array}{c}\text { USA } \\
(5)\end{array}$ & $\begin{array}{c}\text { European } \\
\text { average } / \mathrm{b} / \\
(6)\end{array}$ \\
\hline \multicolumn{7}{|c|}{ Average labor force participation rate, ages 50-69 /c/ } \\
\hline Limited education & 45 & 49 & 46 & 31 & 33 & 26 \\
\hline Moderate education & 49 & 61 & 50 & 41 & 52 & 39 \\
\hline High education & 59 & 71 & 62 & 52 & 61 & 51 \\
\hline \multicolumn{7}{|c|}{ Exit rate: Labor force participation /d/ } \\
\hline Limited education & 45 & 35 & 49 & 52 & 41 & 56 \\
\hline Moderate education & 44 & 31 & 47 & 49 & 33 & 51 \\
\hline High education & 35 & 24 & 36 & 42 & 28 & 43 \\
\hline \multicolumn{7}{|c|}{ Exit rate: Percent of population at work /e/ } \\
\hline Limited education & 45 & 34 & 49 & 51 & 40 & 55 \\
\hline Moderate education & 46 & 31 & 49 & 49 & 34 & 53 \\
\hline High education & 36 & 25 & 38 & 42 & 29 & 44 \\
\hline \multicolumn{7}{|c|}{ Exit rate: Average weekly hours at work /f/ } \\
\hline Limited education & 46 & 37 & 49 & 53 & 44 & 56 \\
\hline Moderate education & 48 & 35 & 50 & 51 & 38 & 54 \\
\hline High education & 39 & 31 & 40 & 44 & 32 & 46 \\
\hline
\end{tabular}

\section{Notes:}

/a/ Unweighted average for all 14 European countries and the United States.

/b/ Population-weighted average for 14 European countries.

/c/ Average labor force participation rate between ages 50 and 69.

/d/ Reduction in estimated labor force participation between ages 50 and 69, measured as a percent of participation rate among persons 45-49 years old (see text).

/e/ Reduction in estimated percentage of the population typically at work between ages 50 and 69, measured as a percent of active work rate among persons $45-49$ years old (see text).

/f/ Reduction in average weekly hours at work in the population between ages 50 and 69, measured as a percent of average weekly hours among among the population 45-49 years old (see text).

Source: Author's tabulations of quarterly 2004 European Labour Force Survey (LFS) data for Austria, Belgium, Denmark, Finland, France, Germany, Greece, Ireland, Italy, the Netherlands, Norway, Portugal, Spain, and Sweden, and tabulations of the U.S. Current Population Survey (CPS) files for January-December 2004. (See sources of Table 1.) 


\section{Table 3. Male Labor Force Period Exit Rates in Twenty-one OECD Countries, 2003-2006}

\begin{tabular}{|c|c|c|c|c|c|c|c|}
\hline & \multirow{2}{*}{$\begin{array}{c}\text { Participation } \\
\text { rate, age } \\
\mathbf{4 5 - 4 9} \\
(1) \\
\end{array}$} & \multicolumn{4}{|c|}{ Exit rate through age -- } & \multirow{2}{*}{$\begin{array}{c}\begin{array}{c}\text { Labor } \\
\text { force }\end{array} \\
\text { exit rate, } \\
50-69 \\
(6) \\
\end{array}$} & \multirow{2}{*}{$\begin{array}{c}\text { Average } \\
\text { participatior } \\
\text { rate, } \\
\mathbf{5 0 - 6 9} \\
(7) \\
\end{array}$} \\
\hline & & $\begin{array}{c}50-54 \\
(2) \\
\end{array}$ & $\begin{array}{c}55-59 \\
(3) \\
\end{array}$ & $\begin{array}{c}\text { 60-64 } \\
(4) \\
\end{array}$ & $\begin{array}{c}\text { 65-69 } \\
(5) \\
\end{array}$ & & \\
\hline Belgium & 91 & 10 & 39 & 76 & 94 & 55 & 41 \\
\hline France & 94 & 3 & 29 & 80 & 96 & 52 & 45 \\
\hline Austria & 94 & 7 & 28 & 80 & 92 & 52 & 45 \\
\hline Italy & 94 & 7 & 39 & 68 & 88 & 51 & 47 \\
\hline Finland & 90 & 6 & 22 & 60 & 90 & 44 & 50 \\
\hline Netherlands & 91 & 4 & 15 & 65 & 87 & 43 & 52 \\
\hline Germany & 95 & 4 & 15 & 59 & 92 & 42 & 55 \\
\hline Greece & 95 & 6 & 23 & 53 & 84 & 42 & 56 \\
\hline Spain & 92 & 4 & 18 & 47 & 93 & 41 & 55 \\
\hline 21-country average & 92 & 4 & 17 & 48 & 79 & 37 & 58 \\
\hline Canada & 91 & 3 & 17 & 42 & 76 & 34 & 60 \\
\hline Ireland & 91 & 6 & 18 & 37 & 74 & 34 & 60 \\
\hline Australia & 90 & 4 & 16 & 41 & 74 & 34 & 59 \\
\hline Portugal & 93 & 6 & 22 & 45 & 63 & 34 & 62 \\
\hline United Kingdom & 91 & 4 & 14 & 39 & 79 & 34 & 60 \\
\hline Denmark & 92 & 2 & 4 & 44 & 79 & 32 & 62 \\
\hline Sweden & 91 & 2 & 7 & 28 & 81 & 30 & 64 \\
\hline Switzerland & 95 & 1 & 6 & 32 & 77 & 29 & 68 \\
\hline United States & 89 & 4 & 13 & 35 & 63 & 29 & 64 \\
\hline Norway & 90 & 3 & 9 & 30 & 71 & 28 & 65 \\
\hline New Zealand & 93 & 2 & 7 & 25 & 65 & 25 & 70 \\
\hline Japan & 97 & 1 & 4 & 27 & 52 & 21 & 77 \\
\hline
\end{tabular}

Note: The exit rate is the proportional drop in economic activity rates from age 45-49 to the indicated ages, on average, in the years 2003-2006. Countries are ranked from highest to lowest by their average exit rates (column 6). The reported 21country average represents the unweighted average of the countries included in the table.

Source: Author's estimates based on labor force participation rates obtained from SourceOECD supplemented with author's tabulations of Labour Force Survey data for selected European countries. 


\section{Table 4. Female Labor Force Period Exit Rates in Twenty-one OECD Countries, 2003-2006}

\begin{tabular}{|c|c|c|c|c|c|c|c|}
\hline & \multirow{2}{*}{$\begin{array}{c}\text { Participation } \\
\text { rate, age } \\
\mathbf{4 5 - 4 9} \\
(1) \\
\end{array}$} & \multicolumn{4}{|c|}{ Exit rate through age -- } & \multirow{2}{*}{$\begin{array}{c}\begin{array}{c}\text { Labor } \\
\text { force }\end{array} \\
\text { exit rate, } \\
50-69 \\
(6) \\
\end{array}$} & \multirow{2}{*}{$\begin{array}{c}\text { Average } \\
\text { participatior } \\
\text { rate, } \\
\mathbf{5 0 - 6 9} \\
(7) \\
\end{array}$} \\
\hline & & $\begin{array}{c}\mathbf{5 0 - 5 4} \\
(2) \\
\end{array}$ & $\begin{array}{c}55-59 \\
\text { (3) } \\
\end{array}$ & $\begin{array}{c}\text { 60-64 } \\
(4) \\
\end{array}$ & $\begin{array}{c}\text { 65-69 } \\
(5) \\
\end{array}$ & & \\
\hline Belgium & 71 & 19 & 55 & 87 & 98 & 65 & 25 \\
\hline Austria & 81 & 12 & 53 & 90 & 95 & 63 & 30 \\
\hline Italy & 61 & 16 & 49 & 84 & 95 & 61 & 24 \\
\hline Spain & 63 & 19 & 43 & 68 & 95 & 56 & 27 \\
\hline Greece & 61 & 18 & 48 & 66 & 92 & 56 & 27 \\
\hline Netherlands & 77 & 13 & 37 & 77 & 94 & 55 & 34 \\
\hline France & 83 & 6 & 32 & 80 & 97 & 54 & 38 \\
\hline Germany & 83 & 6 & 24 & 75 & 95 & 50 & 41 \\
\hline Australia & 78 & 9 & 30 & 61 & 87 & 47 & 42 \\
\hline 21-country average & 77 & 8 & 27 & 62 & 87 & 46 & 42 \\
\hline Ireland & 64 & 10 & 31 & 58 & 88 & 46 & 34 \\
\hline Finland & 90 & 4 & 19 & 66 & 95 & 46 & 49 \\
\hline United Kingdom & 81 & 6 & 22 & 62 & 87 & 44 & 45 \\
\hline Canada & 82 & 6 & 26 & 58 & 86 & 44 & 46 \\
\hline Denmark & 86 & 3 & 10 & 67 & 91 & 43 & 49 \\
\hline Portugal & 78 & 11 & 33 & 53 & 72 & 42 & 45 \\
\hline Switzerland & 83 & 5 & 15 & 51 & 86 & 39 & 51 \\
\hline Japan & 73 & 6 & 19 & 46 & 67 & 34 & 48 \\
\hline New Zealand & 82 & 3 & 14 & 42 & 77 & 34 & 54 \\
\hline Sweden & 88 & 3 & 9 & 34 & 89 & 34 & 58 \\
\hline Norway & 84 & 2 & 14 & 38 & 78 & 33 & 56 \\
\hline United States & 78 & 4 & 16 & 41 & 70 & 33 & 52 \\
\hline
\end{tabular}

Note: The exit rate is the proportional drop in economic activity rates from age 45-49 to the indicated ages, on average, in the years 2003-2006. Countries are ranked from highest to lowest by their average exit rates (column 6). The reported 21country average represents the unweighted average of the countries included in the table.

Source: Author's estimates based on labor force participation rates obtained from SourceOECD supplemented with author's tabulations of Labour Force Survey data for selected European countries. 


\section{Table 5. Comparing 2006 Labor Force Exit Rates under Alternative Definitions: Men in Twenty-one OECD Countries}

\begin{tabular}{|c|c|c|c|c|c|c|}
\hline \multirow[b]{3}{*}{ Country } & \multirow{2}{*}{\multicolumn{3}{|c|}{ Labor force exit rate, ages 50-69/a/ }} & \multicolumn{3}{|c|}{$\begin{array}{c}\text { Average labor force participation rate, } \\
\text { ages } 50-69\end{array}$} \\
\hline & & & & \multirow[b]{2}{*}{$\begin{array}{c}\text { Actual, } \\
\mathbf{2 0 0 6} \\
(4)\end{array}$} & \multirow{2}{*}{$\begin{array}{c}\text { For } \\
\text { cohort } \\
\text { born in } \\
1937-41 \\
(5)\end{array}$} & \multirow{2}{*}{$\begin{array}{c}\text { Implied by } \\
\text { partial cohort } \\
\text { rate /b/ } \\
(6)\end{array}$} \\
\hline & $\begin{array}{c}\text { Period rate } \\
\text { (1) }\end{array}$ & $\begin{array}{c}\text { Cohort rate } \\
(2)\end{array}$ & $\begin{array}{c}\text { Partial cohort } \\
\text { rate } \\
(3) \\
\end{array}$ & & & \\
\hline Belgium & 54 & 58 & 53 & 42 & 39 & 43 \\
\hline France & 52 & 54 & 52 & 45 & 44 & 45 \\
\hline Austria & 49 & -- & 49 & 47 & -- & 47 \\
\hline Italy & 50 & 50 & 48 & 47 & 48 & 49 \\
\hline Netherlands /c/ & 42 & 49 & 42 & 52 & 46 & 53 \\
\hline Finland & 43 & -- & 41 & 52 & -- & 53 \\
\hline Greece & 41 & 42 & 40 & 56 & 55 & 58 \\
\hline Spain & 41 & 43 & 39 & 55 & 54 & 56 \\
\hline Germany & 40 & 47 & 38 & 56 & 52 & 59 \\
\hline Portugal & 35 & 33 & 35 & 61 & 62 & 61 \\
\hline All-country average & 37 & 39 & 35 & 59 & 57 & 60 \\
\hline Switzerland & 30 & -- & 33 & 67 & -- & 63 \\
\hline Canada & 34 & 38 & 31 & 60 & 57 & 62 \\
\hline Ireland & 33 & 34 & 31 & 61 & 59 & 64 \\
\hline United Kingdom & 33 & 37 & 29 & 61 & 59 & 64 \\
\hline Norway & 29 & 34 & 29 & 65 & 64 & 64 \\
\hline United States & 29 & 31 & 29 & 64 & 64 & 64 \\
\hline Denmark & 32 & 38 & 29 & 62 & 58 & 65 \\
\hline Australia & 32 & 37 & 28 & 61 & 58 & 65 \\
\hline Sweden & 29 & 34 & 28 & 65 & 63 & 66 \\
\hline Japan & 21 & 20 & 22 & 77 & 78 & 76 \\
\hline New Zealand & 22 & 29 & 17 & 72 & 68 & 77 \\
\hline
\end{tabular}

\footnotetext{
Notes:

/a/ The "labor force exit rate" is the percent reduction in labor supply between ages 50 and 69 below the level that would be observed if labor supply in those ages remained at its level between ages 45-49. For an explanation of "period," "cohort," and "partial cohort" exit rates, see text. Countries are ranked from highest to lowest by their partial cohort exit rates (column 3).

/b/ Calculated using the partial cohort exit rate and the labor force participation rate of 45-49 year-olds in 2006.

/c/ Estimates for the Netherlands are based on 1985-2005 data rather than data for 1986-2006. Consequently, the period estimates are based on cross-section data for 2005, and the cohort estimates refer to the population born between 19361940 rather than 1937-1941.

Source: Author's estimates based on labor force participation rates obtained from SourceOECD supplemented with author's tabulations of Labour Force Survey data for selected European countries.
} 


\section{Table 6. Comparing 2006 Labor Force Exit Rates under Alternative Definitions: Women in Twenty-one OECD Countries}

\begin{tabular}{|c|c|c|c|c|c|c|}
\hline \multirow[b]{3}{*}{ Country } & \multirow{2}{*}{\multicolumn{3}{|c|}{ Labor force exit rate, ages 50-69 /a/ }} & \multicolumn{3}{|c|}{$\begin{array}{c}\text { Average labor force participation rate, } \\
\text { ages } 50-69\end{array}$} \\
\hline & & & & \multirow[b]{2}{*}{$\begin{array}{c}\text { Actual, } \\
\mathbf{2 0 0 6} \\
(4) \\
\end{array}$} & \multirow{2}{*}{ 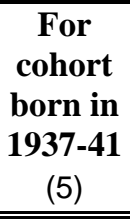 } & \multirow{2}{*}{$\begin{array}{c}\text { Implied by } \\
\text { partial cohort } \\
\text { rate /b/ } \\
(6) \\
\end{array}$} \\
\hline & $\begin{array}{c}\text { Period rate } \\
(1) \\
\end{array}$ & $\begin{array}{c}\text { Cohort rate } \\
(2) \\
\end{array}$ & $\begin{array}{c}\text { Partial cohort } \\
\text { rate } \\
\text { (3) } \\
\end{array}$ & & & \\
\hline Belgium & 64 & 65 & 54 & 27 & 15 & 34 \\
\hline Austria & 60 & & 51 & 33 & & 40 \\
\hline France & 54 & 52 & 49 & 39 & 32 & 43 \\
\hline Italy & 60 & 58 & 48 & 25 & 17 & 32 \\
\hline Greece & 56 & 50 & 42 & 28 & 22 & 37 \\
\hline Netherlands /c/ & 54 & 47 & 41 & 35 & 21 & 45 \\
\hline Finland & 43 & & 41 & 51 & & 54 \\
\hline Germany & 48 & 41 & 40 & 44 & 34 & 50 \\
\hline United Kingdom & 43 & 46 & 37 & 46 & 40 & 51 \\
\hline Denmark & 42 & 50 & 36 & 50 & 42 & 55 \\
\hline All-country average & 45 & 42 & 36 & 43 & 35 & 50 \\
\hline Norway & 34 & 37 & 35 & 55 & 52 & 55 \\
\hline Switzerland & 38 & & 34 & 52 & & 55 \\
\hline Canada & 42 & 42 & 33 & 48 & 38 & 55 \\
\hline Sweden & 33 & 38 & 33 & 59 & 57 & 59 \\
\hline Portugal & 42 & 28 & 32 & 46 & 39 & 54 \\
\hline Australia & 44 & 46 & 31 & 44 & 33 & 54 \\
\hline Japan & 34 & 31 & 30 & 49 & 47 & 52 \\
\hline United States & 31 & 30 & 29 & 53 & 49 & 55 \\
\hline Spain & 55 & 31 & 28 & 30 & 19 & 47 \\
\hline New Zealand & 32 & 37 & 24 & 56 & 47 & 62 \\
\hline Ireland & 42 & 27 & 16 & 38 & 23 & 56 \\
\hline
\end{tabular}

\footnotetext{
Notes:

/a/ The "labor force exit rate" is the percent reduction in labor supply between ages 50 and 69 below the level that would be observed if labor supply in those ages remained at its level between ages 45-49. For an explanation of "period," "cohort," and "partial cohort" exit rates, see text. Countries are ranked from highest to lowest by their partial cohort exit rates (column 3).

/b/ Calculated using the partial cohort exit rate and the labor force participation rate of 45-49 year-olds in 2006.

/c/ Estimates for the Netherlands are based on 1985-2005 data rather than data for 1986-2006. Consequently, the period estimates are based on cross-section data for 2005, and the cohort estimates refer to the population born between 19361940 rather than 1937-1941.

Source: Author's estimates based on labor force participation rates obtained from SourceOECD supplemented with author's tabulations of Labour Force Survey data for selected European countries.
} 
Table 7. Change in Labor Force Exit Rates through 2006: Experiences of Men in Twenty-one OECD Countries

Percentage points

Change in period exit rate between indicated years /a/

Change in partial cohort exit rate between indicated years /a/

\begin{tabular}{|c|c|c|c|c|c|c|c|c|c|c|c|}
\hline Country & $\begin{array}{r}1980- \\
2006 \\
\end{array}$ & $\begin{array}{r}1985- \\
2006 \\
\end{array}$ & $\begin{array}{r}1990- \\
2006 \\
\end{array}$ & $\begin{array}{r}1995- \\
2006 \\
\end{array}$ & $\begin{array}{r}2000- \\
2006 \\
\end{array}$ & Country & $\begin{array}{r}1980- \\
2006 \\
\end{array}$ & $\begin{array}{r}1985- \\
2006 \\
\end{array}$ & $\begin{array}{r}1990- \\
2006 \\
\end{array}$ & $\begin{array}{r}1995- \\
2006 \\
\end{array}$ & $\begin{array}{r}2000- \\
2006 \\
\end{array}$ \\
\hline Australia & -3.6 & -7.6 & -6.2 & -6.8 & -5.5 & Australia & -- & -14.9 & -10.1 & -12.3 & -12.1 \\
\hline Austria & -- & -- & -- & -2.8 & -4.0 & Austria & -- & -- & -- & -- & -4.8 \\
\hline Belgium & -- & 2.8 & -4.9 & -2.2 & -3.1 & Belgium & -- & -- & -9.5 & -2.0 & -4.6 \\
\hline Canada & 2.8 & -0.6 & -3.3 & -6.1 & -5.7 & Canada & -- & -5.9 & -7.4 & -11.8 & -8.1 \\
\hline Denmark & -- & 0.2 & -0.4 & -2.7 & -7.4 & Denmark & -- & -- & 1.7 & -10.6 & -11.8 \\
\hline Finland & -- & -- & -5.9 & -8.6 & -5.5 & Finland & -- & -- & -- & -12.1 & -4.9 \\
\hline France & -- & 3.6 & 0.5 & -0.9 & -1.5 & France & -- & 0.6 & 0.0 & -1.6 & -1.7 \\
\hline Germany & -- & -- & -- & -7.2 & -5.4 & Germany & -- & -- & -- & -8.9 & -7.7 \\
\hline Greece & -- & 6.8 & 1.9 & 3.1 & 0.0 & Greece & -- & -- & -2.2 & 2.5 & -2.3 \\
\hline Ireland & -- & 4.5 & 0.8 & 0.0 & -0.6 & Ireland & -- & -- & -4.8 & -6.7 & -0.7 \\
\hline Italy & -- & 5.1 & 3.7 & -0.9 & -2.8 & Italy & -- & -- & 0.1 & -8.2 & -4.6 \\
\hline Japan & 4.8 & 1.6 & 1.6 & 2.6 & 1.4 & Japan & 4.9 & 1.1 & 4.2 & 5.6 & 1.4 \\
\hline Netherlands /b/ & -- & -5.7 & -6.9 & -10.0 & -5.5 & Netherlands /b/ & -- & -- & -8.2 & -11.0 & -3.1 \\
\hline Norway & 12.1 & 5.0 & 3.2 & 0.2 & -1.1 & Norway & 14.0 & 10.7 & -3.8 & -1.3 & 0.4 \\
\hline Portugal & -- & -- & 1.7 & -1.3 & 2.0 & Portugal & -- & -- & 3.1 & -3.4 & 3.8 \\
\hline Spain & 9.3 & 3.0 & -0.9 & -4.4 & -2.3 & Spain & 3.9 & -1.5 & -2.4 & -7.7 & -2.6 \\
\hline Sweden & -0.7 & -2.9 & -2.6 & -4.1 & -2.5 & Sweden & -2.8 & -4.7 & -5.1 & -9.8 & -5.7 \\
\hline Switzerland & -- & -- & -- & 1.5 & 0.8 & Switzerland & -- & -- & -- & -- & 0.7 \\
\hline United Kingdom & -- & -2.8 & -3.9 & -5.7 & -4.4 & United Kingdom & -- & -- & -8.3 & -13.5 & -9.2 \\
\hline United States & -1.7 & -4.9 & -3.6 & -4.2 & -2.4 & United States & -3.9 & -6.3 & -4.2 & -7.5 & -2.3 \\
\hline Average & 3.3 & 0.6 & -2.5 & -3.6 & -3.0 & Average & 3.2 & -2.6 & -3.6 & -7.3 & -4.4 \\
\hline
\end{tabular}

Notes:

/a/ The "labor force exit rate" is the percent reduction in labor supply between ages 50 and 69 below the level that would be observed if labor supply in those ages remained at its level between ages 45-49. For an explanation of "period" and "partial cohort" exit rates, see text.

/b/ Data for the Netherlands end in 2005.

Source: Author's estimates based on labor force participation rates obtained from SourceOECD supplemented with author's tabulations of Labour Force Survey data for selected European countries. 
Table 8. Change in Labor Force Exit Rates through 2006: Experiences of Women in Twenty-one OECD Countries Percentage points

\begin{tabular}{|c|c|c|c|c|c|c|c|c|c|c|c|}
\hline & \multicolumn{5}{|c|}{ Change in period exit rate between indicated years /a/ } & \multicolumn{6}{|c|}{ Change in partial cohort exit rate between indicated years /a/ } \\
\hline Country & $\begin{array}{r}1980- \\
2006 \\
\end{array}$ & $\begin{array}{r}1985- \\
2006 \\
\end{array}$ & $\begin{array}{r}1990- \\
2006 \\
\end{array}$ & $\begin{array}{r}1995- \\
2006 \\
\end{array}$ & $\begin{array}{r}2000- \\
2006 \\
\end{array}$ & Country & $\begin{array}{r}1980- \\
2006 \\
\end{array}$ & $\begin{array}{r}1985- \\
2006 \\
\end{array}$ & $\begin{array}{r}1990- \\
2006 \\
\end{array}$ & $\begin{array}{r}1995- \\
2006 \\
\end{array}$ & $\begin{array}{r}2000- \\
2006 \\
\end{array}$ \\
\hline Australia & -13.6 & -17.6 & -15.2 & -13.5 & -8.1 & Australia & -- & -27.0 & -11.8 & -17.5 & -14.2 \\
\hline Austria & -- & -- & -- & -3.1 & -6.2 & Austria & -- & -- & -- & -- & -11.1 \\
\hline Belgium & -- & -5.1 & -9.5 & -5.5 & -5.8 & Belgium & -- & -- & -15.9 & -1.2 & -6.7 \\
\hline Canada & -4.6 & -8.3 & -10.3 & -10.1 & -7.7 & Canada & -- & -3.8 & -10.2 & -14.9 & -11.3 \\
\hline Denmark & -- & -7.1 & -7.0 & -13.2 & -5.3 & Denmark & -- & -- & -3.9 & -22.4 & -7.5 \\
\hline Finland & -- & -- & -8.9 & -9.4 & -7.7 & Finland & -- & -- & -- & -11.9 & -9.8 \\
\hline France & -- & 0.5 & 0.0 & -2.2 & -1.5 & France & -- & 0.5 & -0.3 & 1.0 & -3.8 \\
\hline Germany & -- & -- & -- & -9.1 & -6.9 & Germany & -- & -- & -- & -2.9 & -7.8 \\
\hline Greece & -- & 13.8 & 8.9 & 8.0 & 2.8 & Greece & -- & -- & -8.1 & -4.9 & 0.8 \\
\hline Ireland & -- & 4.0 & -1.7 & -9.2 & -9.7 & Ireland & -- & -- & -19.2 & -18.7 & -0.9 \\
\hline Italy & -- & 1.8 & -1.2 & -4.9 & -4.6 & Italy & -- & -- & -6.9 & -13.6 & -7.5 \\
\hline Japan & 1.4 & -1.2 & -1.2 & 0.7 & 0.5 & Japan & 3.5 & 0.4 & 3.8 & -0.8 & -1.2 \\
\hline Netherlands /b/ & -- & -9.2 & -9.3 & -10.5 & -8.0 & Netherlands /b/ & -- & -- & -3.0 & -12.2 & -9.0 \\
\hline New Zealand & -- & -- & -24.0 & -19.2 & -14.1 & New Zealand & -- & -- & -- & -21.0 & -16.3 \\
\hline Norway & -1.8 & -2.2 & -4.1 & -1.5 & -3.1 & Norway & -- & 5.5 & -0.9 & 0.1 & 4.9 \\
\hline Portugal & -- & -- & -5.9 & -5.9 & -2.8 & Portugal & -- & -- & -3.6 & -1.2 & -0.7 \\
\hline Spain & 24.0 & 19.3 & 6.6 & -1.3 & -4.7 & Spain & -5.8 & -13.3 & 2.3 & -8.3 & -15.0 \\
\hline Sweden & -9.8 & -8.5 & -5.5 & -6.2 & -2.6 & Sweden & 1.9 & -1.8 & -1.5 & -7.7 & -5.5 \\
\hline Switzerland & -- & -- & -- & -4.7 & -2.2 & Switzerland & -- & -- & -- & -- & -4.2 \\
\hline United Kingdom & -- & -8.2 & -7.3 & -6.4 & -5.1 & United Kingdom & -- & -- & -8.1 & -9.8 & -8.8 \\
\hline United States & -6.6 & -10.5 & -10.4 & -8.7 & -7.2 & United States & 2.2 & -4.3 & 0.1 & -4.5 & -4.7 \\
\hline Average & -1.6 & -2.6 & -5.9 & -6.5 & -5.2 & Average & 0.4 & -5.5 & -5.4 & -9.1 & -6.7 \\
\hline
\end{tabular}

Notes:

/a/ The "labor force exit rate" is the percent reduction in labor supply between ages 50 and 69 below the level that would be observed if labor supply in those ages remained at its level between ages 45-49. For an explanation of "period" and "partial cohort" exit rates, see text.

/b/ Data for the Netherlands end in 2005.

Source: Author's estimates based on labor force participation rates obtained from SourceOECD supplemented with author's tabulations of Labour Force Survey data for selected European countries. 


\section{Table 9A. Change in Labor Force Participation Rates in Twenty-one OECD Countries, 1960-2006: Males Age 45-49}

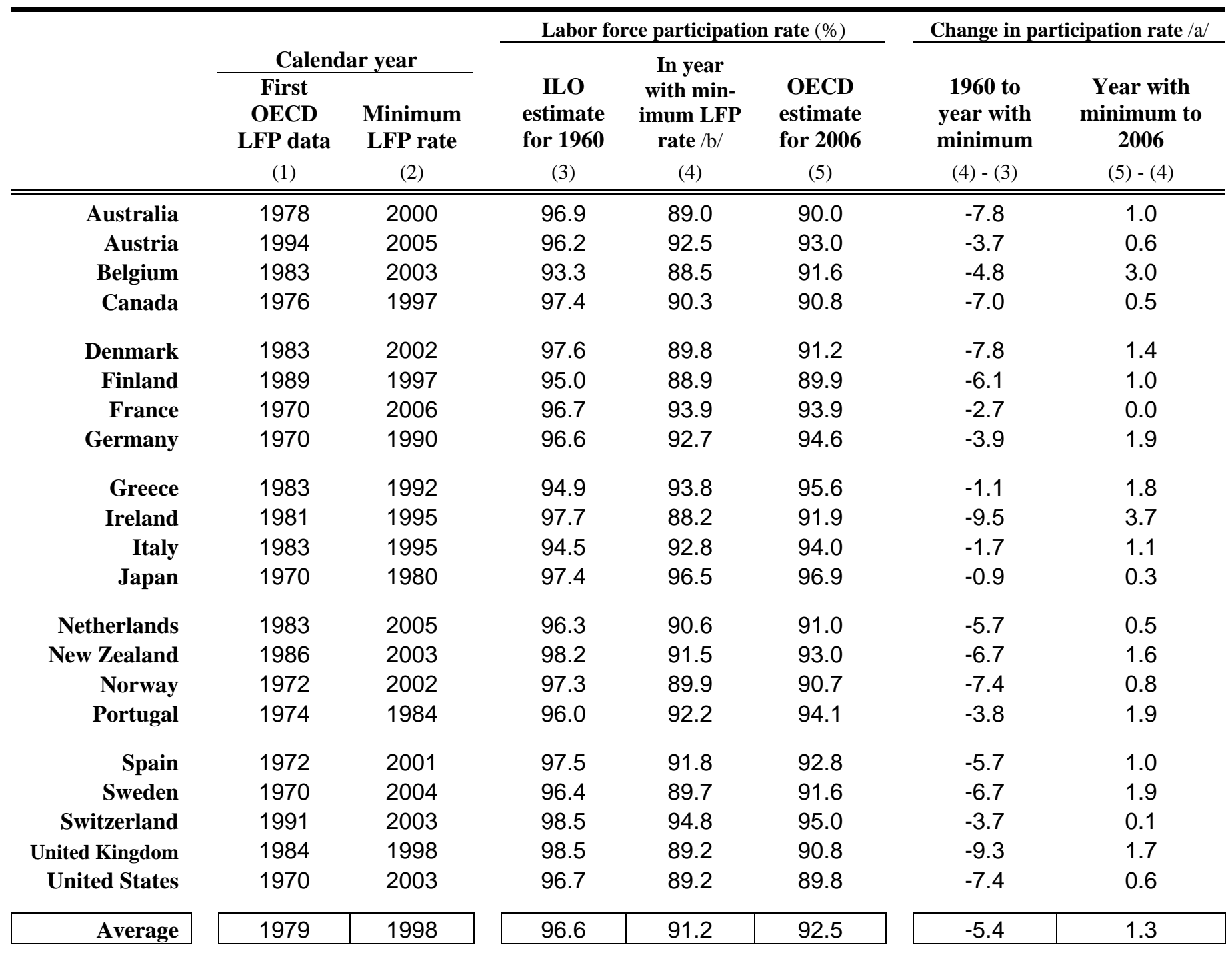

Notes:

/a/ Percentage-point change.

/b/ The year with minimum labor force participation rate in the OECD data bank. The actual year is indicated in column 2.

Source: Author's estimates based on labor force participation rates obtained from SourceOECD supplemented with author's tabulations of Labour Force Survey data for selected European countries. 


\section{Table 9B. Change in Labor Force Participation Rates in Twenty-one OECD Countries, 1960-2006: Males Age 50-54}

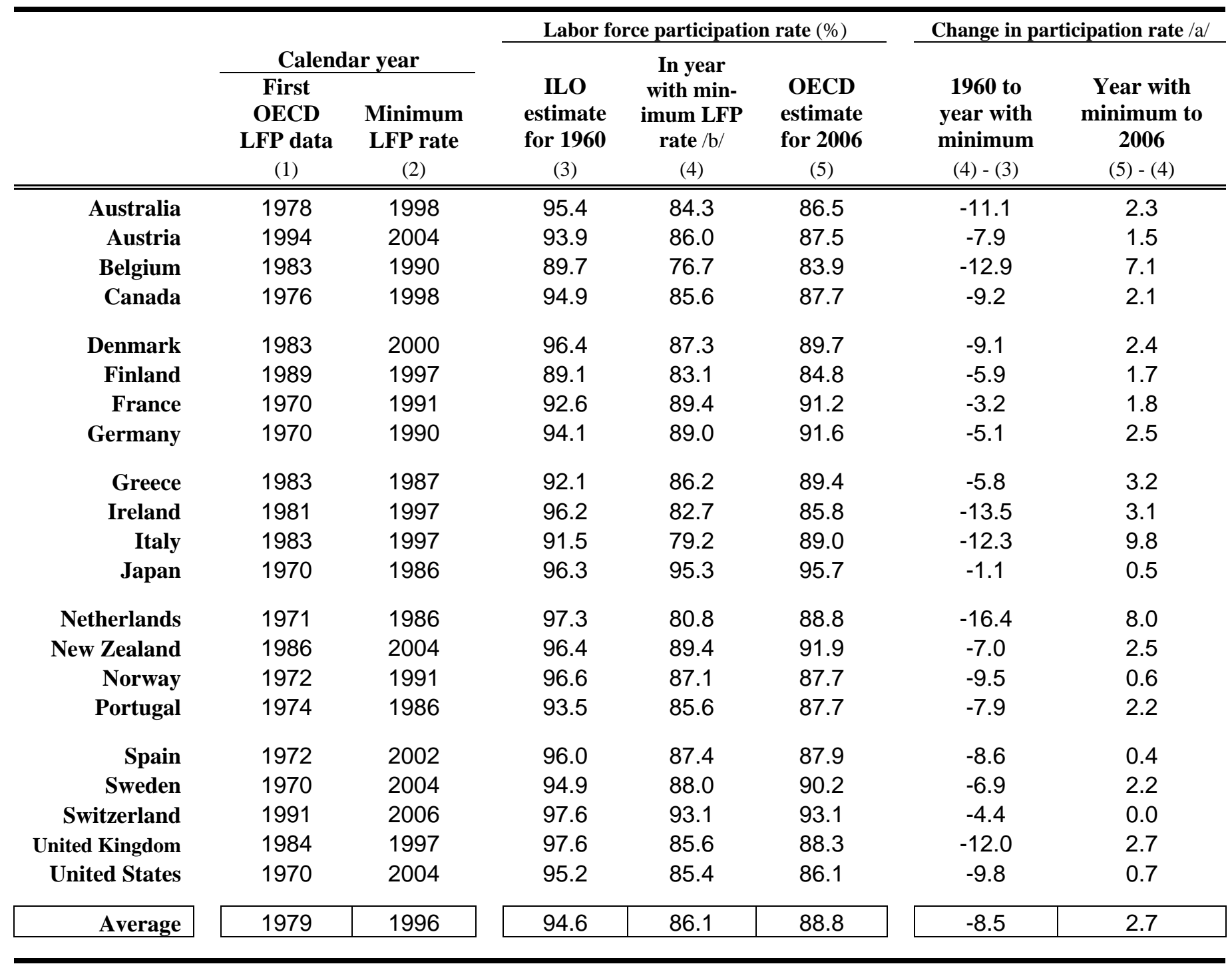

Notes:

/a/ Percentage-point change.

/b/ The year with minimum labor force participation rate in the OECD data bank. The actual year is indicated in column 2.

Source: Author's estimates based on labor force participation rates obtained from SourceOECD supplemented with author's tabulations of Labour Force Survey data for selected European countries. 


\section{Table 9C. Change in Labor Force Participation Rates in Twenty-one OECD Countries, 1960-2006: Males Age 55-59}

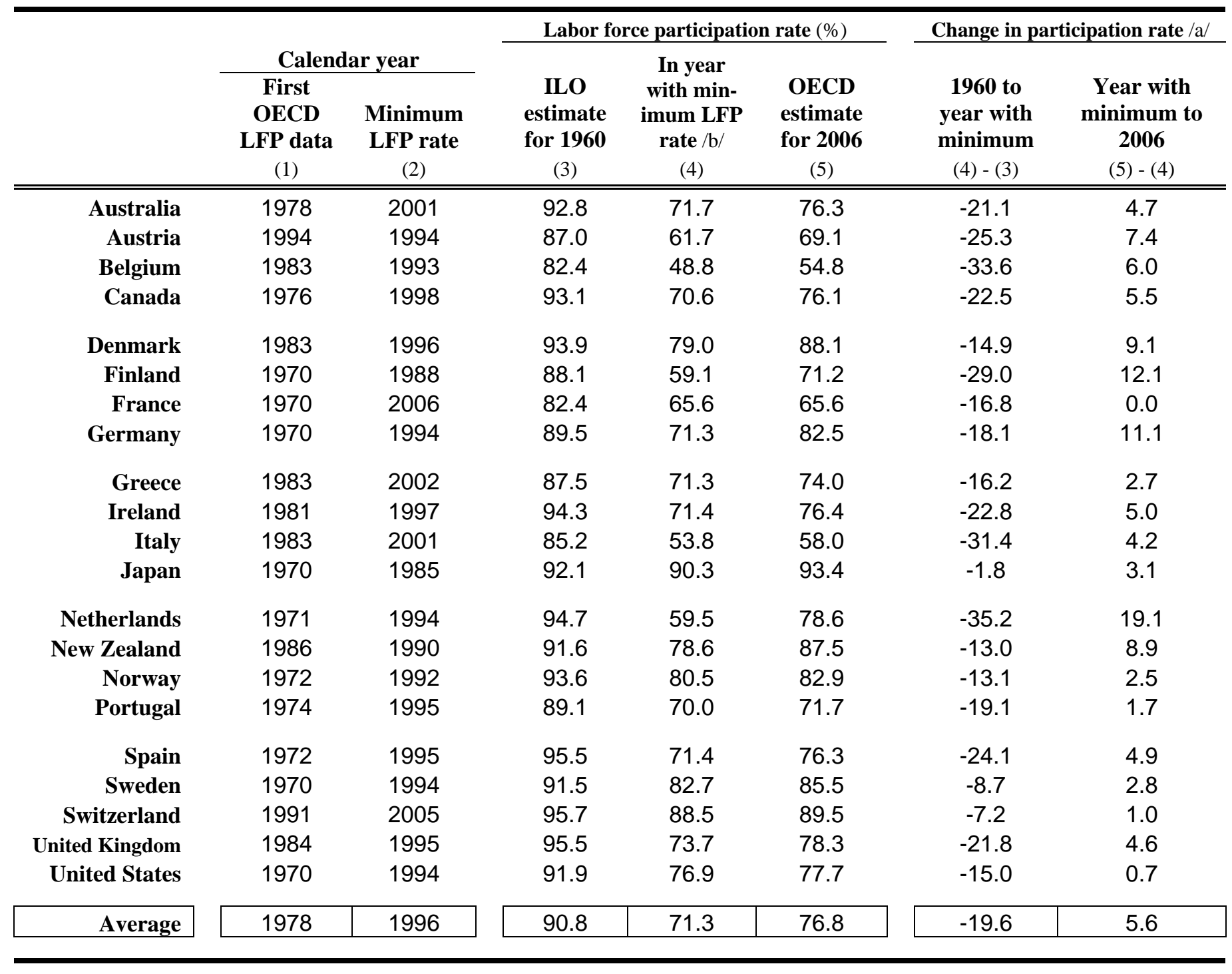

Notes:

/a/ Percentage-point change.

/b/ The year with minimum labor force participation rate in the OECD data bank. The actual year is indicated in column 2.

Source: Author's estimates based on labor force participation rates obtained from SourceOECD supplemented with author's tabulations of Labour Force Survey data for selected European countries. 


\section{Table 9D. Change in Labor Force Participation Rates in Twenty-one OECD Countries, 1960-2006: Males Age 60-64}

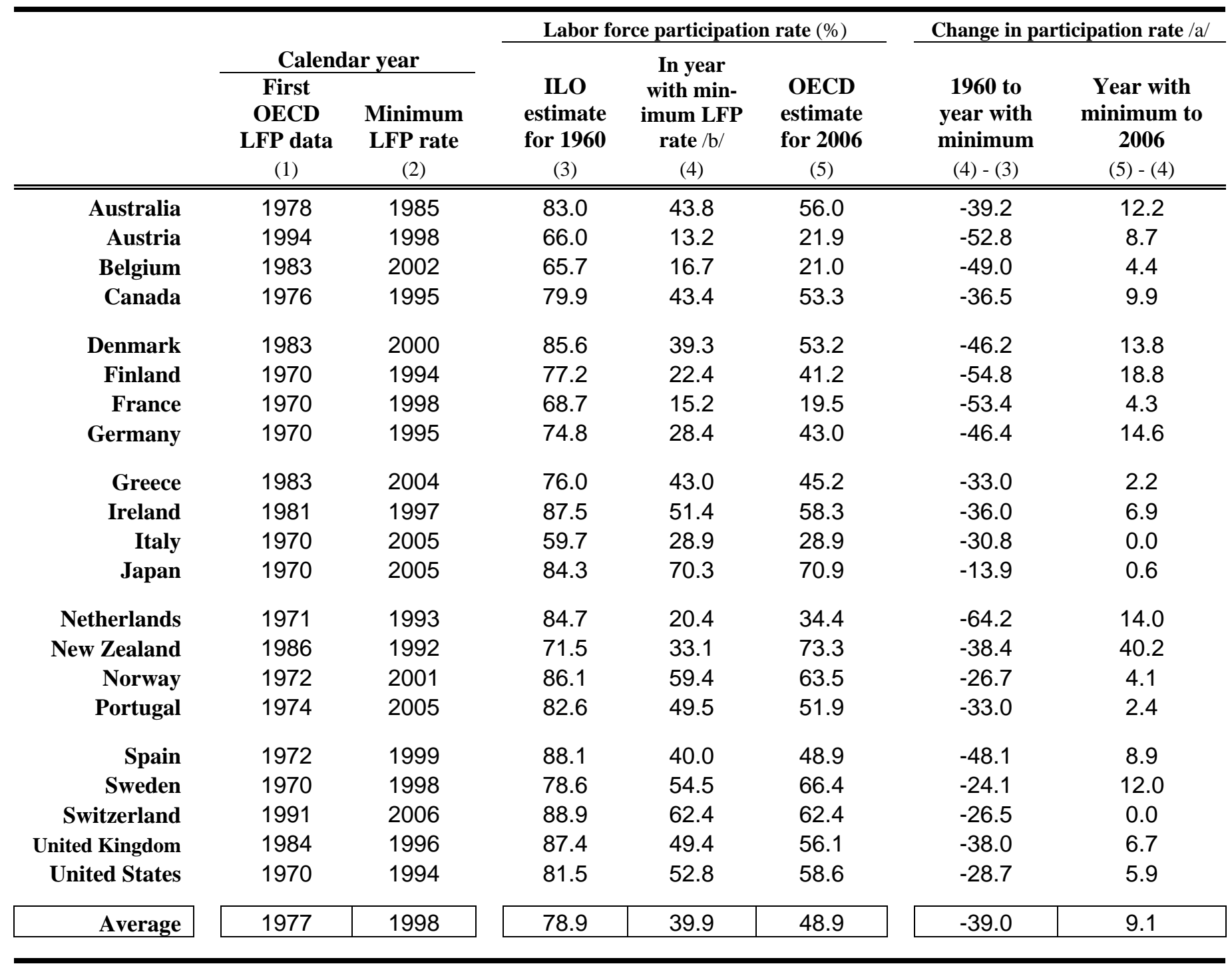

Notes:

/a/ Percentage-point change.

/b/ The year with minimum labor force participation rate in the OECD data bank. The actual year is indicated in column 2.

Source: Author's estimates based on labor force participation rates obtained from SourceOECD supplemented with author's tabulations of Labour Force Survey data for selected European countries. 


\section{Table 10. Change in Labor Force Participation Rates in Twenty-one OECD Countries, 1970-2006: Males Age 65-69}

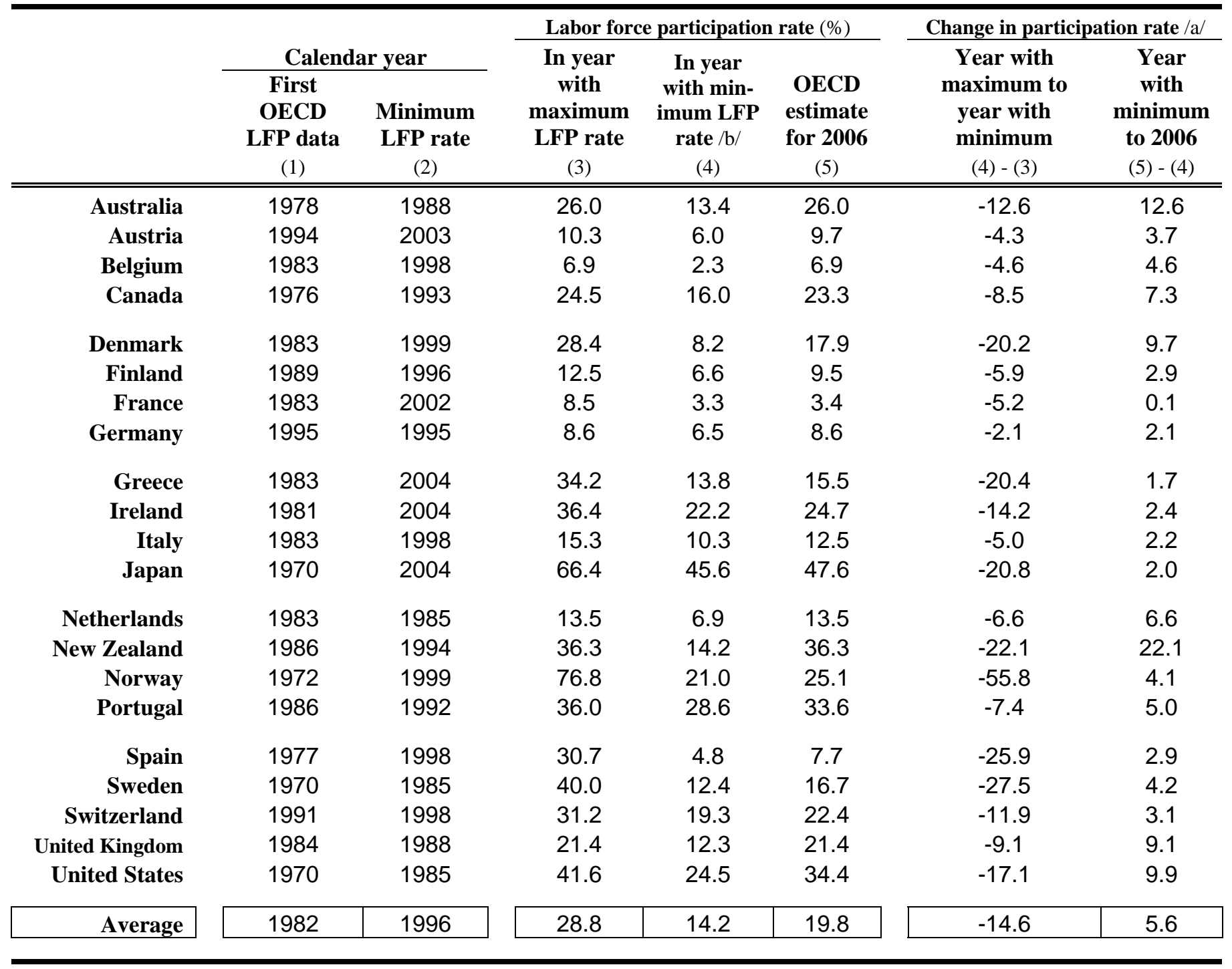

Notes:

/a/ Percentage-point change.

/b/ The year with minimum labor force participation rate in the OECD data bank. The actual year is indicated in column 2.

Source: Author's estimates based on labor force participation rates obtained from SourceOECD supplemented with author's tabulations of Labour Force Survey data for selected European countries. 


\section{Appendix Table A1. Male Labor Force Period Exit Rates in Fifteen OECD Countries, 2004}

\begin{tabular}{|c|c|c|c|c|c|c|}
\hline \multirow[b]{2}{*}{ Country } & \multicolumn{2}{|c|}{$\begin{array}{c}\text { Labor force } \\
\text { participation rate }\end{array}$} & \multirow{2}{*}{$\begin{array}{c}\text { Labor force } \\
\text { exit rate, ages } \\
50-74 / a / \\
\text { (3) }\end{array}$} & \multicolumn{2}{|c|}{$\begin{array}{c}\text { Average hours of work } \\
\text { per person /b/ }\end{array}$} & \multirow{2}{*}{$\begin{array}{c}\text { Labor force } \\
\text { exit rate, ages } \\
50-74 / \mathrm{c} / \\
(6) \\
\end{array}$} \\
\hline & $\begin{array}{c}\text { Age 45-49 } \\
(1) \\
\end{array}$ & $\begin{array}{c}\text { Age 50-74 } \\
(2) \\
\end{array}$ & & $\begin{array}{c}\text { Age 45-49 } \\
(4) \\
\end{array}$ & $\begin{array}{c}\text { Age 50-74 } \\
(5)\end{array}$ & \\
\hline Belgium & 92.1 & 32.8 & 64 & 31.7 & 10.4 & 67 \\
\hline Austria & 93.4 & 35.8 & 62 & 37.4 & 13.6 & 64 \\
\hline France & 93.6 & 34.6 & 63 & 31.0 & 11.5 & 63 \\
\hline Italy & 94.0 & 37.8 & 60 & 34.8 & 13.5 & 61 \\
\hline Finland & 89.7 & 40.2 & 55 & 29.7 & 12.4 & 58 \\
\hline Netherlands & 93.1 & 43.9 & 53 & 31.6 & 13.3 & 58 \\
\hline Germany & 94.2 & 43.8 & 54 & 34.9 & 15.3 & 56 \\
\hline 15-country average /d/ & 92.2 & 44.8 & 51 & 33.7 & 15.4 & 54 \\
\hline Spain & 91.8 & 43.6 & 52 & 33.2 & 15.5 & 53 \\
\hline Greece & 94.9 & 44.7 & 53 & 39.0 & 18.3 & 53 \\
\hline Denmark & 92.5 & 51.3 & 45 & 32.8 & 16.3 & 50 \\
\hline Norway & 90.2 & 51.7 & 43 & 31.0 & 16.1 & 48 \\
\hline Sweden & 89.4 & 52.5 & 41 & 29.9 & 15.8 & 47 \\
\hline Ireland & 91.8 & 50.6 & 45 & 36.5 & 19.8 & 46 \\
\hline Portugal & 92.9 & 54.3 & 42 & 34.8 & 19.0 & 45 \\
\hline United States & 89.3 & 54.5 & 39 & 36.6 & 20.5 & 44 \\
\hline European average /e/ & 93.3 & 41.3 & 56 & 33.6 & 14.3 & 58 \\
\hline
\end{tabular}

Note: Countries are ranked by their work-hours exit rates, from highest to lowest exit rate (column 6).

/a/ Reduction in estimated labor force participation, measured as a percent of participation rate among persons 45-49 years old.

/b/ Hours worked in the survey reference week, including zeroes for persons not employed or at work in that week.

/c/ Reduction in estimated weekly work hours, measured as a percent of average weekly hours in the population 45-49 years old.

/d/ Unweighted average of European countries and the United States.

/e/ Population-weighted average of fourteen European countries.

Source: Author's tabulations of quarterly 2004 European Labour Force Survey (LFS) data for Austria, Belgium, Denmark, Finland, France, Germany, Greece, Ireland, Italy, the Netherlands, Norway, Portugal, Spain, and Sweden, and tabulations of the U.S. Current Population Survey (CPS) files for January-December 2004.

(See sources of Table 1.) 


\section{Appendix Table A2. Female Labor Force Period Exit Rates in Fifteen OECD Countries, 2004}

\begin{tabular}{|c|c|c|c|c|c|c|}
\hline \multirow[b]{2}{*}{ Country } & \multicolumn{2}{|c|}{$\begin{array}{c}\text { Labor force } \\
\text { participation rate } \\
\end{array}$} & \multirow{2}{*}{$\begin{array}{c}\text { Labor force } \\
\text { exit rate, ages } \\
50-74 / \mathrm{a} / \\
(3) \\
\end{array}$} & \multicolumn{2}{|c|}{$\begin{array}{c}\text { Average hours of work } \\
\text { per person /b/ }\end{array}$} & \multirow{2}{*}{$\begin{array}{c}\text { Labor force } \\
\text { exit rate, ages } \\
50-74 / \mathrm{c} / \\
(6) \\
\end{array}$} \\
\hline & $\begin{array}{c}\text { Age 45-49 } \\
(1) \\
\end{array}$ & $\begin{array}{c}\text { Age 50-74 } \\
(2) \\
\end{array}$ & & $\begin{array}{c}\text { Age } 45-49 \\
(4) \\
\end{array}$ & $\begin{array}{c}\text { Age 50-74 } \\
(5) \\
\end{array}$ & \\
\hline Belgium & 71.3 & 20.0 & 72 & 17.6 & 4.7 & 73 \\
\hline Austria & 79.7 & 23.0 & 71 & 24.4 & 6.8 & 72 \\
\hline Italy & 61.0 & 19.0 & 69 & 17.2 & 5.4 & 69 \\
\hline Netherlands & 76.9 & 27.9 & 64 & 15.9 & 5.2 & 67 \\
\hline Greece & 60.8 & 21.1 & 65 & 20.7 & 7.1 & 66 \\
\hline Spain & 61.7 & 21.3 & 65 & 17.6 & 6.1 & 65 \\
\hline France & 81.3 & 28.8 & 65 & 21.4 & 7.5 & 65 \\
\hline Germany & 82.1 & 32.6 & 60 & 22.2 & 8.2 & 63 \\
\hline 15-country average /d/ & 76.1 & 31.4 & 59 & 21.6 & 8.5 & 61 \\
\hline Finland & 89.9 & 38.3 & 57 & 26.0 & 10.4 & 60 \\
\hline Ireland & 63.3 & 26.6 & 58 & 16.8 & 6.8 & 60 \\
\hline Denmark & 87.4 & 40.1 & 54 & 24.4 & 10.6 & 56 \\
\hline Portugal & 77.0 & 38.0 & 51 & 25.1 & 11.2 & 55 \\
\hline Norway & 83.7 & 43.9 & 48 & 22.3 & 10.9 & 51 \\
\hline Sweden & 87.7 & 46.8 & 47 & 24.5 & 12.1 & 51 \\
\hline United States & 78.2 & 44.2 & 43 & 27.3 & 14.3 & 48 \\
\hline European average /e/ & 74.2 & 27.6 & 63 & 20.3 & 7.3 & 64 \\
\hline
\end{tabular}

Note: Countries are ranked by their work-hours exit rates, from highest to lowest exit rate (column 6).

/a/ Reduction in estimated labor force participation, measured as a percent of participation rate among persons 45-49 years old.

/b/ Hours worked in the survey reference week, including zeroes for persons not employed or at work in that week.

/c/ Reduction in estimated weekly work hours, measured as a percent of average weekly hours in the population $45-49$ years old.

/d/ Unweighted average of European countries and the United States.

/e/ Population-weighted average of fourteen European countries.

Source: Author's tabulations of quarterly 2004 European Labour Force Survey (LFS) data for Austria, Belgium, Denmark, Finland, France, Germany, Greece, Ireland, Italy, the Netherlands, Norway, Portugal, Spain, and Sweden, and tabulations of the U.S. Current Population Survey (CPS) files for January-December 2004.

(See sources of Table 1.) 
Figure 1. Measures of Aggregate Work Effort among Men, by Age, 2004

Percent of male population in labor force

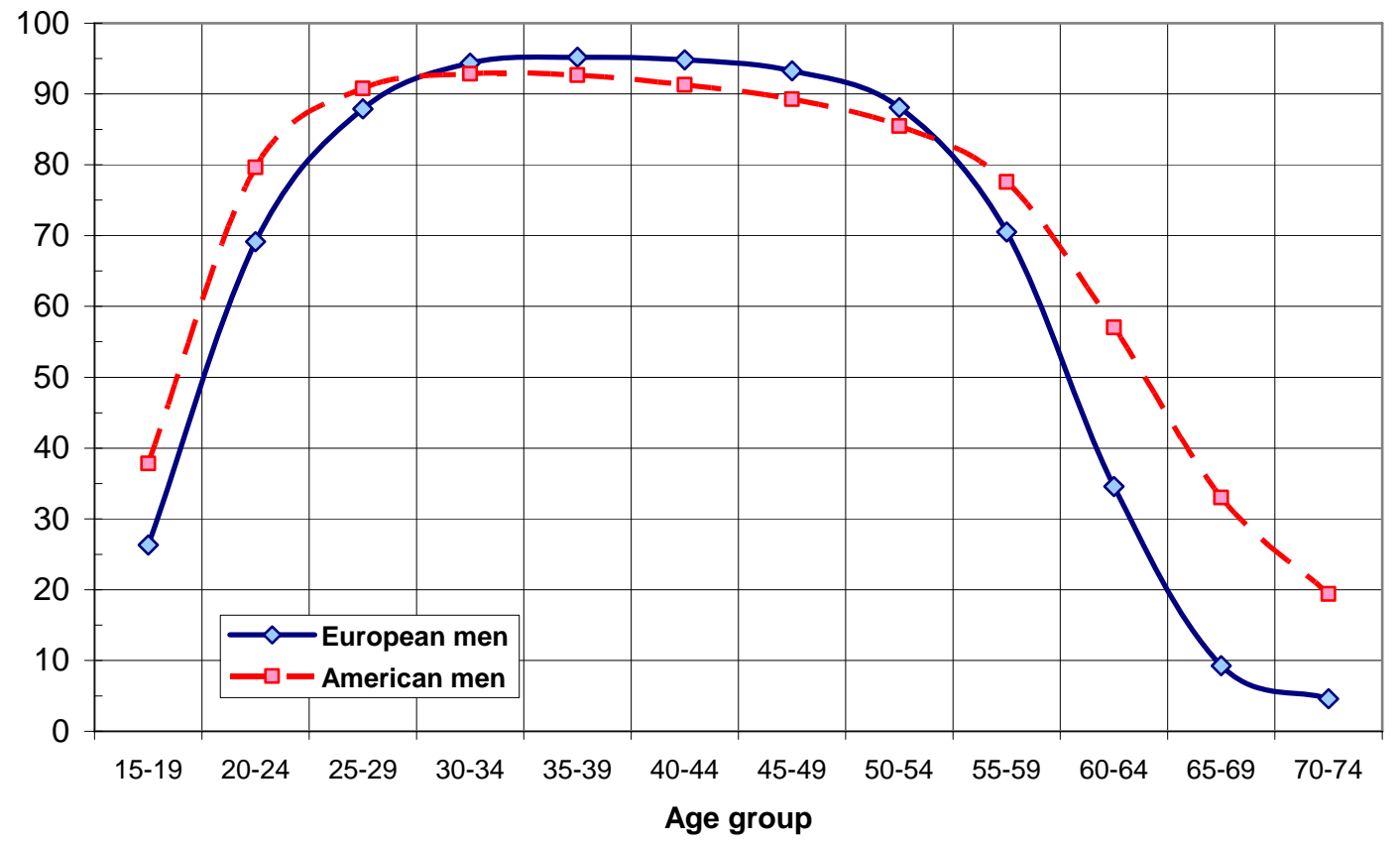

Unconditional average hours worked among men (per week)

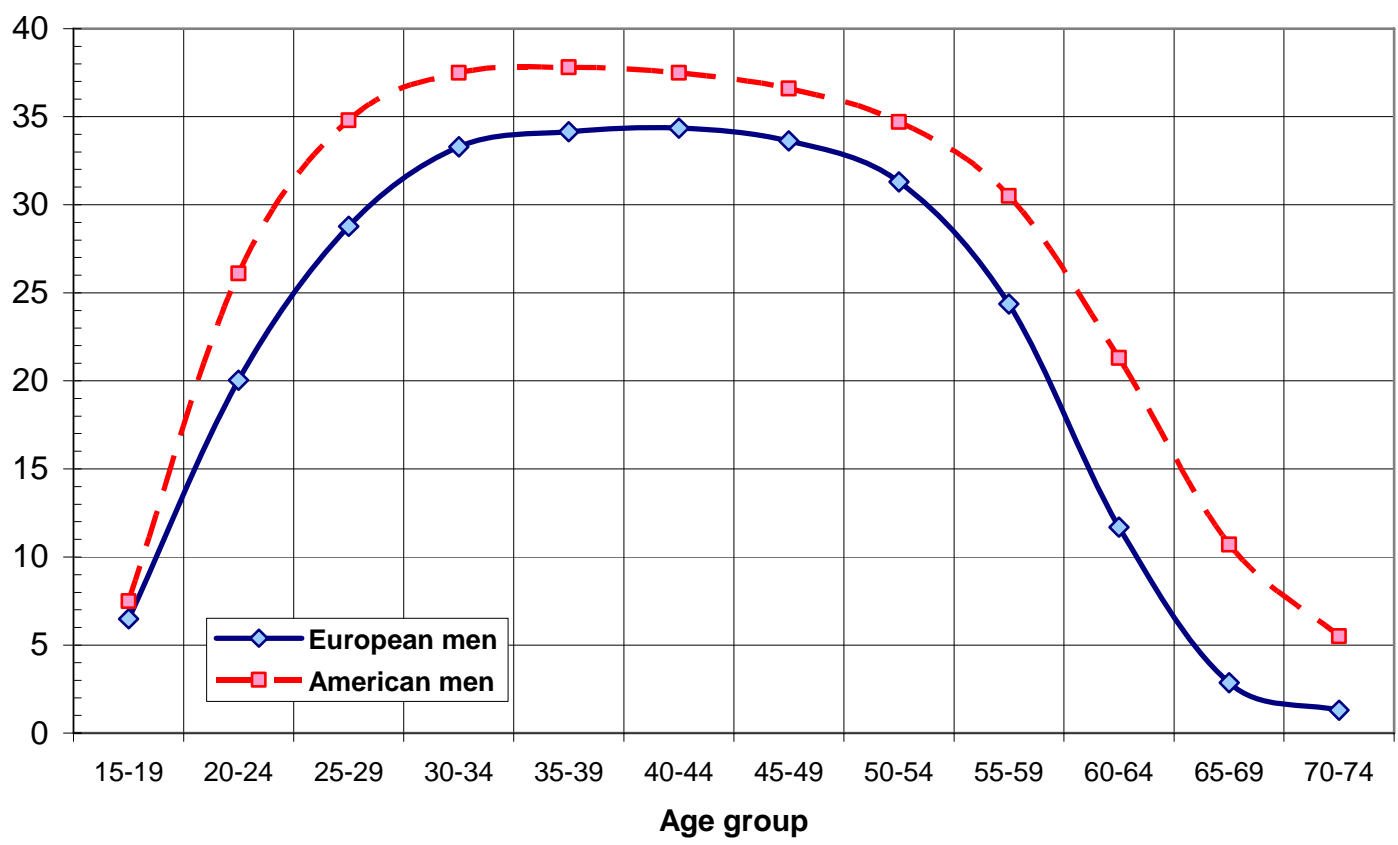

Source: Tabulations of European Labour Force Survey (LFS) data of the second quarter of 2004 for Germany and of quarterly 2004 European Labour Force Survey (LFS) data for Austria, Belgium, Denmark, Finland, France, Greece, Ireland, Italy, the Netherlands, Norway, Portugal, Spain, and Sweden, and tabulations of the U.S. Current Population Survey (CPS) files for January-December 2004. European estimates reflect weighted averages for the 14 European countries, where the weights are derived from national population counts for persons 15-74 years old. (See note to Table 1.) 
Figure 2. Measures of Aggregate Work Effort among Women, by Age, 2004

Percent of female population in labor force

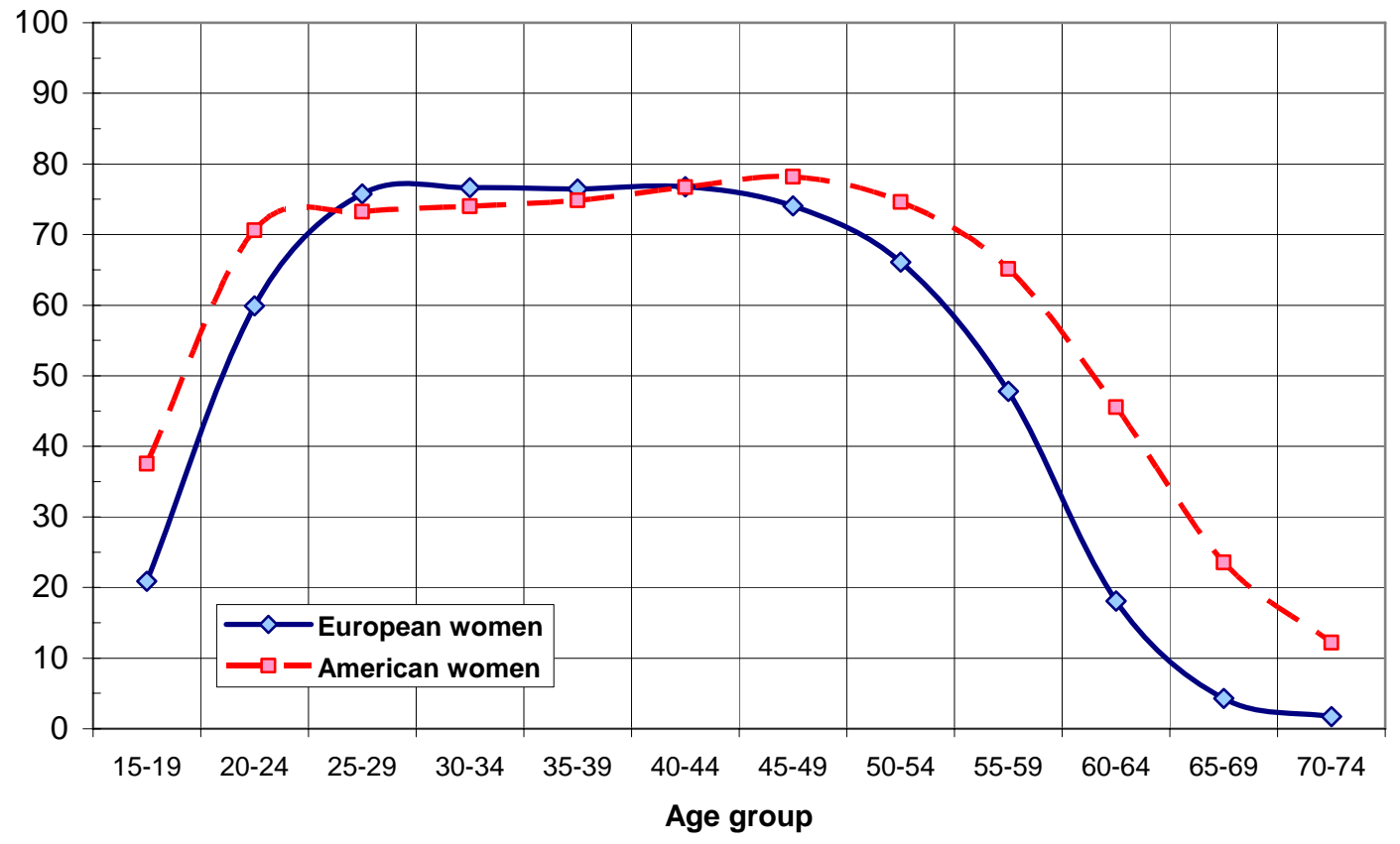

Unconditional average hours worked among women (per week)

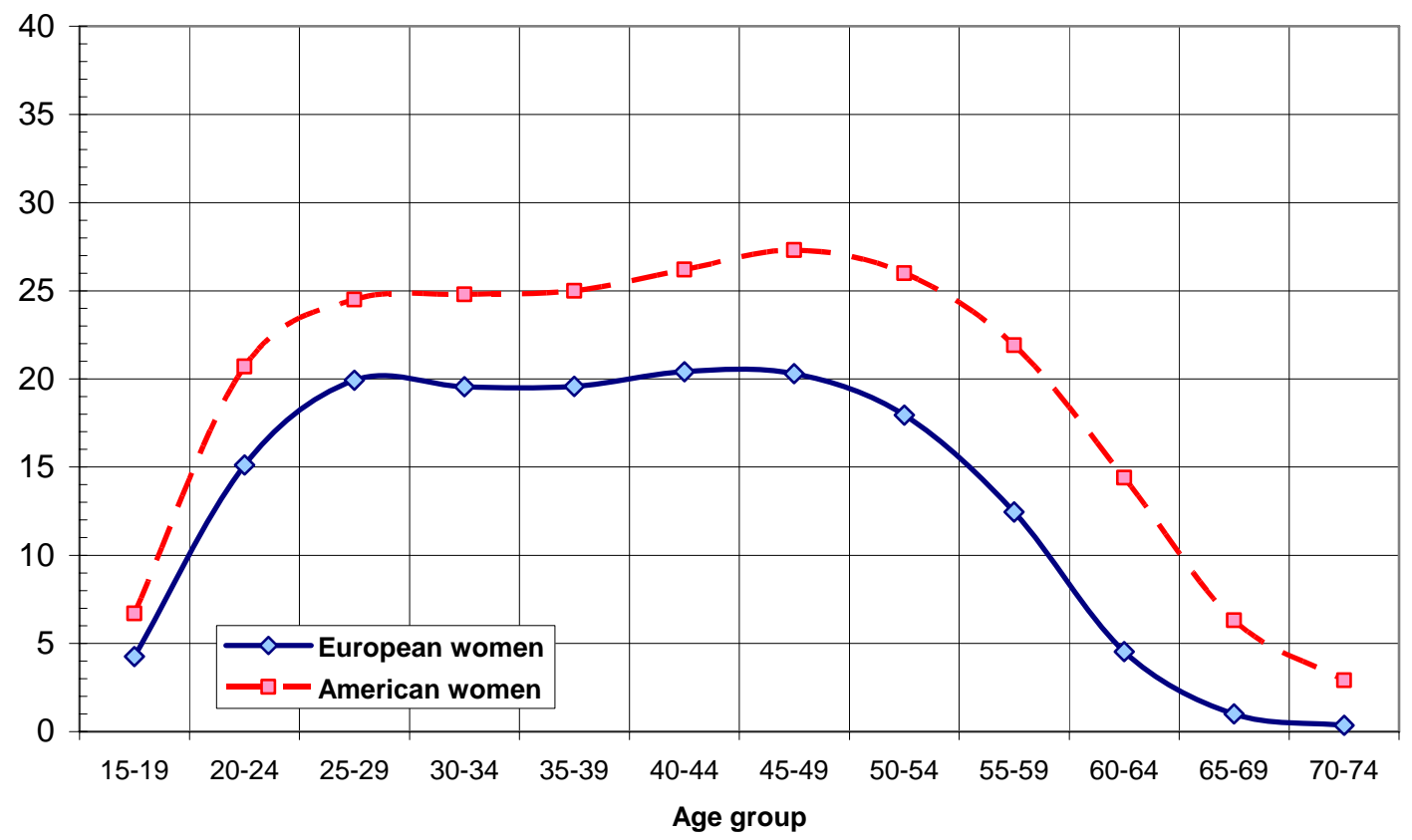

Source: Tabulations of European Labour Force Survey (LFS) data of the second quarter of 2004 for Germany and of quarterly 2004 European Labour Force Survey (LFS) data for Austria, Belgium, Denmark, Finland, France, Greece, Ireland, Italy, the Netherlands, Norway, Portugal, Spain, and Sweden, and tabulations of the U.S. Current Population Survey (CPS) files for January-December 2004. European estimates reflect weighted averages for the 14 European countries, where the weights are derived from national population counts for persons 15-74 years old. (See note to Table 1.) 
Figure 3. Speed of Retirement among European and American Men, 2004

Labor supplied at age $a$ as percent of labor supplied at age $R$

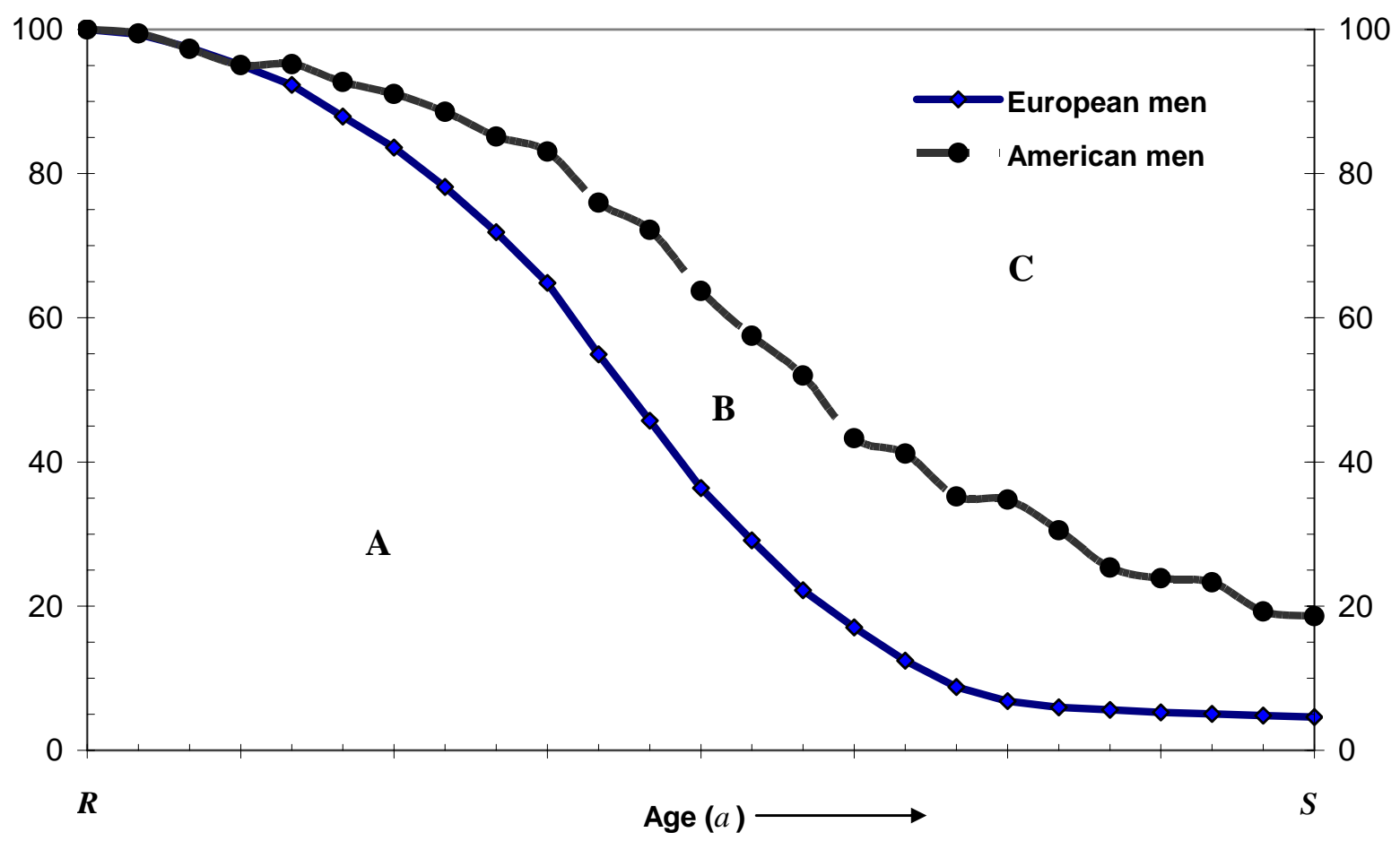

Source: See Figure 1. The indicator of labor supply used in this illustration is the male labor force participation rate. 


\section{Figure 4. Rate of Retirement Using Three Measures of Labor Force}

Withdrawal, U.S. Workers, 2003-2005

Labor supply at age $\mathbf{5 0}=\mathbf{1 0 0}$

American Men

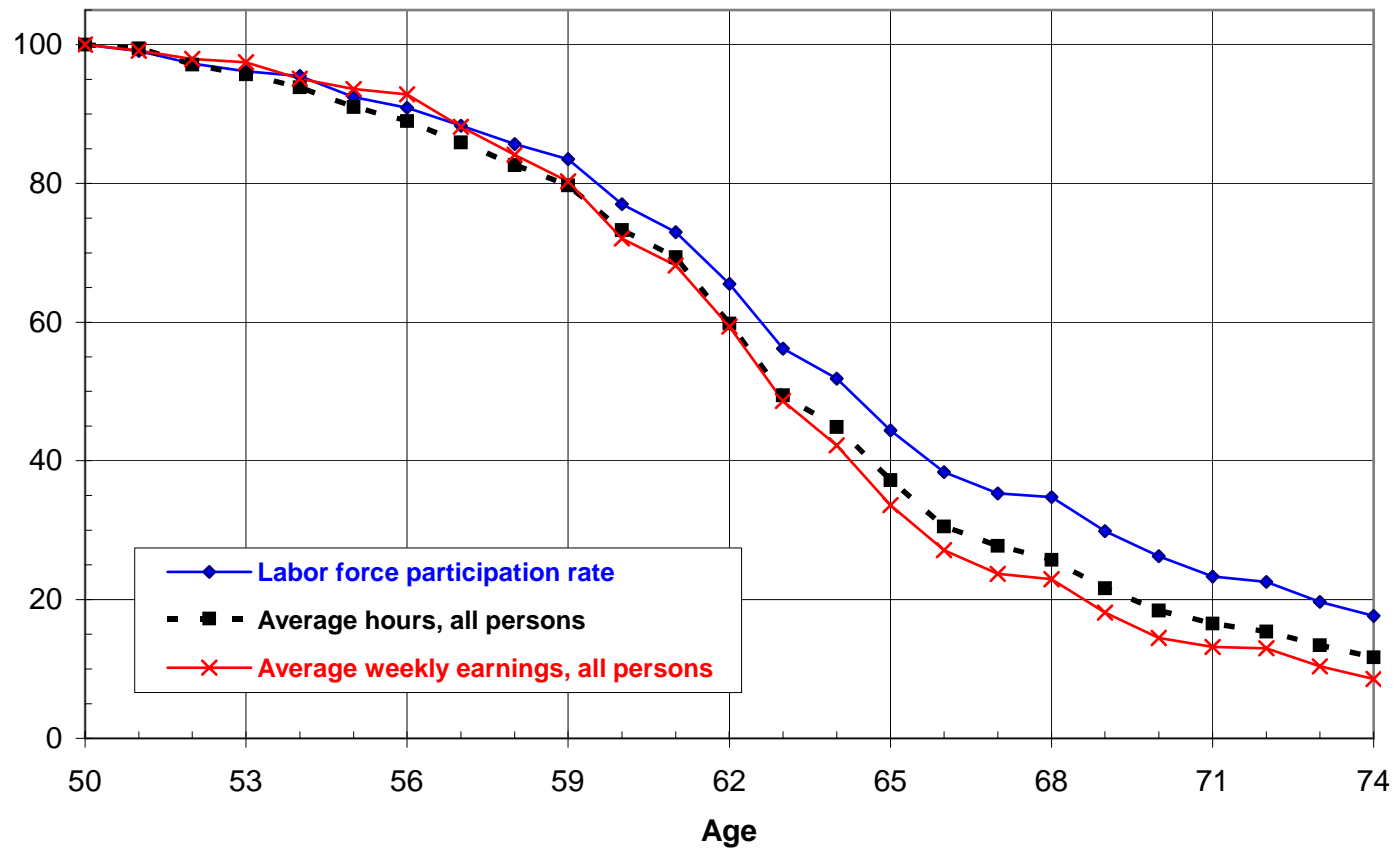

Labor supply at age $\mathbf{5 0}=\mathbf{1 0 0}$

American Women

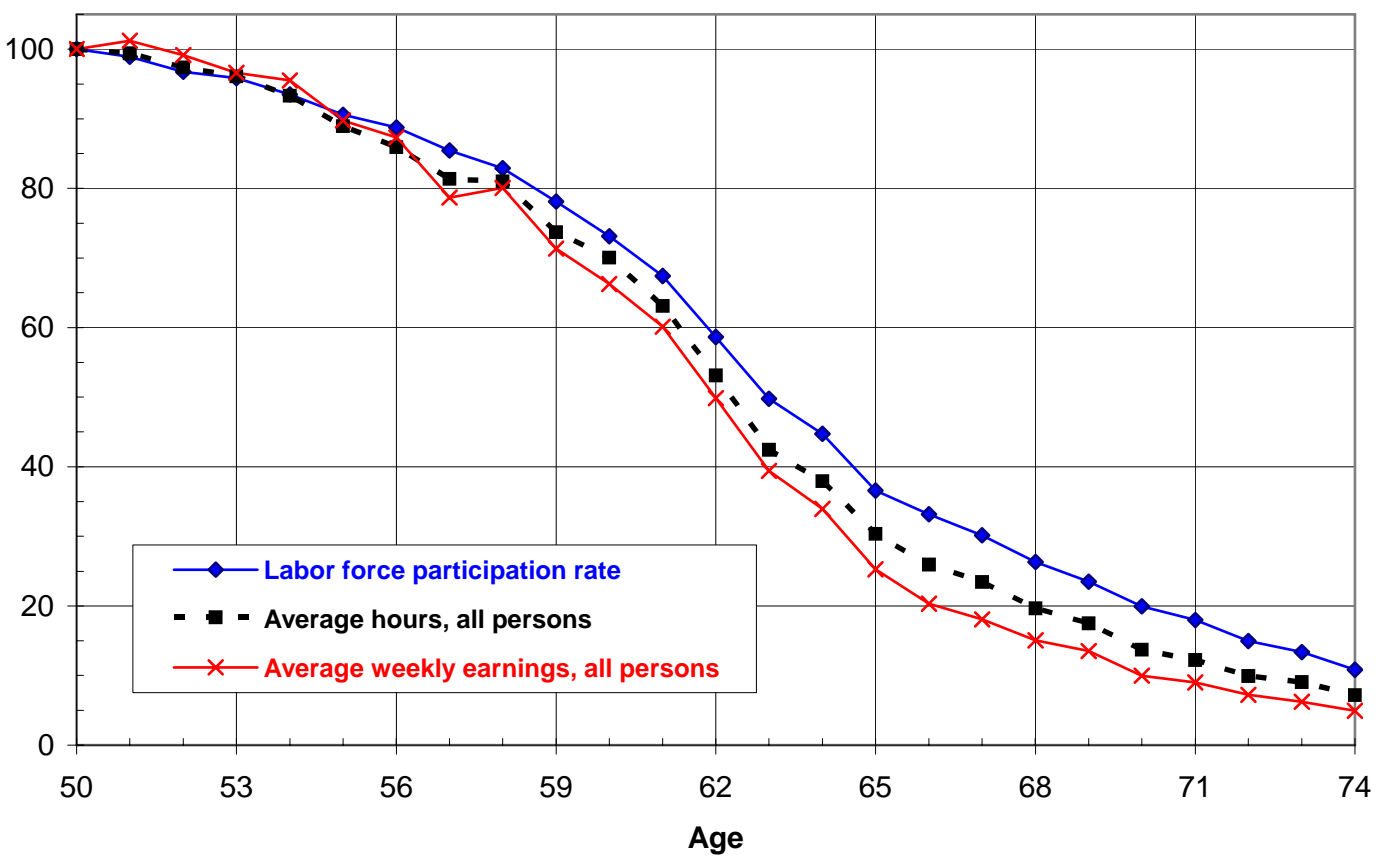

Source: Tabulations of January 2003 - December 2005 U.S. Current Population Survey outgoing rotation group files. The labor supply estimates at each year of age represent averages over the 36-month period. 


\section{Figure 5. U.S. Labor Force Exit Measured with Cross-Section and Cohort Data}

\section{Labor force exit measured with cross-section data, 1988-1992}

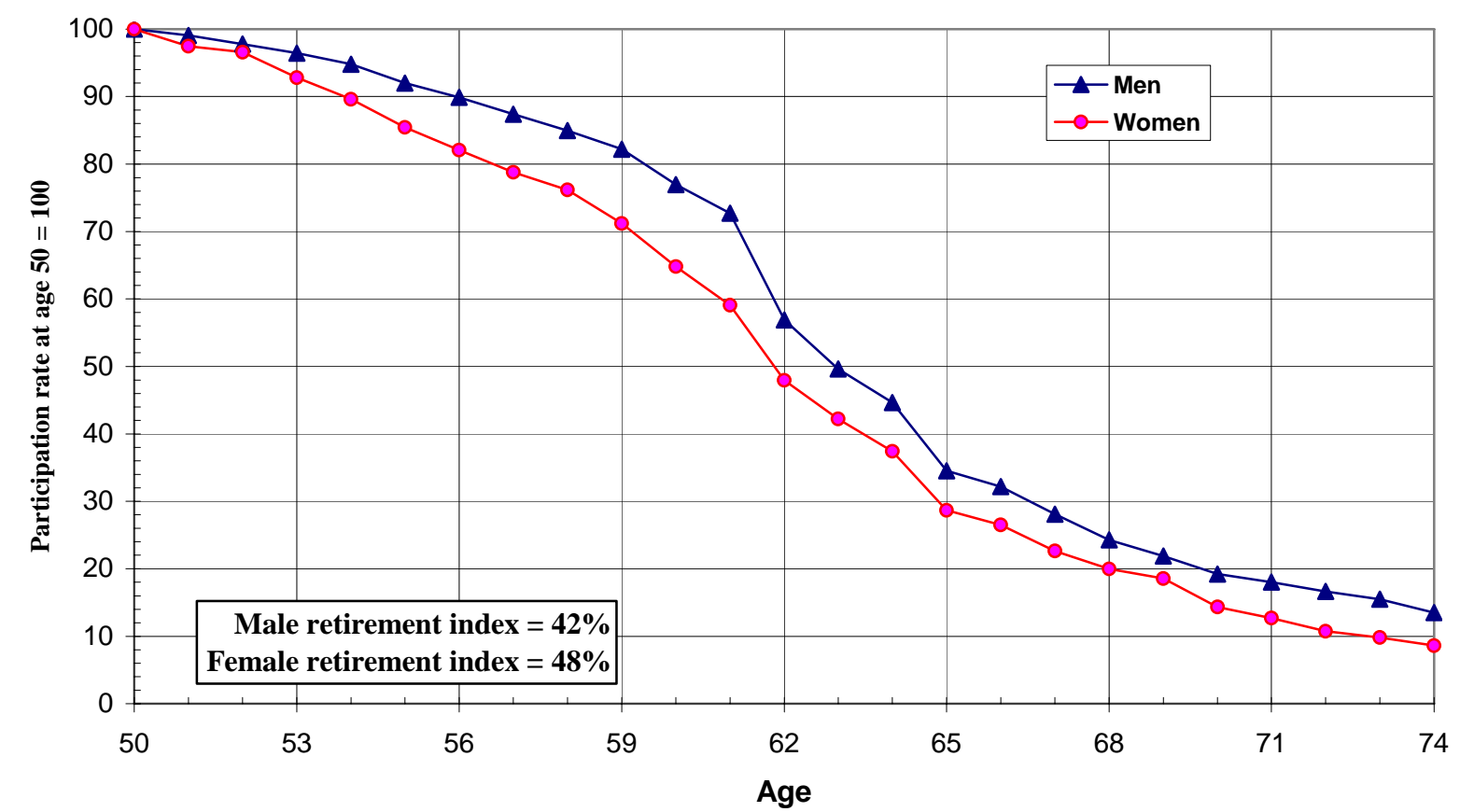

Labor force exit measured with cohort data for Americans born in 1926-1930

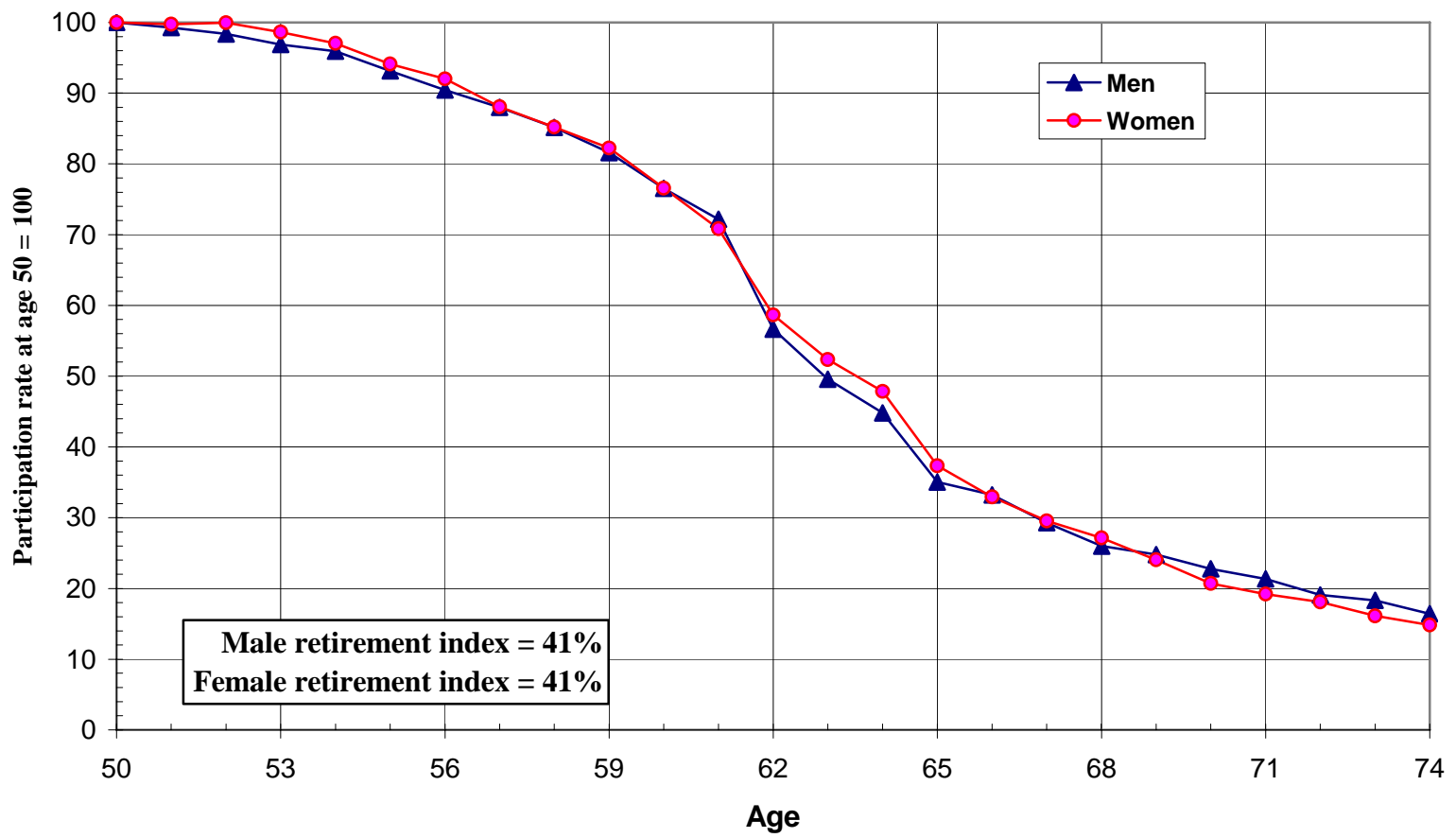

Source: Author's tabulations of 1988-1992 monthly CPS files (top panel) and 1977-2006 monthly CPS files (bottom panel). 
Figure 6. Rate of Retirement Using Three Measures of Labor Force Withdrawal, U.S. Workers Born between 1929 and 1931 [Cohort exit]

Labor supply at age $\mathbf{5 0}=\mathbf{1 0 0}$

American Men

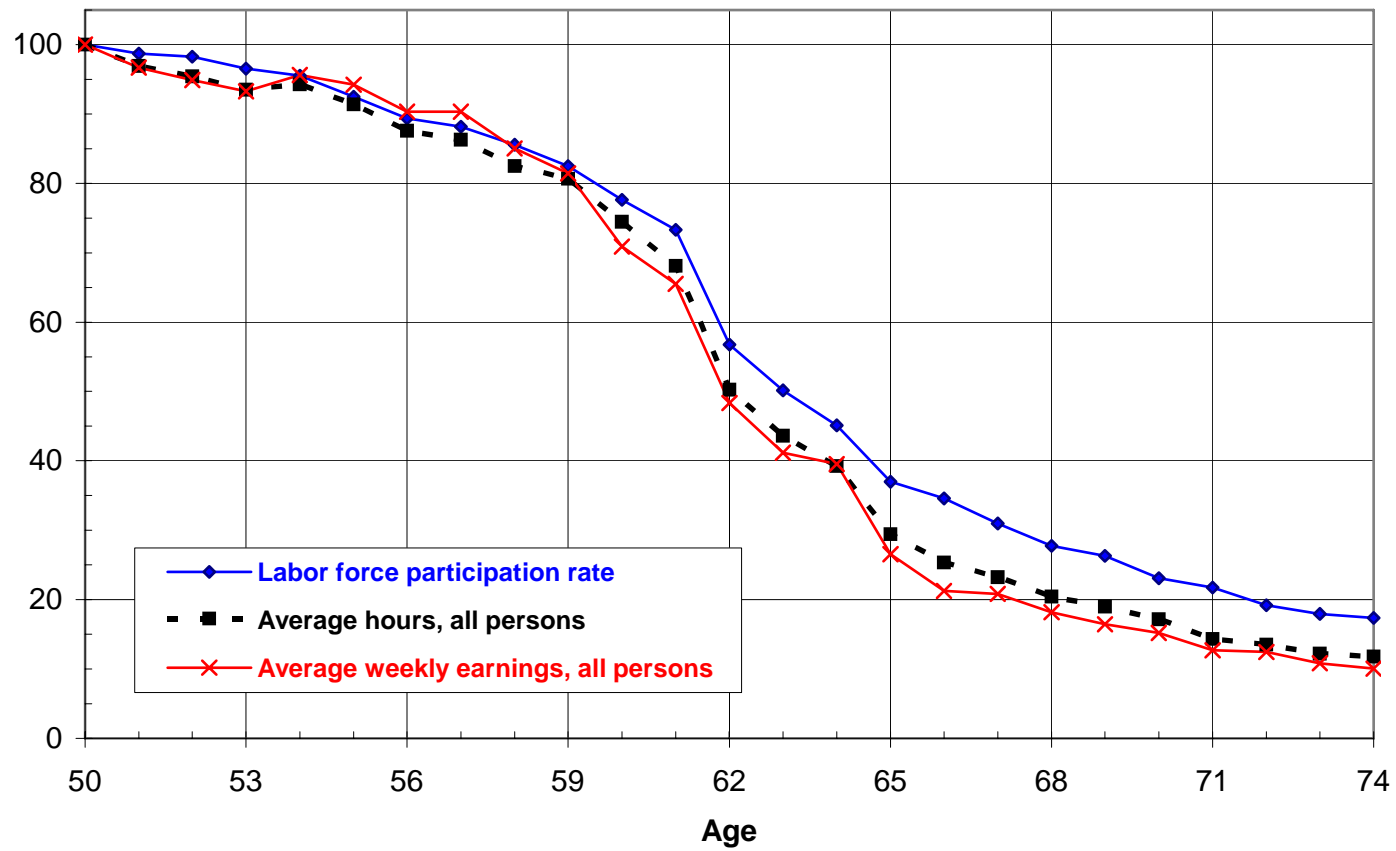

Labor supply at age $\mathbf{5 0}=\mathbf{1 0 0}$

American Women

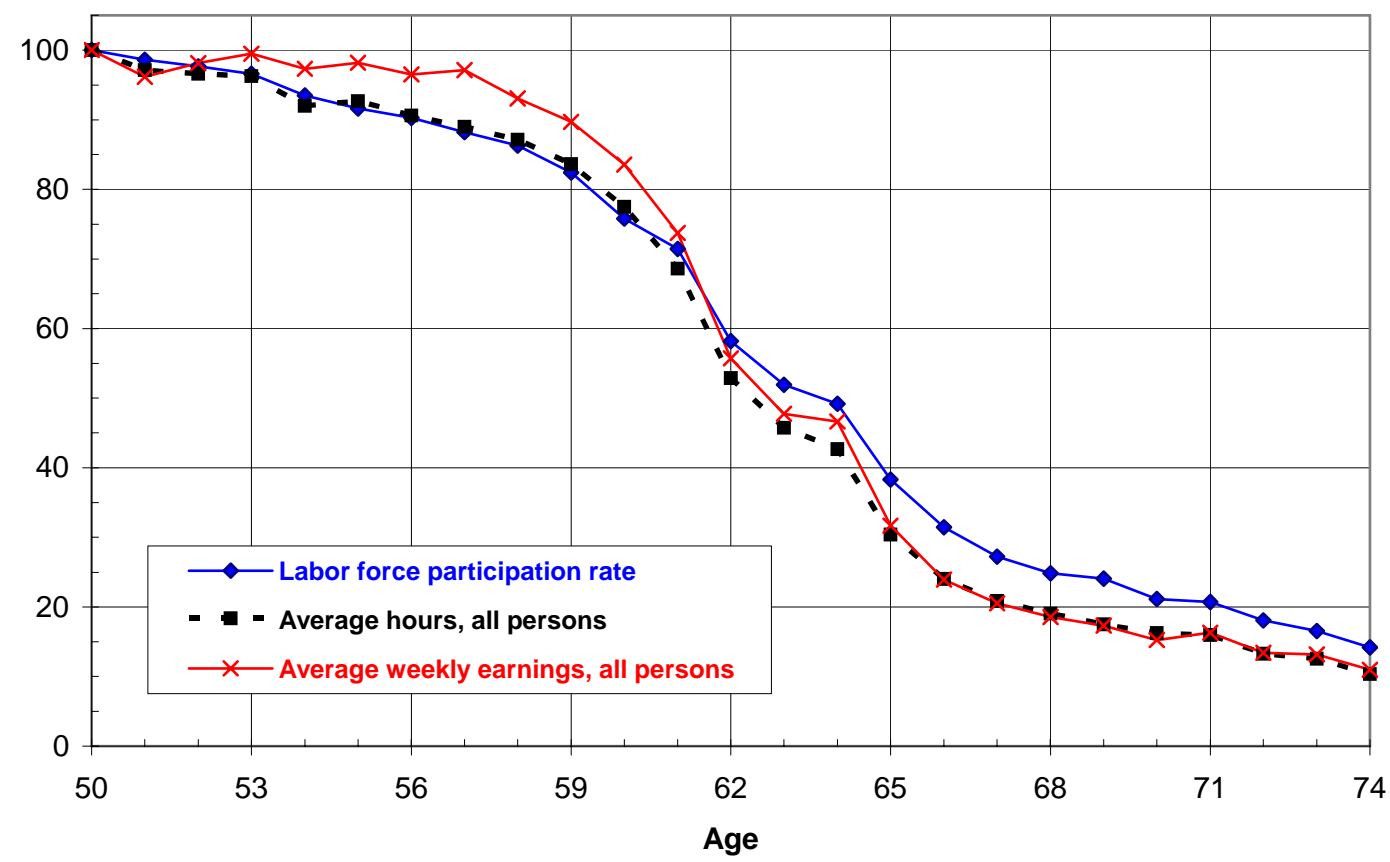

Source: Tabulations of January 1979 - December 2006 U.S. Current Population Survey outgoing rotation group files. The labor supply estimates at each year of age represent averages at that age for the three birth-year cohorts. 


\section{Figure 7. Trend in Male U.S. Retirement Rate and Old-Age Labor Force Participation under Three Definitions, 1967-2006}

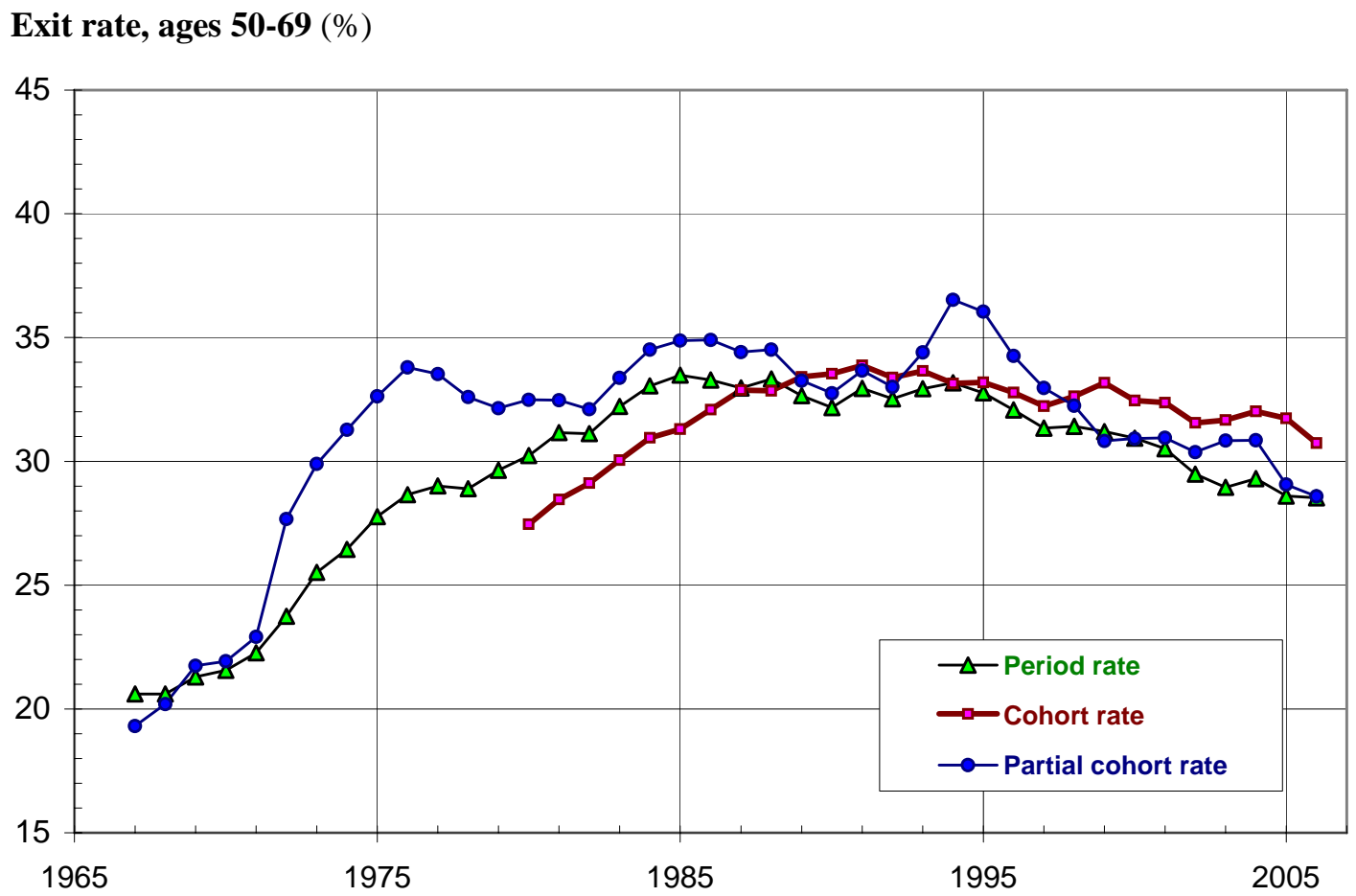

Average labor force participation rate, ages 50-69 (\%)

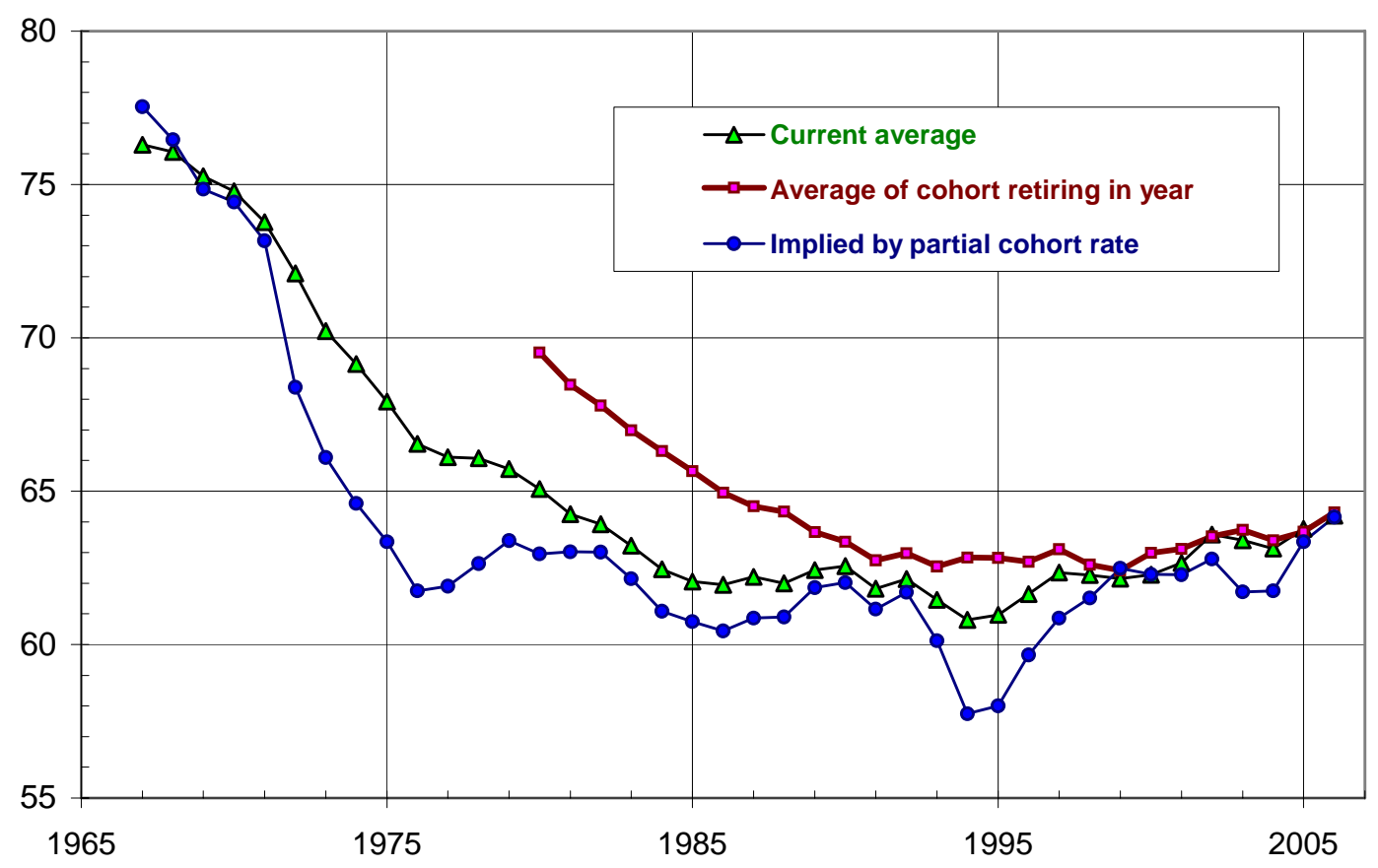

Source: Author's estimates based on labor force participation rates obtained from U.S. BLS and SourceOECD. 
Figure 8. Trend in Female U.S. Retirement Rate and Old-Age Labor Force Participation under Three Definitions, 1967-2006

Exit rate, ages 50-69 (\%)

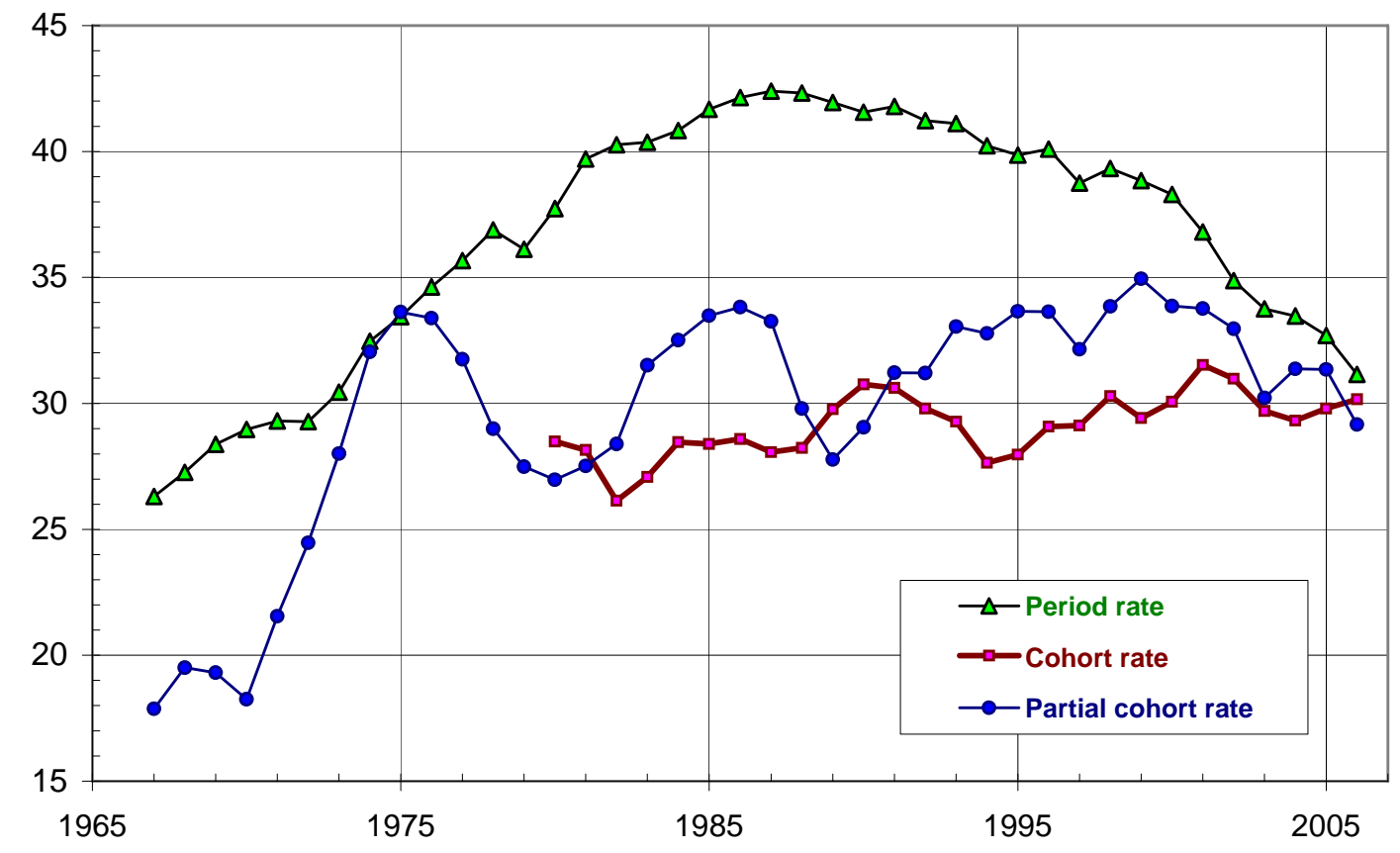

Average labor force participation rate, ages 50-69 (\%)

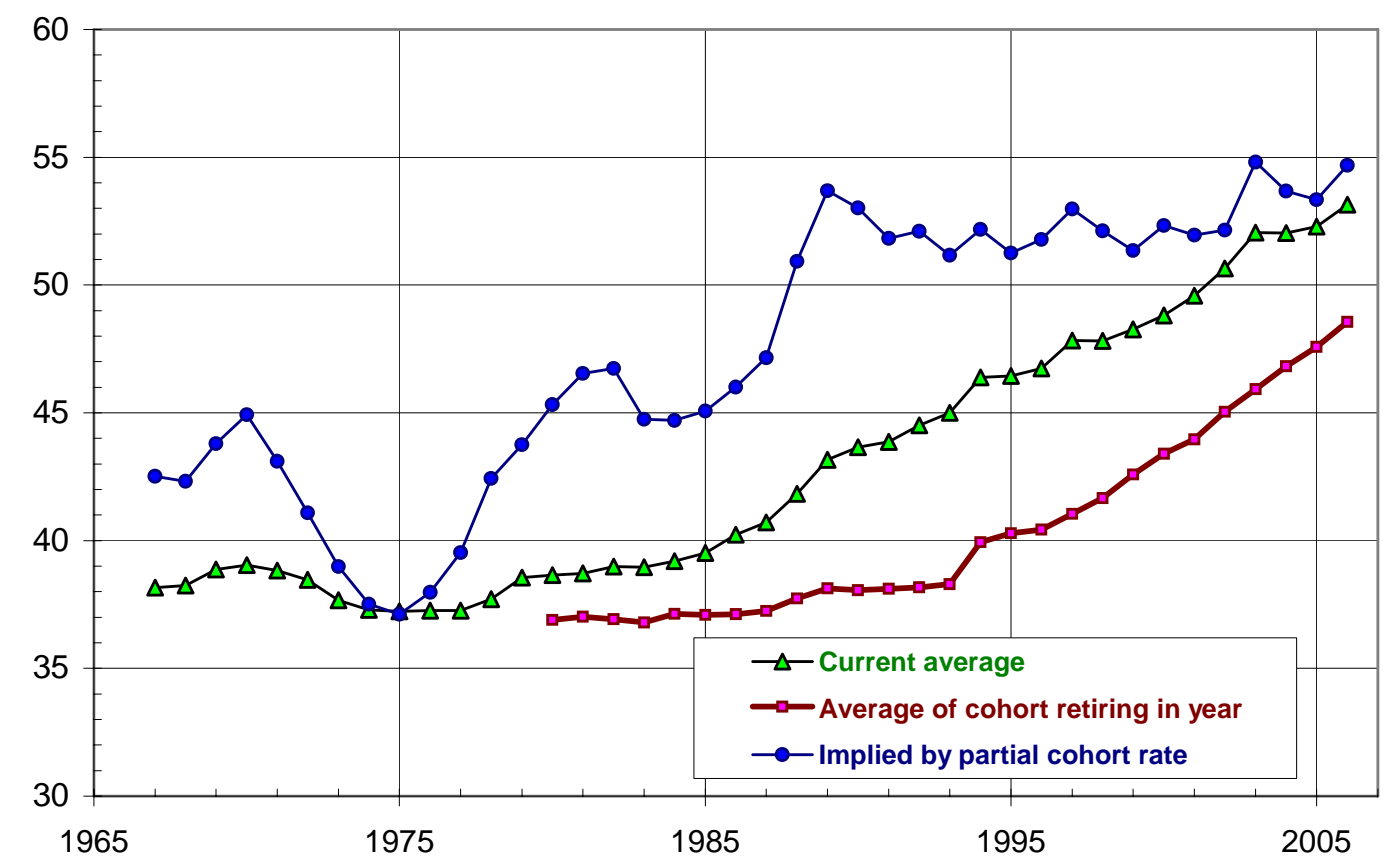

Source: Author's estimates based on labor force participation rates obtained from U.S. BLS and SourceOECD. 
Figure 9. U.S. Men's Labor Force Exit Rates over Five-year Periods Estimated with Cohort Data, 1965-2006

Labor force exit rates, younger ages (\%)

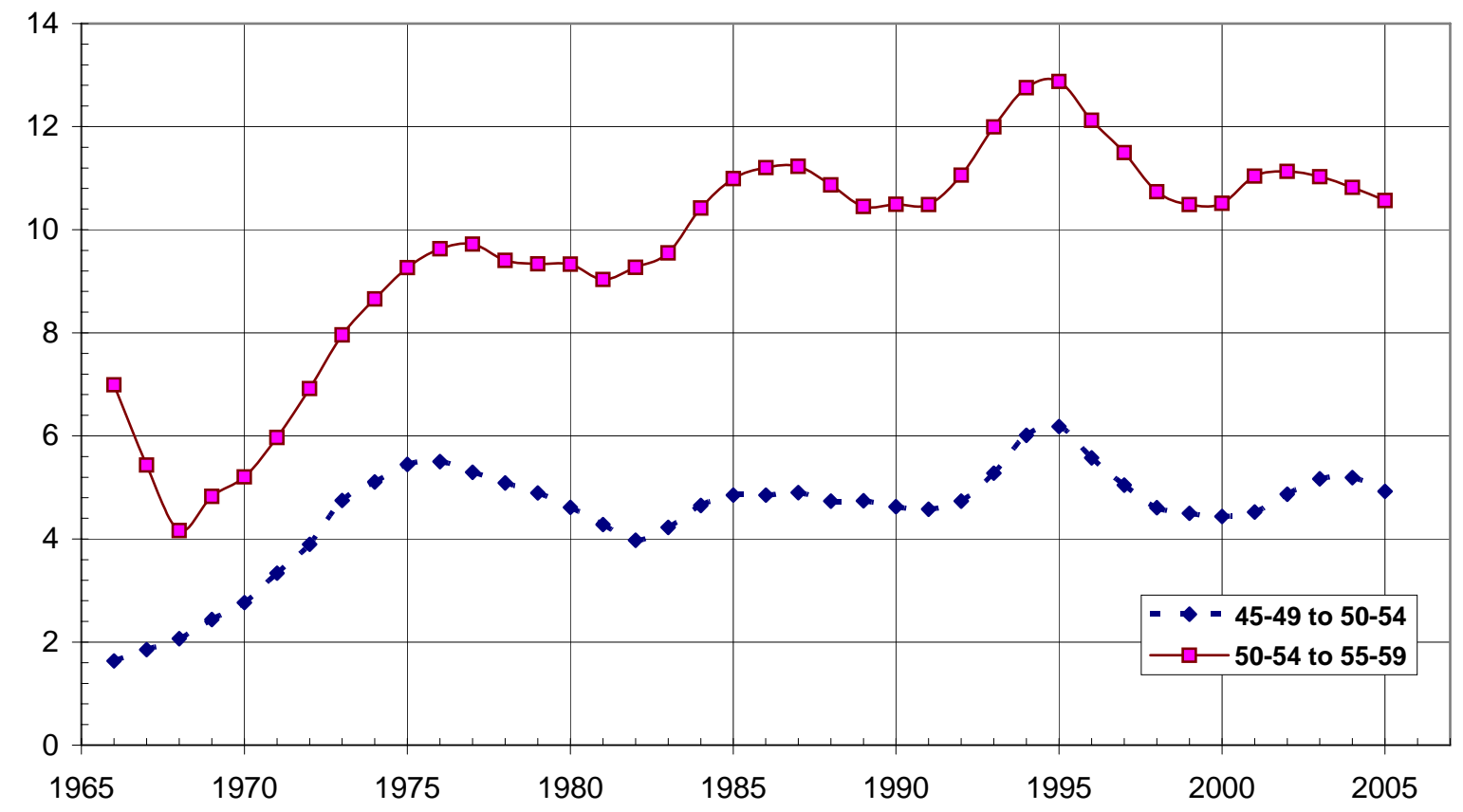

Labor force exit rates, older ages (\%)

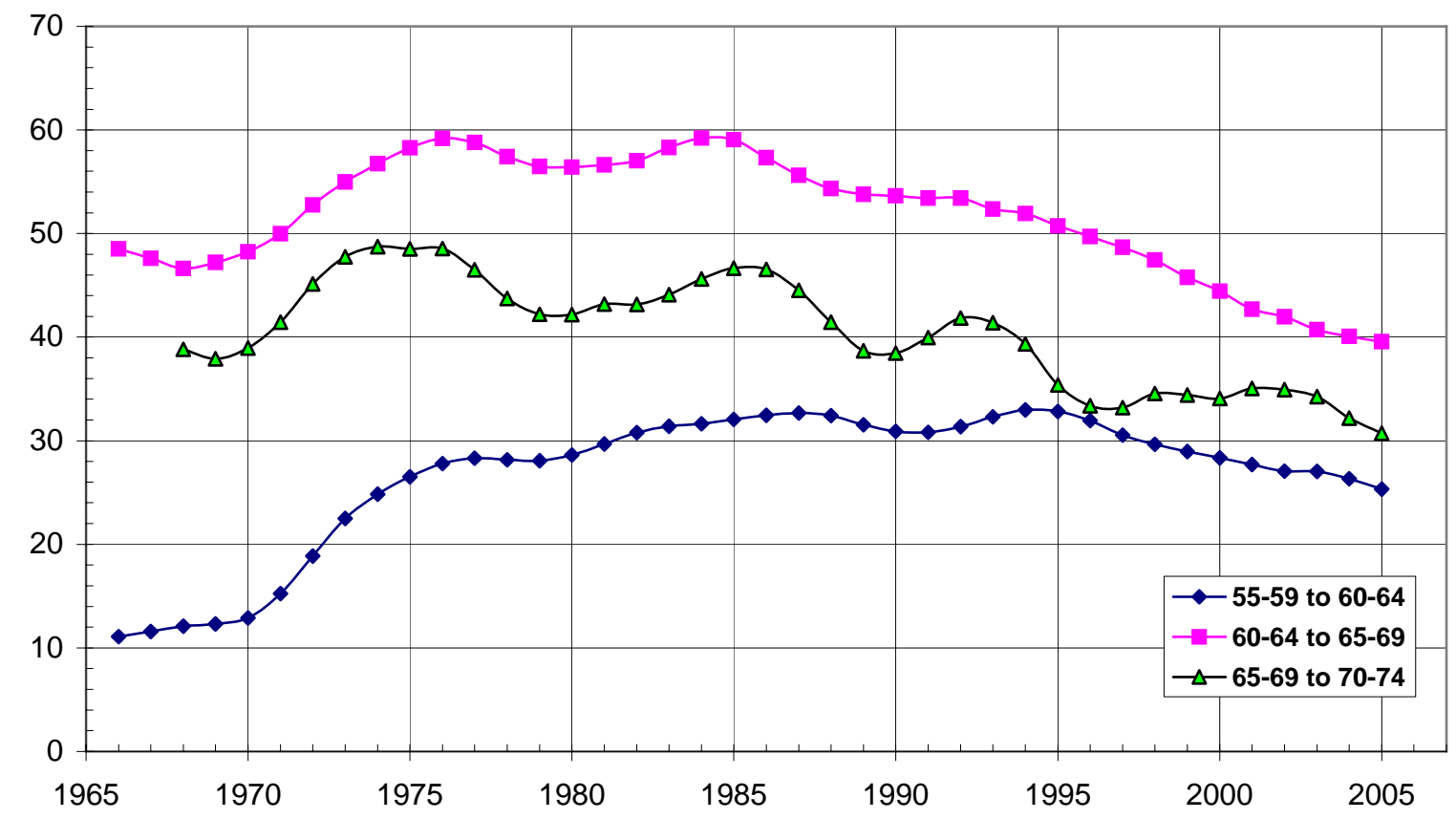

Note: The "cohort exit rate" is the proportional decline in the labor force participation rate for a birth cohort over a five-year period ending in the indicated years. The results shown represent centered 3-year averages of the estimated rates.

Source: Author's tabulations of labor force participation rate data from SourceOECD and U.S. BLS. 
Figure 10. U.S. Women's Labor Force Exit Rates over Five-year Periods Estimated with Cohort Data, 1965-2006

Labor force exit rates, younger ages (\%)

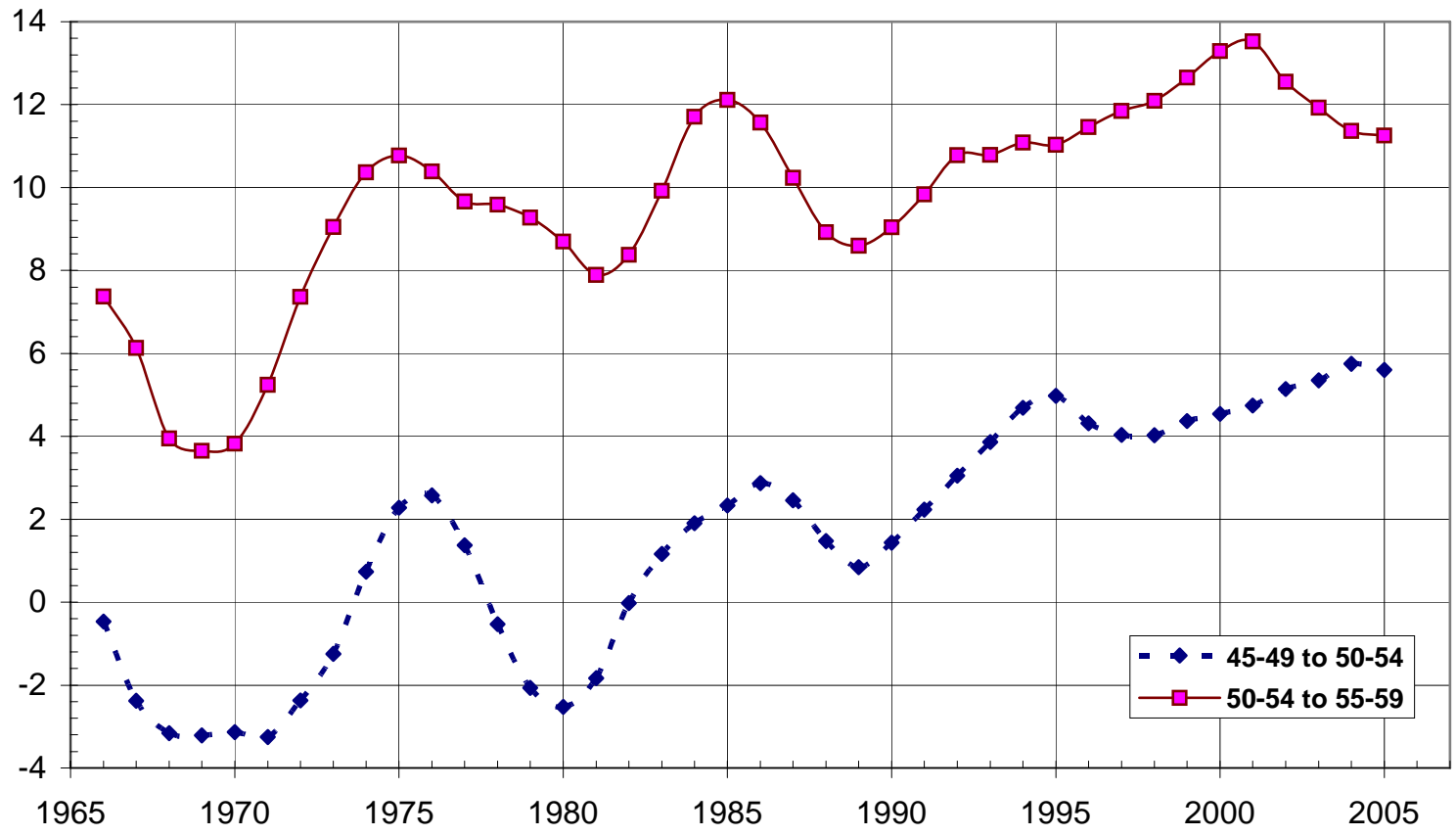

Labor force rates, older ages (\%)

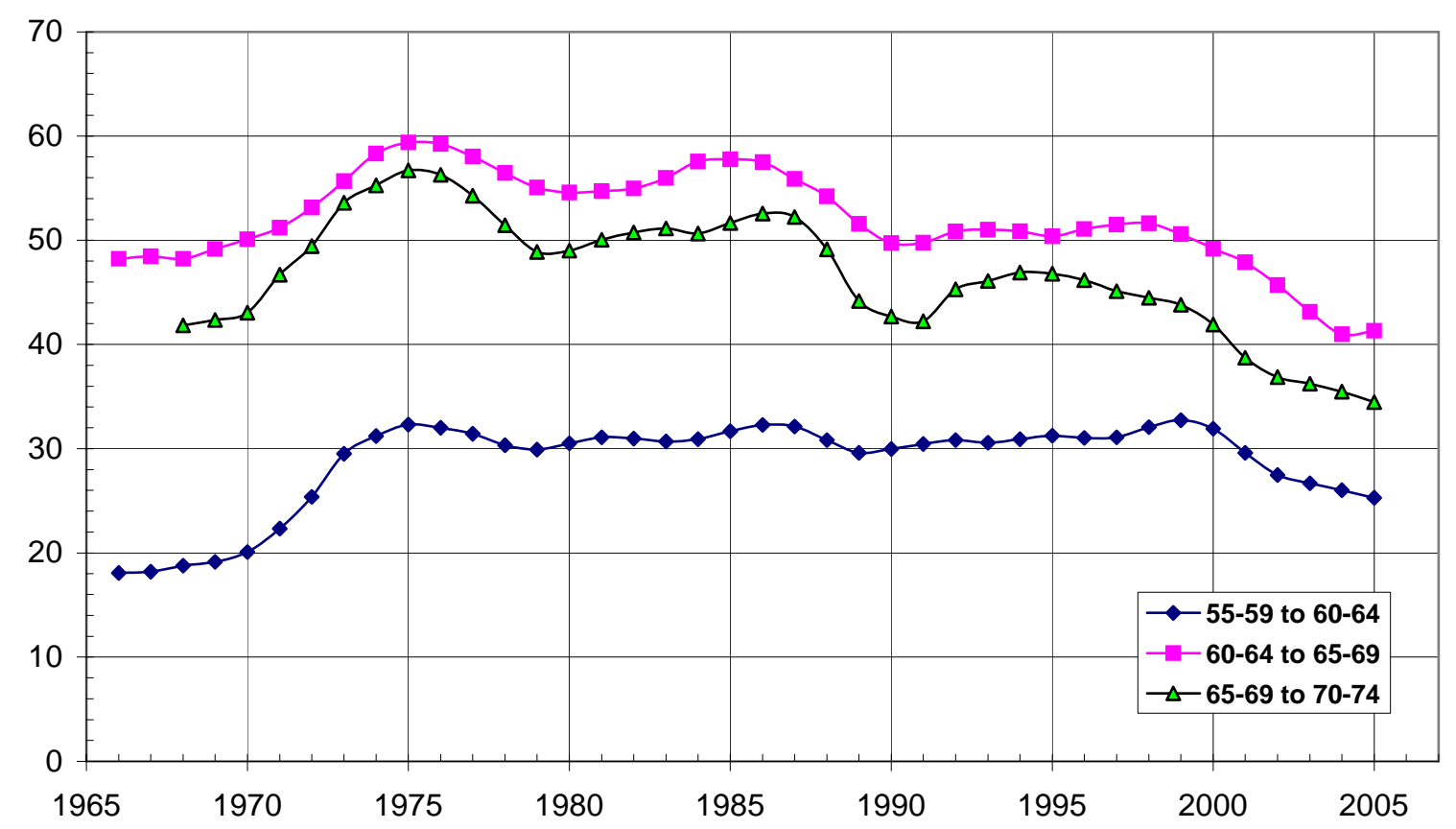

Note: The "cohort exit rate" is the proportional decline in the labor force participation rate for a birth cohort over a five-year period ending in the indicated years. The results shown represent centered 3-year averages of the estimated rates.

Source: Author's tabulations of labor force participation rate data from SourceOECD and U.S. BLS. 


\section{RECENT WORKING PAPERS FROM THE \\ CENTER FOR RETIREMENT RESEARCH AT BOSTON COLLEGE}

The Implications of Career Lengths for Social Security

Melissa M. Favreault and C. Eugene Steuerle

Do Out-of-Pocket Health Care Costs Delay Retirement?

Richard W. Johnson, Rudolph G. Penner, and Desmond Toohey

How the Income and Tax Treatment of Saving and Social Security Benefits May Affect Boomers' Retirement Incomes

Barbara A. Butrica, Karen E. Smith, and Eric J. Toder

Saving and Wealth Accumulation in the PSID, 1984-2005

Barry P. Bosworth and Sarah Anders

Older Women's Income and Wealth Packages in Cross-National Perspective

Timothy M. Smeeding, Janet C. Gornick, Eva Sierminska, and Maurice Leach

How Many Struggle to Get By in Retirement?

Barbara A. Butrica, Daniel Murphy, and Sheila R. Zedlewski, January 2008

The Impact of Late-Career Health and Employment Shocks on Social Security and Other Wealth

Richard W. Johnson, Gordon B.T. Mermin, and Dan Murphy, December 2007

The Effect of Economic Conditions on the Employment of Workers Nearing Retirement Age

Till von Wachter, December 2007

The Costs of Owning Employer Stocks: Lessons From Taiwan

Yi-Tsung Lee, Yu-Jane Liu, and Ning Zhu, December 2007

Health Insurance and the Labor Supply Decisions of Older Workers: Evidence from the U.S. Department of Veterans Affairs

Melissa A. Boyle and Joanna N. Lahey, December 2007

Why Are Companies Freezing Their Pensions?

Alicia H. Munnell and Mauricio Soto, December 2007

All working papers are available on the Center for Retirement Research website

( $h t t p: / / w w w . b c . e d u / c r r)$ and can be requested by e-mail (crr@bc.edu) or phone (617-552-1762). 